\title{
FENOLOGIA DA CANA-DE-AÇÚCAR (Saccharum spp.) SOB EFEITO DO FÓSFORO
}

\author{
CARLOS SUGUITANI
}

Engenheiro Agrônomo

Orientador: Prof. Dr. SIZUO MATSUOKA

\begin{abstract}
Dissertação apresentada à Escola Superior de Agricultura "Luiz de Queiroz", Universidade de São Paulo, para obtenção do título de Mestre em Agronomia, Área de Concentração: Fitotecnia.
\end{abstract}

\author{
PIRACICABA \\ Estado de São Paulo - Brasil \\ Novembro - 2001
}


Dados Internacionais de Catalogação na Publicação (CIP) DIVISÃo DE BIBLIOTECA E DOCUMENTAÇÃO - ESALQ/USP

\section{Suguitani, Carlos}

Fenologia da cana-de-açúcar (Saccharum spp.) sob efeito do fósforo / Carlos

Suguitani. - - Piracicaba, 2001.

79 p. : il.

Dissertação (mestrado) -. Escola Superior de Agricultura Luiz de Queiroz, 2001. Bibliografia.

1. Cana-de-açúcar 2. Crescimento vegetal 3. Fenologia 4. Fósforo 5. Perfilhação 6. Variedade I. Titulo

CDD 633.61

"Permitida a cópia total ou parcial deste documento, desde que citada a fonte - $\mathbf{O}$ autor" 
À minha mãe Shizuka que com muita dedicação, trabalho e paciência sempre me auxiliou durante minha caminhada até aqui.

À meu pai Takeo (in memoriam)

$E$ aos meus irmãos Nilton, Naoki e Seiko pelo apoio.

DEDICO

À Renata pelo carinho e palavras de conforto

OFEREÇO 


\section{AGRADECIMENTOS}

Ao Prof. Dr. Sizuo Matsuoka pela orientação, dedicação, companheirismo, ensinamentos e estímulo à realização da presente pesquisa.

Ao Centro de Ciências Agrárias, UFSCar-campus Araras, pelo apoio técnico e por ter permitido a realização deste trabalho tanto em Araras, quanto na estação experimental de Valparaíso.

Aos técnicos de campo Juninho, Rogério e Geraldo, do Departamento de Biotecnologia Vegetal, e aos do campo experimental de Valparaíso, Adriano, Vladmir, Valdir e Lungas, que me auxiliaram em todas as avaliações do experimento.

Às secretárias Sônia, Cidinha e Fernanda pela amizade e ajuda na parte burocrática e no envio e recebimento de documentos.

Aos professores Antônio C. A. Gheller e Miguel A. Manieiro pelo incentivo e amizade.

À meus avós Kunio e Katayo Suguitani pela amizade e inúmeros momentos de alegria.

À FAPESP pelo apoio financeiro dado ao projeto. 
Aos meus amigos Cristiano, Márcio, Tiago, Daniele, Eduardo e outros pós-graduandos pelo companheirismo.

À meus familiares que sempre me deram apoio.

A todos que, direta ou indiretamente, colaboraram para a realização da dissertação. 


\section{SUMÁRIO}

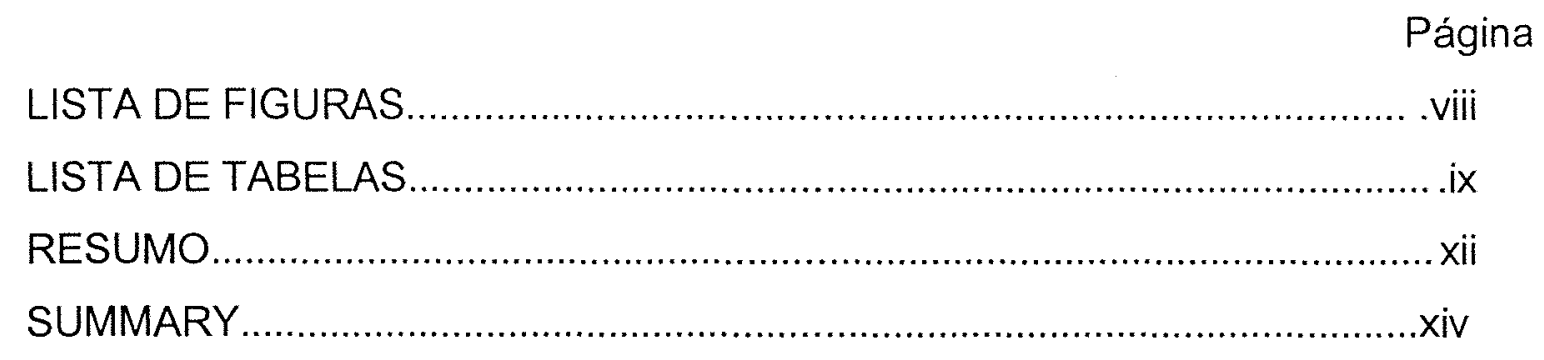

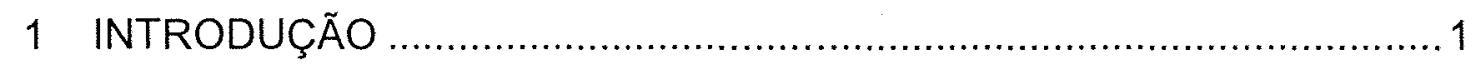

2 REVISÃO DE LITERATURA .......................................................

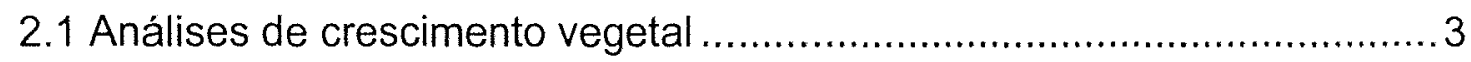

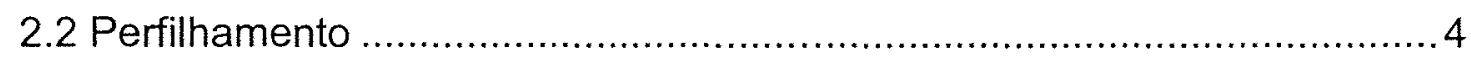

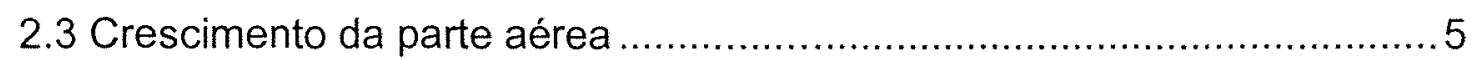

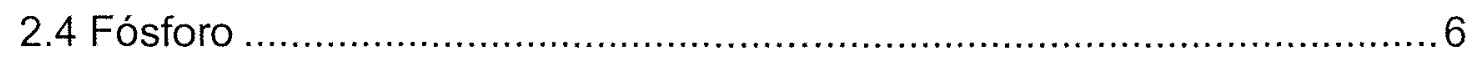

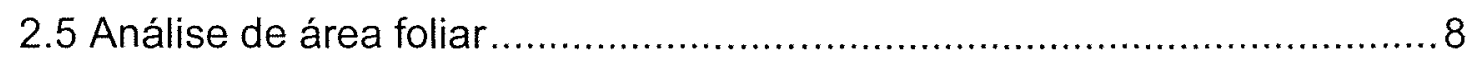

2.6 Variedades de cana-de-açúcar...................................................... 10

3 MATERIAL E MÉTODOS ….......................................................... 11

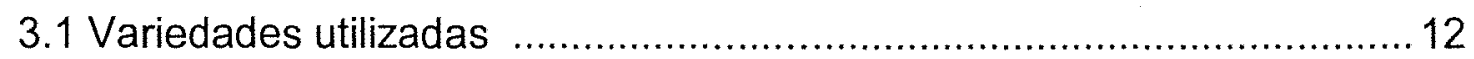

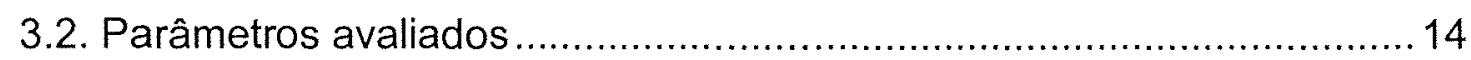

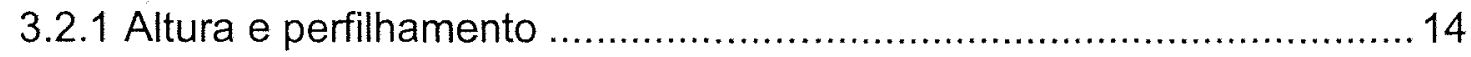

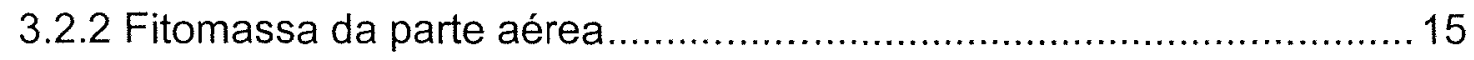

3.2.3 Área foliar e indice de área foliar ................................................ 16

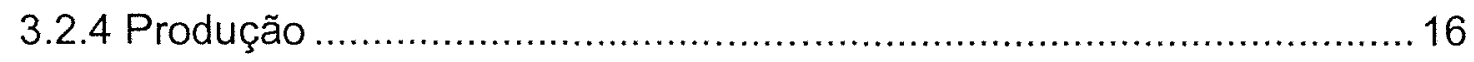

3.2.5 Parâmetros tecnológicos .............................................................. 16

4 RESULTADOS E DISCUSSÃO …................................................ 17 


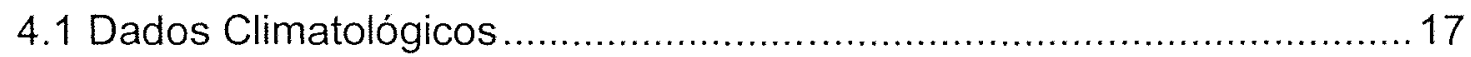

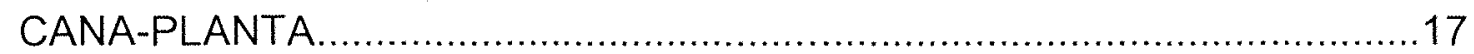

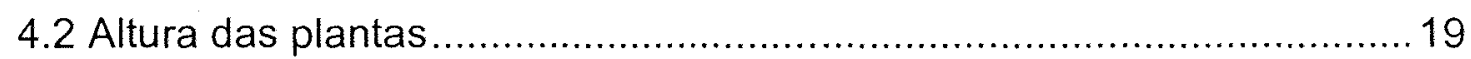

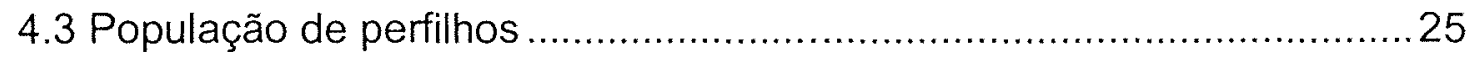

4.4 Dinâmica foliar em Araras .................................................................. 30

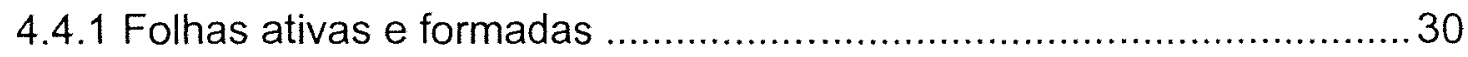

4.4.1 Índice de área foliar em Araras...................................................... 33

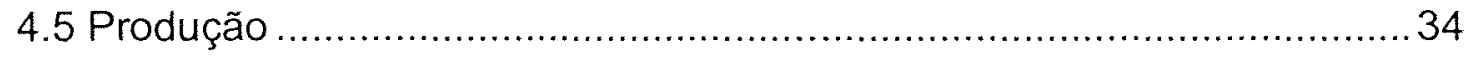

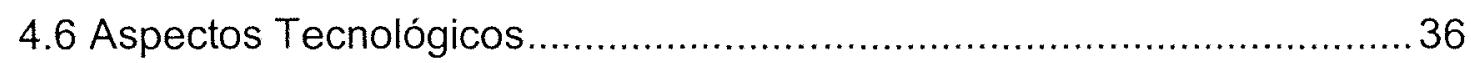

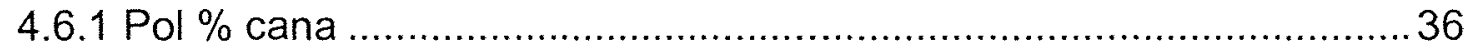

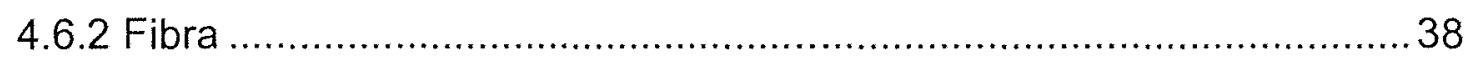

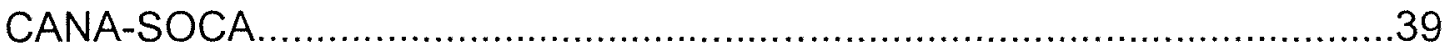

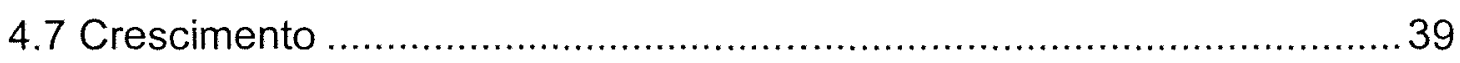

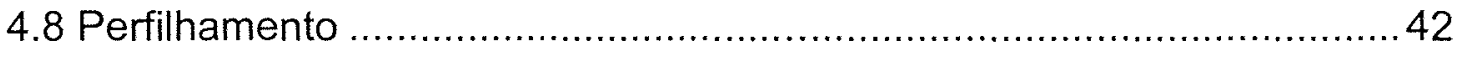

4.9 Dinâmica foliar em cana-soca ....................................................... 45

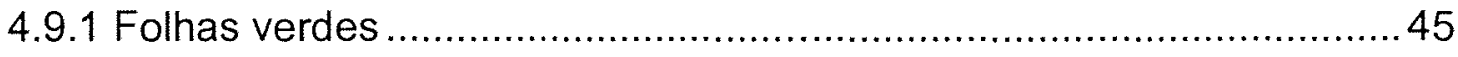

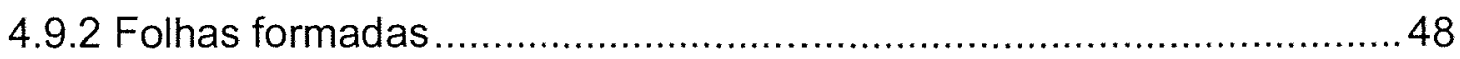

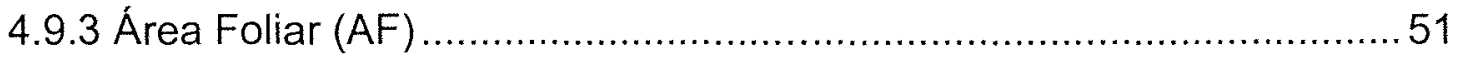

4.9.4 Índice de área foliar (IAF) em Araras..............................................55

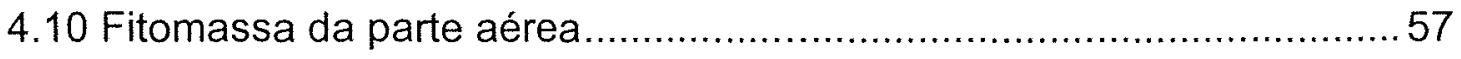

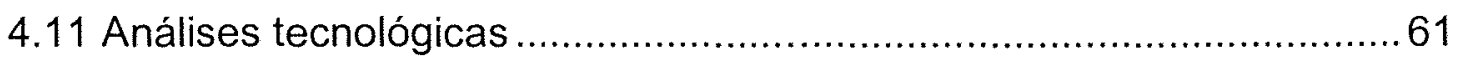

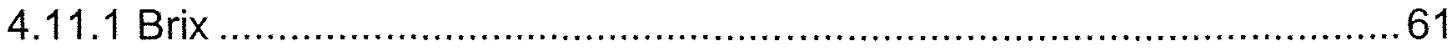

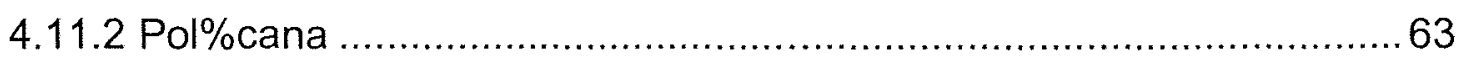

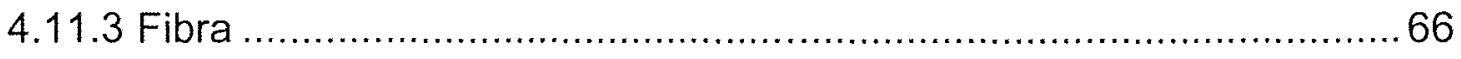

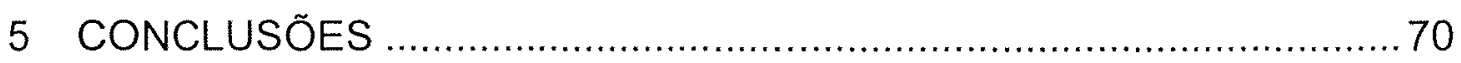

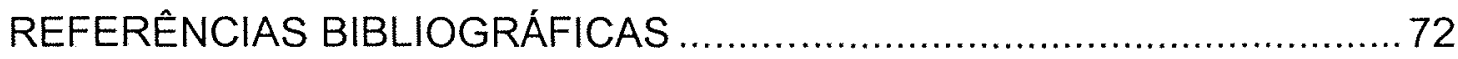




\section{LISTA DE FIGURAS}

1 Esquema da separação do colmo em partes, de acordo com o período de desenvolvimento. Da esquerda para direita, porções formadas de agosto

a dezembro, de dezembro a março e março a agosto. 15

2 Extrato do balanço hídrico de Araras. .............................................. 17

3 Temperatura máxima, mínima, média e pluviometria do Centro de Ciências Agrárias de Araras............................................................... 18

4 Extrato do balanço hídrico de Valparaíso ........................................... 18

5 Temperatura máxima, mínima, média e pluviometria de Valparaíso provenientes da estação meteorológica do IAC - Adamantina............... 19

6 Altura das plantas em diferentes variedades ....................................... 22

7 Altura média das variedades em estudo em Valparaíso. .........................24

8 Quantidade de perfilhos, em cana planta, por variedade em Araras........ 27

9 Perfilhos por metro nas diferentes variedades em Valparaíso. ................ 29

10 Evolução da AF, em cana-soca, no decorrer do experimento de Araras. 53

11 Evolução do AF nas diferentes variedades cultivadas em Valparaiso. ...55

12 Acúmulo de fitomassa referente aos tratamentos utilizados em Araras. . 58

13 Acúmulo de fitomassa da parte aérea dos tratamentos de Valparaíso ...60 


\section{LISTA DE TABELAS}

1 Análise química do solo de Araras. .................................................... 11

2 Análise química do solo de Valparaiso .............................................. 11

3 Adubações fosfatadas feitas por tratamento. ..................................... 12

4 Altura de plantas nos diferentes tratamentos e avaliações em Araras.... 20

5 Diferença varietal em relação ao crescimento em diferentes épocas.......2 21

6 Altura de plantas de acordo com as doses de fósforo .......................... 22

7 Altura das plantas nos diferentes tratamentos em Valparaíso ................. 23

8 Médias de altura entre variedades em Valparaíso ................................ 23

9 Médias de altura entre variedades em Valparaíso ................................. 24

10 Quantidade de perfilhos por metro em diferentes doses de fósforo em

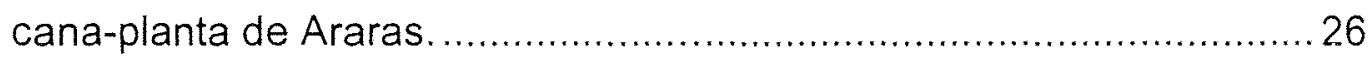

11 Dinâmica da população de perfilhos em função da variedade em Araras.27

12 População de perfilhos considerando médias por dose de fósforo. ....... 28

13 Número de perfilhos nos diferentes tratamentos em Valparaíso ........... 28

14 Número de perfilhos por metro das diferentes variedades em

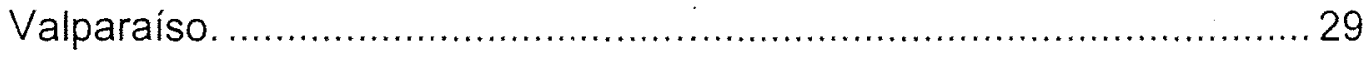

15 População de perfilhos em diferentes doses de fósforo em Valparaíso. 30

16 Número de folhas ativas e formadas durante o experimento nos diferentes tratamentos em Araras.

17 Médias de folhas ativas e formadas, em cana planta, para diferentes variedades em Araras.

18 Médias de folhas ativas e formadas para diferentes variedades em Araras.

19 IAF de diferentes tratamentos em Araras. 
20 Produtividade dos tratamentos em estudo em Araras......................... 34

21 Produtividade dos tratamentos em estudo ........................................ 35

22 Pol \% cana em cana-planta de Araras nos diferentes tratamentos em

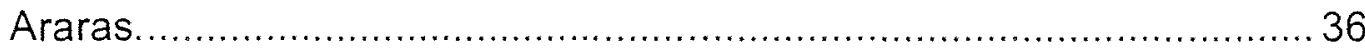

23 Valores de pol \% cana em cana-planta de Valparaiso nos diferentes tratamentos. 37

24 Teor de fibra em cana-planta de Araras nos diferentes tratamentos..... 38

25 Teor de fibra em cana-planta das diferentes variedades nas doses de fósforo aplicadas em Valparaíso.

26 Crescimento da cana-planta em Araras, em quatro doses de fósforo em três períodos.

27. Diferença varietal quanto ao crescimento de cana-planta em Araras... 41

28 Crescimento de cana-planta em Valparaíso em quatro doses de fósforo em três períodos.

29 Diferença varietal em relação ao crescimento em diferentes épocas em Valparaíso.

30 População de plantas de diferentes tratamentos em Araras.

31 População de perfilhos por variedade em Araras................................. 44

32 População de perfilhos por variedade em Araras.................................. 44

33 População de plantas em diferentes variedades.................................. 45

34 Número de folhas verdes nos diferentes tratamentos......................... 46

35 Número médio de folhas verdes por variedade em Araras. ................. 47

36 Número de folhas verdes encontradas nos diferentes tratamentos em Valparaíso.

37 Número de folhas verdes de cada variedade em estudo no decorrer do experimento em Valparaíso.

38 Formação de folhas durante o experimento em diferentes tratamentos em Araras.

39 Formação de folhas das variedades em estudo cultivadas em Araras... 49

40 Número de folhas surgidas em cada época avaliada em Valparaíso. .... 50 
41 Número de folhas formadas por variedade em Valparaíso.

42 Número de folhas formadas por variedade em Araras......................... 51

43 Número de folhas formadas por variedade em Araras......................... 52

$44 \mathrm{AF}$ dos diferentes tratamentos analisados em Valparaíso ................... 54

$45 \mathrm{AF}$ das variedades em estudo em Valparaíso.................................... 54

46 IAF dos diferentes tratamentos em Araras.......................................... 56

47 Médias de IAF por variedade em Araras. .......................................... 56

48 Fitomassa da parte aérea dos diferentes tratamentos em Araras ......... 57

49 Média de fitomassa por variedade em Araras.................................... 58

50 Fitomassa da parte aérea dos diferentes tratamentos em Valparaíso. . 59

51 Quantidade de fitomassa acumulada por variedade em Valparaíso. .... 60

52 Valores de brix para diferentes tratamentos em Araras. ...................... 61

53 Médias de brix das diferentes variedades cultivadas em Araras...........662

54 Teor de brix dos tratamentos em Valparaiso.......................................62 62

55 Brix médio das variedades em Valparaíso. ....................................... 63

56 Pol\%cana dos tratamentos em Araras. ................................................. 64

57 Pol\%cana das das variedades em diferentes períodos em Araras. ...... 64

58 Pol\%cana dos diferentes tratamentos analisados em Valparaíso.......... 65

59 Pol\%cana das diferentes variedades em Valparaíso. ..........................66

60 Pol\%cana das diferentes variedades em Valparaíso. ..........................66 66

61 Fibra das variedades em estudo utilizadas em Araras.........................6 67

62 Fibra das variedades em estudo utilizadas em Valparaíso. ..................68 68

63 Fibra das variedades avaliadas em Valparaíso ...................................69 


\title{
FENOLOGIA DA CANA-DE-AÇÚCAR SOB EFEITO DO FÓSFORO
}

\author{
Autor: CARLOS SUGUITANI \\ Orientador: Prof. Dr. SIZUO MATSUOKA
}

\section{RESUMO}

\begin{abstract}
A interação harmoniosa ambiente $x$ variedade é que determina e a produtividade da cana-de-açúcar. Apesar de haver muitos trabalhos relacionados à adubação, há carência de dados biométricos relacionados à fenologia da cana-de-açúcar sob diferentes niveis de $P$, e total deficiência em se tratando das modernas variedades dessa cultura. Esse conhecimento é importante para se determinar a ecofisiologia da planta e para o correto manejo da cultura, dessa forma buscou-se estabelecer biometricamente a fenologia de quatro modernas variedades de cana-de-açúcar, RB835486, RB835054, RB855113 e RB855536, sob dosagens diferenciadas de fósforo e estabelecer indices fisiológicos resultantes da interação genótipo $x$ ambiente. Os parâmetros avaliados foram altura, perfilhamento, dinâmica foliar (folhas verdes e surgidas, área foliar e índice de área foliar), produtividade, brix, pol\%cana, fibra, volume e teor de fósforo no caldo. Os ensaios foram instalados em dois locais, na UFSCar-campus Araras e na estação experimental da UFSCar em Valparaíso. Não houve interação significativa entre doses e variedades em
\end{abstract}


estudo, na quase totalidade das avaliações. As diferenças encontradas no experimento estão relacionadas com médias de variedades. De forma geral, verificou-se que o maior crescimento vegetativo, em cana planta, ocorre de novembro a abril e o perfilhamento mais intenso de agosto a novembro. $O$ perfilhamento, em cana planta, foi mais intenso de julho a novembro e as variedades RB8551153 e RB855536 foram as que apresentaram maior população. Essas mesmas variedades foram as que obtiveram maior produtividade em Araras, já em Valparaíso a RB855536 apresentou produção menor que as demais. Em relação à soca, o maior crescimento das plantas foi no período de dezembro a março, devido às chuvas que antecedem e ocorrem neste intervalo de meses. Associando o período de amostragem com a porcentagem de fitomassa aérea acumulado, observou-se que $20 \%$ do total de massa fresca de julho a dezembro, 50 a $60 \%$ de dezembro a março e 20 a $30 \%$ de março até a colheita. 


\title{
SUGARCANE PHENOLOGY UNDER THE PHOSPHORUS EFFECT
}

\author{
Author: CARLOS SUGUITANI \\ Advisor: Prof. Dr. SIZUO MATSUOKA
}

\section{SUMMARY}

The harmonious interaction between environment $x$ variety determines sugarcane productivity. There are some research work related to adubation, but there are still lack of biometrics data related to the sugarcane phenology under different phosphorus levels, and total deficiency related to the modern varieties of this culture. This is a very important knowledge to determine the plant ecophisiology and correct maneuver of this culture. Because of that we tried to establish biometrics measurements of the phenology of four (4) modern sugarcane varieties - RB835486, RB835054, RB855113 e RB855536- under differentiated phosphorus leveals, and establish physiological index resulting from the interaction genotype $x$ environment. The evaluated parameters were high, tillering, leaf dynamic (green leaves and emerged), leaf area, and index of leaf area), productivity, brix, cane pol\% and fiber. The samples were installed in two different places: UFSCar (São Carlos Federal University)-campus Araras, and experimental station of UFSCar in Valparaiso. The interaction results between levels and varieties in the samples were not significant in almost all of 
the evaluations. The experiment founded differences are related with the media of varieties. In general, was verified that the biggest vegetative growing on each plant occurs from November to April, and the most intense tillering between August to November. The tillering, on each plant, were more intense from July to November, and the varieties RB8551153 and RB855536 were the ones that presented the biggest population. These same varieties were the ones which obtained biggest productivity in Araras, but in Valparaiso the RB855536 variety presented smaller production comparing to the others. In relation to next cicle, the biggest plant growing was during the period from December to march, because of the rainy period that precede and happens during this period of months. Associating the period of sampling with the accumulated percentage of the phytomass, it was observed that $20 \%$ of the fresh total mass ocurrered from July to December, $50 \%$ to $60 \%$ from December to March, and $20 \%$ to $30 \%$ from March to the harvest. 


\section{INTRODUÇÃO}

A cana-de-açúcar (Saccharum spp.) pertence à familia Poaceae, sendo considerada originária do Sudeste Asiático, na grande região centrada em Nova Guiné e Indonésia (Daniels \& Roach, 1987). Inicialmente cultivava-se principalmente a espécie Saccharum officinarum L. Com o passar do tempo, entretanto, cultivares desta espécie passaram a sofrer problemas de doenças e de adaptação ecológica. Surgiram então os programas de melhoramento genético para obtenção de híbridos interespecíficos resistentes e mais bem adaptados para as diversas condições em que essa cultura se expandiu pelo mundo (Figueiredo et al., 1995; Matsuoka et al., 1999), para cultivo numa ampla faixa, de $35^{\circ} \mathrm{N}$ a $30^{\circ} \mathrm{S}$, e em altitudes que variam desde o nivel do mar até $1.000 \mathrm{~m}$ (Magalhães, 1987).

O melhorista sempre tem como meta obter variedades com elevada produtividade, ou outros caracteres "finais" desejáveis. Mas estes são o resultado de um sistema dinâmico que vai continuamente variando, desde a germinação ou estabelecimento da planta até a sua maturidade ou colheita. $E$ esse modelo de mudanças não é o mesmo para todos os genótipos, num mesmo ambiente, ou para um mesmo genótipo em distintos ambientes (Allard \& Bradshaw, 1964). Além disso, ao longo dos anos o ambiente vem se modificando, tanto pelo uso contínuo da terra como pelas inevitáveis mudanças tecnológicas.

Ao final do século $X X$, o Brasil se tornou o maior produtor mundial de cana-de-açúcar, de açúcar e de álcool do mundo (Balsadi et al., 1996). Essa liderança foi atingida em função da criação do Proálcool, em 1975, um programa governamental de incentivo à produção de álcool combustível, 
programa este pioneiro no mundo em termos de um combustivel renovável de biomassa (Leite, 1987).

Providencialmente, nesse mesmo período floresceram dois grandes programas de melhoramento genético da cana-de-açúcar (Matsuoka et al., 1999), cujas variedades são hoje predominantemente cultivadas (Centro de Tecnologia Copersucar, 2001) e propiciam produtividades bem mais elevadas que as que se obtinham nas décadas de 70 e 80 do século recém findo (Hoffmann, 1997; Hoffmann et al., 1999). Essas variedades foram desenvolvidas com base em seleção e experimentação nos distintos ambientes de cultivo da cana-de-açúcar (UFSCar, 1998), mas sempre considerando dados finais de produtividade, sem nenhum detalhamento fenológico ao que se sabe.

A produção da cana-de-açúcar, pela parte da planta, é resultado de vários componentes fenológicos, tais como: número de perfilhos, altura de colmos, diâmetro de colmos, densidade dos colmos, etc. Segundo vários autores, o parâmetro que apresenta maior correlação com a produção é o número de colmos, seguido pela altura, diâmetro de colmos e densidade, nessa ordem (Cesnik \& Vencovsky, 1974, Mariotti, 1971; Miller \& James, 1974). Todos eles são caracteres governados geneticamente, porém estão sujeitos à influência ambiental (Skinner, 1981).

Assim, quando se considera a interação genótipo - ambiente, a produção final pode indicar o grau de magnitude dessa interação, mas não explica o processo fenológico desse efeito, ou seja, quais os parâmetros que efetivamente interagem com os distintos ambientes. $O$ conhecimento do modelo de desenvolvimento de cada planta é, pois, de extrema importância para o melhorista aperfeiçoar os seus métodos de melhoramento ou, para o agrônomo, os seus métodos de manejo agrícola.

Este estudo constituiu numa primeira tentativa de se avaliar alguns parâmetros fenológicos em dois locais de significativa importância na produção canavieira do Estado de São Paulo, uma região tradicional e, outra, uma área nova que se desenvolveu com o Proálcool (Matsuoka et al., 1999). 


\section{REVISÃO DE LITERATURA}

\subsection{Análises de crescimento vegetal}

A análise de crescimento fundamenta-se basicamente no fato de que cerca de $90 \%$ da matéria que se acumula nas plantas é resultado do seu processo fotossintético (Benincasa, 1988). No caso da cana-de-açúcar, uma grande parte dos açúcares resultantes da fotossíntese migra e se acumula no colmo, estando, assim, diretamente relacionada com a produção e rentabilidade da cultura. A análise de crescimento é importante para conhecer diferenças funcionais e estruturais entre cultivares de uma mesma espécie (Benincasa, 1988), investigar a adaptabilidade ecológica das culturas ou de variedades a novos ambientes, além de avaliar os efeitos dos diversos manejos sobre o genótipo. Essa avaliação quantitativa do crescimento é o primeiro passo na análise da produção de comunidades vegetais e um instrumento básico no auxílio de pesquisadores em programas de melhoramento (Pereira \& Machado, 1987). Este crescimento é avaliado através de modificações na morfologia no decorrer do período. Os tipos de análise de crescimento utilizados no experimento podem ser divididos da seguinte forma: (a) linear, que compreende a análise da altura da planta, comprimento do caule, comprimento e largura das folhas e diâmetro de colmo; (b) superficial, relacionada à determinação da superfície fotossintética; (c) peso e número de unidades estruturais, que são as determinações do número de colmos ou perfilhos, e a produção que é resultado da pesagem dos mesmos (Benincasa, 1988). 


\subsection{Perfilhamento}

Perfilhamento é o processo de emissão de colmos ou hastes por uma mesma planta, os quais por sua vez recebem a denominação de perfilhos. Ele ocorre a partir da porção subterrânea e varia de espécie para espécie. variedades dentro da mesma espécie, e manejo cultural.

Machado et. al. (1982), Rocha (1984) e Prado (1988), dentre outros, observaram que durante o ciclo da cana-de-açúcar ocorre queda no número de colmos, com o máximo obtido nos meses de setembro, outubro e novembro e com queda brusca em janeiro, desde então decrescendo mais lentamente até a época da colheita. Além do efeito genético, isso varia com a época de plantio ou colheita, neste segundo caso para as soqueiras, e de inúmeros outros fatores ambientais, direta ou indiretamente.

A capacidade de perfilhamento e a sobrevivência dos perfilhos são aspectos importantes, pois são caracteristicas que apresentam maior correlação com a produção (James, 1971; Mariotti, 1972).

O número de perfilhos varia conforme a variedade, dependendo das suas caracteristicas genéticas. Por exemplo, a espécie $S$. officinarum apresenta baixo perfilhamento, enquanto $S$. spontaneum é de alto perfilhamento (Stevenson, 1965). No processo seletivo para obtenção de novas variedades, normalmente se eliminam os genótipos que apresentem tanto excesso como baixo perfilhamento, por fugirem de características desejadas comercialmente.

A baixa luminosidade tende a reduzir $\circ$ perfilhamento da planta. Christoffoleti (1986) relata que plantas que foram deixadas em casa-devegetação, com baixa luminosidade, apresentaram perfilhos mortos, o que não ocorreu quando a mesma variedade foi plantada em ambiente com luminosidade maior.

O processo de perfilhamento é regulado por uma auxina que é formada no topo e que desce em fluxo contínuo em direção à base. A auxina exerce nesse caso um duplo efeito: alongamento do colmo e o impedimento do desenvolvimento das gemas laterais (dominância apical). Com alta 
luminosidade o fluxo de auxina diminui e observa-se então decréscimo no grau de inibição das gemas laterais, o que resulta numa maior formação de perfilhos (Casagrande, 1991).

O perfilhamento também aumenta com o aumento da temperatura até o máximo ao redor dos $30^{\circ} \mathrm{C}$ (Casagrande, 1991). Por outro lado, os nutrientes mais necessários para bom perfilhamento são o $N$ e o $P$ (Clements, 1980; Dillewijn, 1952; Fósforo, 1996; Malavolta et al., 1967). Especialmente o P, é um elemento essencial para bom perfilhamento, como foi relatado em muitas gramíneas (Rodríguez et al., 1999).

Em cana-de-açúcar a longevidade de soqueiras é outra característica de alta importância para a economicidade da agroindústria. Essa característica tem alta dependência da capacidade de perfilhamento, especialmente em lavouras modernas, sujeitas a intenso pisoteio por veículos e máquinas. Por essa razão é que os programas de melhoramento genético têm tido necessidade de incorporar genes de S. spontaneum.

\subsection{Crescimento da parte aérea}

O crescimento da planta, em relação à matéria seca da parte aérea, pode ser dividido em três etapas: fase inicial, em que o crescimento é lento, que vai de março a outubro (plantio-200 dias); fase de crescimento rápido, de outubro a maio, (200-400 dias), que é onde se acumula $75 \%$ da fitomassa total e fase final de crescimento lento, de maio a agosto (400-500 dias), que corresponde a $11 \%$ da fitomassa total (Machado et al., 1982).

Já o acúmulo de matéria seca pela folha também pode ser dividido em três fases, que se assemelha com o anterior: fase de crescimento lento, março a julho (plantio-100 dias); fase de crescimento rápido, de outubro a maio que é onde se acumula $75 \%$ da matéria seca das folhas (100-250 dias) e, por último, uma fase de crescimento lento que começa aos 250 dias após plantio e se estabiliza aos 300 dias (fevereiro) (Machado et al., 1982). Gascho \& Shih (1983) observaram que no sexto mês de desenvolvimento da cultura é que o IAF 
(índice área foliar) é máximo. O IAF é a relação entre a área foliar total e a área do solo sombreada pelas folhas. Um IAF elevado reflete uma alta produção de fotossintatos e, conseqüentemente, maior produção de sacarose.

Além dos aspectos ligados à variedade, existem outros importantes que exercem influência no crescimento da parte aérea da planta, podendo ser citados a luminosidade, a temperatura do ar, a disponibilidade de água, e a disponibilidade de nutrientes.

A cana-de-açúcar, por ser uma planta $C_{4}$, é altamente eficiente fotossintéticamente. Camargo (1968) observou que quando a cana é cultivada em pleno sol os colmos se apresentaram mais grossos, mais curtos, as folhas mais largas e verdes e o perfilhamento foi mais intenso. Com o aumento da temperatura acima de $20^{\circ} \mathrm{C}$ ocorre aumento no comprimento, diâmetro e número de internódios (Planalsucar, 1986), sendo ideal para bom desenvolvimento a faixa de 20 a $35^{\circ} \mathrm{C}$ (Casagrande, 1991).

A água obviamente é essencial para o crescimento. Mesmo em condições de pluviosidade relativamente adequada a cana-de-açúcar respondeu positivamente ao suprimento regular de água (Leme et al., 1984; Sousa, 1976).

\subsection{Fósforo}

O fósforo é dos três macronutrientes 0 exigido em menores quantidades pelas plantas, mas é o mais usado em adubações no Brasil. Dentre os principais motivos estão a pobreza natural dos solos brasileiros em fósforo e a sua forte interação com os colóides do solo. As perdas desse nutriente no sistema agrícola se dão principalmente por erosão e pela colheita.

O fósforo é o elemento que mais limita o crescimento em uma planta. Este nutriente participa de inúmeros compostos que são essenciais para o metabolismo. O suprimento adequado de $P$ desde o início do desenvolvimento vegetal é importante para formação dos primórdios das partes reprodutivas (Raij, 1987). O elemento $P$ faz parte da estrutura de ésteres de carboidratos, 
fosfolipídios, coenzimas e ácidos nucléicos, auxiliando nos processos de absorção iônica, fotossíntese, respiração, sínteses, multiplicação e diferenciação celular, herança, armazenamento e transferência de energia e na fixação biológica de nitrogênio (Malavolta et al., 1997).

O fósforo tem a propriedade de aumentar a eficiência da utilização de água pela planta (menos perda), bem como a absorção e a utilização de outros nutrientes, venham eles do solo ou do adubo, contribuindo para aumentar a resistência da planta a algumas doenças, a suportar baixas temperaturas e a falta de umidade (Fósforo, 1996).

Em cana-de-açúcar o $P$ assume grande importância no vigor do enraizamento e no perfilhamento (Clements, 1980; Malavolta et al., 1967) e, portanto, na produtividade final.

A deficiência de fósforo afeta a formação de folhas, engrossamento do colmo e diminui a quantidade de clorofila nas folhas e conseqüentemente a fotossintese, sendo esse efeito mais acentuado do que os de falta de $\mathrm{N}$ e $\mathrm{K}$ (Estéves, 1986).

O fósforo é absorvido preferencialmente pelas raizes na forma de ion ortofosfato, $\mathrm{H}_{2} \mathrm{PO}_{4}^{-}$. O elemento normalmente permanece onde é colocado pela intemperização dos minerais ou pela adubação. Portanto, pouco fósforo é perdido por lixiviação, apesar dele poder movimentar-se um pouco mais em solos arenosos do que em solos argilosos (Raij, 1983).

Segundo o artigo MOVIMENTO do fósforo no solo (1990) quase todo o fósforo movimenta-se no solo por difusão, um processo lento e de pouca amplitude, que depende da umidade do solo. Condições de seca reduzem drasticamente a difusão e a absorção.

$\mathrm{Na}$ fase sólida do solo o fósforo se encontra predominantemente ligado ao $\mathrm{Fe}, \mathrm{Al}$ e $\mathrm{Ca}$, além de estar presente também na matéria orgânica; estes compostos apresentam baixa solubilidade e por isso é que o fósforo se apresenta em teores baixos na solução do solo (Raij, 1983). Quando se aplica fertilizantes fosfatados, parte vai para a fase sólida do solo, ficando como 
fósforo lábil que, com o passar dos anos, passa por um processo de "envelhecimento", passando para uma forma mais estável e de difícil solubilização (não lábil).

Existem diferenças de absorção entre plantas. Por exemplo, plantas que crescem rápido possuem sistema radicular pouco desenvolvido e, portanto, aproveitam mal a quantidade de fósforo presente no solo. Por essa razão, neste caso, há necessidade de se aplicar maior quantidade ao solo. Já uma planta de ciclo longo apresenta um sistema radicular mais desenvolvido o que resulta no bom aproveitamento de teores relativamente baixos de $P$ (Raij, 1983).

A maior capacidade da planta de absorver $\mathrm{Ca}$, a capacidade da raiz de acidificar a rizosfera e a presença de micorrizas nas raízes, favorecem o aproveitamento do fósforo pela planta (Siqueira, 1990). Foram observadas infecções micorrízicas em raízes de cana-de-açúcar em várias regiões do mundo (Andreola, 1982), sendo verificado também colonizações em área do presente estudo (Takahashi et al., 1998), o que pode ser mais um fator interferente na absorção do $P$.

\subsection{Análise de área foliar}

A folha é o órgão responsável pela produção de carboidratos, através da fotossíntese, fenômeno essencial para um bom desenvolvimento vegetal e conseqüentemente para uma boa produtividade. A determinação da área foliar (AF) é de extrema importância para trabalhos de ecofisiologia, pois, associando-a com outros parâmetros (Pereira \& Machado, 1987), se pode observar o comportamento da cana-de-açúcar nos diversos ambientes, e assim relacionar a variedade com seu potencial produtivo, produção de matéria seca e açúcar, em condições ambientais específicas (Pereira \& Machado, 1986).

Os métodos utilizados comumente para determinação da área foliar de uma cultura normalmente são destrutivos, complexos e demorados. O mais rotineiramente utilizado é o desenvolvido por Francis et al. (1969), que consiste em se fazer à medição de todas as folhas da planta e determinar a AF através 
de uma fórmula que leva em consideração a largura e o comprimento da folha, e um fator de correção, devido ao fato da folha possuir diferentes larguras no decorrer do seu comprimento.

Estudos de Hermann \& Câmara (1999) propuseram a utilização de uma outra fórmula para determinação da AF, já que o anterior era destrutivo e trabalhoso. O novo método apresentou boa correlação com aquele de Francis et al. (1969). A fórmula proposta pelos autores foram:

$$
\begin{aligned}
\text { AFC }=C \times L \times 0,75 \times(N+2) \quad & C=\text { comprimento da folha }+3 ; \\
& L=\text { largura da folha }+3 ; \\
& 0,75=\text { fator de forma; } \\
& N=\text { número de folhas abertas com pelo menos } \\
& 20 \% \text { de área verde (folha } 0 \text { a }+7 \text { ); }
\end{aligned}
$$

A grande vantagem deste método é a facilidade e rapidez de obtenção dos dados quando comparado ao de Francis et al. (1969). Quando se dispõe de mais recursos, modernos equipamentos permitem medidas diretas, dispensando tais medidas indiretas.

Outro parâmetro, o Índice de Área Foliar (IAF) expressa a proporção de área foliar em relação à área do solo, isto é, a densidade de cobertura (Loomis \& Williams, 1969). Tem a finalidade, portanto, de indicar a densidade do dossel que propicia a melhor ocupação do solo num dado momento.

O IAF numa cultura depende de uma série de fatores, uns intrinsecos à planta (variedade) e outros ao manejo antrópico. Do lado da planta, o que afeta basicamente o IAF é a organização espacial das folhas, os principais determinantes disso sendo a morfologia, a disposição e a distribuição vertical e horizontal das folhas; do lado antrópico, a densidade populacional, a forma de condução e o nivel de disponibilização de todos os fatores de produção (manejo do solo, da água e dos fatores biológicos externos à planta).

A capacidade de produção de fitomassa final fica, então, na dependência dessa interação genótipo - ambiente, com o fósforo sendo um dos 
agentes ambientais de grande influência nesses parâmetros, como é relatado nesta revisão. Por sua vez, a densidade foliar pode influir no manejo de plantas competidoras, o que na prática pode ser de grande importância numa agricultura que busca o máximo de otimização dos fatores de produção.

Até pouco tempo, o IAF era determinado de uma forma não muito exata, em razão da dificuldade de se mensurar a área foliar de uma comunidade vegetal. Para se solucionar esse problema, foi desenvolvido um método que determina a cobertura vegetal do solo através de imagens digitalizadas e uso do SIARCS (Jorge, 1996). Consiste em se filmar uma área determinada da cultura e pelo contraste das cores se determinar a exata área coberta.

\subsection{Variedades de cana-de-açúcar}

A agroindústria canavieira tem como base boas variedades de canade-açúcar criadas por ativos programas de melhoramento genético (Matsuoka et al., 1999). São elas que garantem altas produtividades, agrícola e industrial, além de assegurar um mínimo de estabilidade à atividade. Também, em razão dos diversos ambientes de cultivo, elas são intensamente avaliadas nas distintas situações (Matsuoka et al., 1998). Entretanto, há carência de maiores conhecimentos sobre a fenologia dessas variedades, e muito menos se dispõe de dados de ecofisiologia. O conhecimento do modelo de desenvolvimento sob diferentes doses de $P$ seria o ponto de partida para o melhor manejo dessas variedades. 


\section{MATERIAL E MÉTODOS}

Um dos experimentos foi conduzido no Centro de Ciências Agrárias da Universidade Federal de São Carlos, campus de Araras, SP, cujas coordenadas geográficas são latitude $22^{\circ} 18^{\prime} \mathrm{S}$, longitude $47^{\circ} 23^{\prime} \mathrm{W}$ e altitude média de $620 \mathrm{~m}$ (Sousa, 1976), e cujo solo é um LV df, LATOSSOLO VERMELHO Distroférrico típico, textura argilosa / muito argilosa e A moderado. O outro, foi conduzido na Estação Experimental da UFSCar em Valparaiso , cujas coordenadas são latitude $21^{\circ} 16^{\prime} \mathrm{S}$, longitude $50^{\circ} 20^{\prime} \mathrm{W}$ e altitude $370 \mathrm{~m}$ (Dias et al, 1999) e o solo caracterizado como PV (PODZÓLICO VERMELHO Distrófico), com A moderado.

Os solos desses experimentos apresentavam as seguintes composições químicas antes da adubação e correção do solo (Tabela 1 e 2).

Tabela 1. Análise química do solo de Araras.

\begin{tabular}{|c|c|c|c|c|c|c|c|c|}
\hline 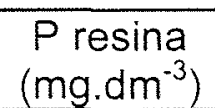 & $\begin{array}{c}\mathrm{MO} \\
\left(\mathrm{mg} \cdot \mathrm{dm}^{-3}\right)\end{array}$ & $\begin{array}{c}\mathrm{pH} \\
\mathrm{CaCl}_{2}\end{array}$ & $\mathrm{~K}$ & $\mathrm{Ca}$ & $\begin{aligned} & M g \\
&-m o l_{c} \cdot d^{-3}\end{aligned}$ & $\mathrm{SB}$ & CTC & $\begin{array}{l}V \\
\%\end{array}$ \\
\hline 7 & 30 & 4,9 & 1,5 & 26 & $6 \quad 36$ & 33,5 & 69,5 & 48 \\
\hline
\end{tabular}

Tabela 2. Análise química do solo de Valparaiso.

\begin{tabular}{ccccccccccc}
\hline $\begin{array}{c}\text { P resina } \\
\left(\mathrm{mg} \cdot \mathrm{dm}^{-3}\right)\end{array}$ & $\begin{array}{c}\mathrm{MO} \\
\left(\mathrm{mg} \cdot \mathrm{dm}^{-3}\right)\end{array}$ & $\begin{array}{c}\mathrm{pH} \\
\mathrm{CaCl}_{2}\end{array}$ & $\mathrm{~K}$ & $\mathrm{Ca}$ & $\mathrm{Mg}$ & $\mathrm{H}+\mathrm{Al}$ & $\mathrm{Al}$ & $\mathrm{SB}$ & $\mathrm{CTC}$ & $\mathrm{V}$ \\
\hline 10 & 11 & 5,2 & 2,2 & 13 & 4 & 15 & 0,8 & 19,2 & 34,2 & 56 \\
\hline
\end{tabular}

Antes de se implantar os tratamentos foram realizados os seguintes tratos:

- $850 \mathrm{~kg} / \mathrm{ha}$ de calcário (PRNT $=100$ ) ou $1.200 \mathrm{~g}$ em $10 \mathrm{~m}$ sulco; 
- $60 \mathrm{~kg} / \mathrm{ha}$ de nitrogênio ou $186 \mathrm{~g}$ de uréia em $10 \mathrm{~m}$ sulco;

- $120 \mathrm{~kg} / \mathrm{ha}$ de potássio $\left(\mathrm{K}_{2} \mathrm{O}\right)$ ou $280 \mathrm{~g}$ de $\mathrm{KCl}$ em $10 \mathrm{~m}$ sulco;

- $5 \mathrm{~kg} / \mathrm{ha}$ de zinco $(\mathrm{Zn})$ ou $35 \mathrm{~g}$ sulfato de zinco em $10 \mathrm{~m}$ sulco;

Os tratamentos de niveis de $P$ foram os que estão apresentados na tabela 3.

Tabela 3. Adubações fosfatadas feitas por tratamento.

\begin{tabular}{cc}
\hline Tratamentos & $\begin{array}{c}\mathrm{P}_{2} \mathrm{O}_{5} \\
(\mathrm{~kg} / \mathrm{ha})\end{array}$ \\
\hline $\mathrm{T} 1$ & 0 \\
$\mathrm{~T} 2$ & 80 \\
$\mathrm{~T} 3$ & 160 \\
$\mathrm{~T} 4$ & 240 \\
\hline
\end{tabular}

Os experimentos foram instalados em esquema fatorial, cada tratamento aplicado a 4 modernas variedades de cana-de-açúcar, cujas características botânicas e agronômicas (Matsuoka et al., 1998; ARIZONO, 2000) estão sumarizadas abaixo, em quatro repetições dentro de quatro blocos, totalizando 64 parcelas. Cada parcela foi constituida de cinco linhas de $10 \mathrm{~m}$. Em cada sulco plantou-se de 15 a 18 gemas por metro.

As avaliações foram realizadas de bimestralmente na cana-planta em Araras e num intervalo de 45 dias aproximadamente em Valparaíso, e, posteriormente, na passagem de uma estação para outra.

\subsection{Variedades utilizadas (UFSCar, 2001)}

\section{RB835054 (RB72454 x NA56-79)}

Apresenta touceiramento médio, colmos eretos, pouco empalhados, de fácil despalha, de diâmetro médio; entrenós médios, de cor verde clara, arroxeados quando expostos, e com manchas de cera escurecidas, alinhados em ziguezague; gemas ovaladas, de tamanho médio, sem almofada. Capitel 
ralo, com folhas verde claras, de largura e comprimento médios, as novas espigas, podendo apresentar-se dobradas nas pontas, e as inferiores arqueadas; aurícula de um só lado, lanceolada, de tamanho médio; bainhas esverdeadas com áreas arroxeadas, sem joçal.

Possui boa brotação, perfilhamento regular, porte ereto, fraco fechamento de entrelinhas e exigente em solos. Ausência de floração e chochamento, é de maturação precoce.

\section{RB835486 (L60-14 x ?)}

Apresenta touceiras ralas, decumbentes na fase aduita, colmos medianamente empalhados, de fácil despalha, diâmetro médio a grosso e de elevado peso, cor arroxeada, com abundante cera; entrenós médios, dispostos em leve ziguezague; gemas arredondadas, com pequena almofada e asas médias; capitel médio, folhas de largura e comprimento médios, eretas, geralmente dispostas em leque, com leve curvatura na ponta; uma aurícula deltóide e outra incipiente; bainha sem joçal.

Possui brotação e perfilhamento regulares, fechamento de entrelinhas bom, brotação de soca regular, mas sempre com boa produção, pode tombar em cana-planta, pouco exigente em solos. Tem maturação precoce, muito rica em açúcar, excelente qualidade de caldo, floração considerada regular e pouco chochamento.

\section{RB855113 (SP70-1143 x RB72454)}

Apresenta alto touceiramento, colmos eretos, empalhados, de diâmetro médio, e de cor verde amarelada, com manchas de cera; entrenós médio, alinhados em leve ziguezague; gemas arredondadas, médias, com almofada estreita; capitel médio, com folhas verde escuras, de largura e comprimento médios, as novas espigadas e dobradas nas pontas, com margem serrilhada agressiva; uma só aurícula e ainda transitória; bainha longa e 
esverdeada, com bordo marrom, com pouco joçal 57, decíduo, mas média quantidade de joçal 60 , duro, agressivo.

Possui boa brotação, muito bom perfilhamento, porte ereto, boa soca, boa adaptabilidade a todos os tipos de solo. É sensivel a herbicida de pós hemergência, tem floração rara e pouco chochamento, maturação média e boa riqueza.

\section{RB855536 (SP70-1143 x RB72454)}

Apresenta bom touceiramento, colmos semi-abertos e eretos, empalhados, mas com bainhas semi-abertas, de fácil despalha, de diâmetro médio, e de cor arroxeada; entrenós médios, alinhados em leve ziguezague, e com média quantidade de cera; gemas ovaladas a arredondadas, médias, com almofada média; capitel médio, com folhas espetadas, bordo palha estreito, com pouco joçal (57 e 60), decíduo.

Possui boa brotação e perfilhamento, rápido fechamento de entrelinhas, excepcional brotação de soca, porte ereto, mas fácil tombamento, excelente desempenho de brotação em cana colhida sem queima prévia. 0 florescimento e chochamento são ausentes. Maturação média, com alto teor de açúcar.

\subsection{Parâmetros avaliados}

\subsubsection{Altura e perfilhamento}

Para a determinação do crescimento foram realizadas medições de altura da planta, partindo do solo até a última região auricular visivel da folha +1 , segundo a numeração sugerida por Kuijper (Dillewijn, 1952). Para isso, marcou-se um metro linear de cada uma das três linhas centrais e dentro dessa marcação selecionou-se 8 colmos para avaliação. Neste mesmo metro, foi realizada a contagem do número de perfilhos. 


\subsubsection{Fitomassa da parte aérea}

A determinação do peso médio dos colmos foi feita através da pesagem de 10 colmos em ocasião da colheita, identificando as porções que foram desenvolvidas em cada época (Figura 1).

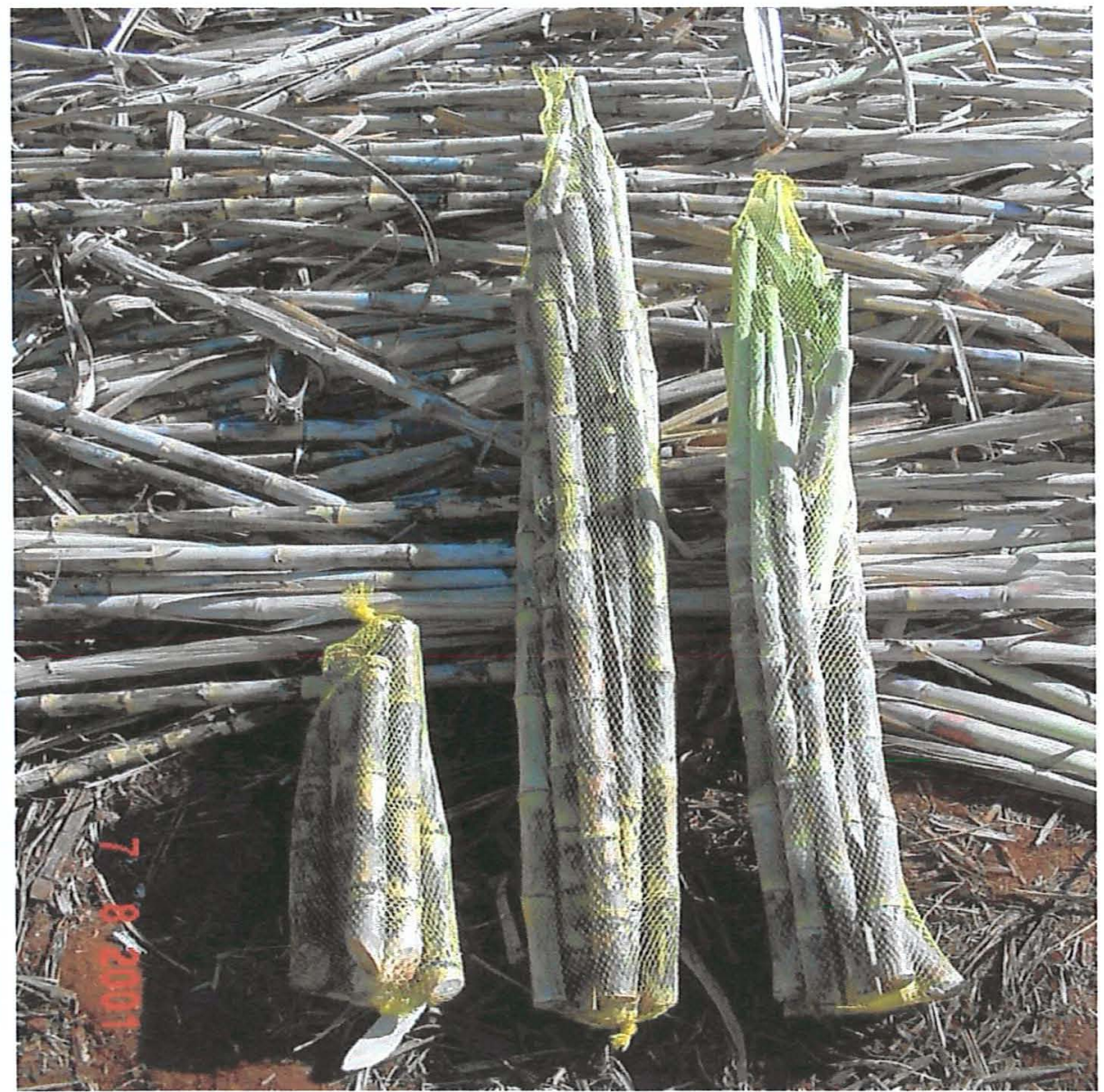

Figura 1 - Esquema da separação do colmo em partes, de acordo com o período de desenvolvimento. Da esquerda para direita, porções formadas de agosto a dezembro, de dezembro a março e março a agosto. 


\subsection{3 Área foliar e índice de área foliar}

$O$ IAF, índice de área foliar, foi obtido através de medições com o aparelho $\mathrm{Cl}-100$ da $\mathrm{CID}$, este aparelho mede o IAF pelo contraste de luz existente entre a atmosfera e a cobertura vegetal. A mesuração foi realizada no centro da entrelinha, na altura da folha fotossintéticamente ativa mais velha, com o intuito de determinar o sombreamento presente nessa altura do dossel.

Para avaliação da área foliar da cana soca foi utilizada a equação descrita por Hermann \& Câmara (1999). Realizou-se medições na folha $+3 \mathrm{com}$ o aparelho LI-3100 da LICOR de dez colmos.

\subsubsection{Produção}

A produção foi determinada contando-se o número de colmos total da parcela e pesando-se 10 colmos por linha, totalizando-se 30 colmos por parcela.

\subsubsection{Parâmetros tecnológicos}

Foram avaliadas a Pol\%cana, fibra e brix no laboratório do Departamento de Tecnologia Agroindustrial, do Centro de Ciências Agrárias, da Universidade Federal de São Carlos. No experimento em Araras, além desses parâmetros avaliou-se também a quantidade de fósforo contida no caldo. 


\section{RESULTADOS E DISCUSSÃO}

\subsection{Dados Climatológicos}

Os extratos do balanço hídrico e os dados climatológicos decendiais de Araras estão apresentados na figuras 2 e 3 e os de Valparaíso, observações coletadas do IAC-Adamantina, nas 4 e 5.

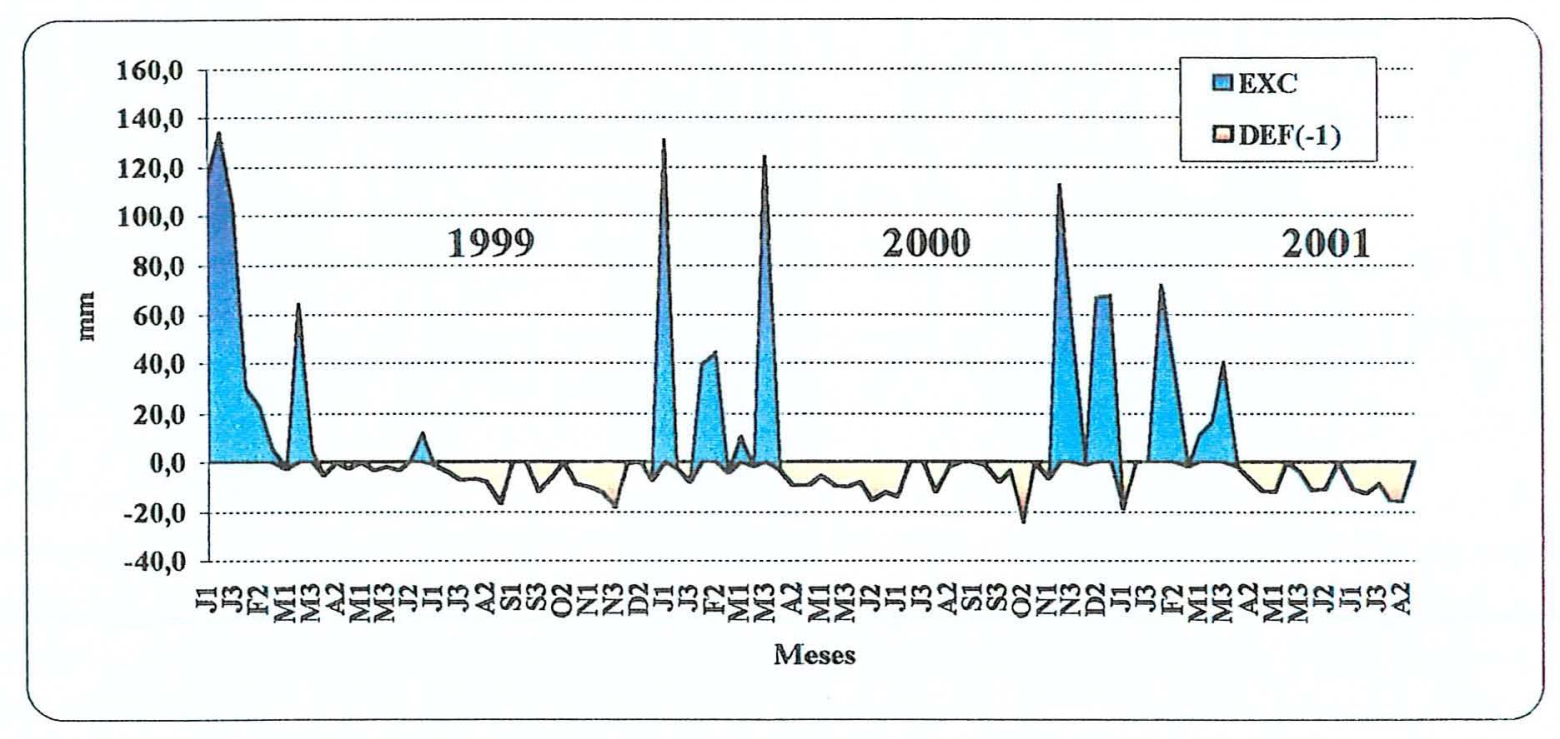

Figura 2 - Extrato do balanço hídrico de Araras. 


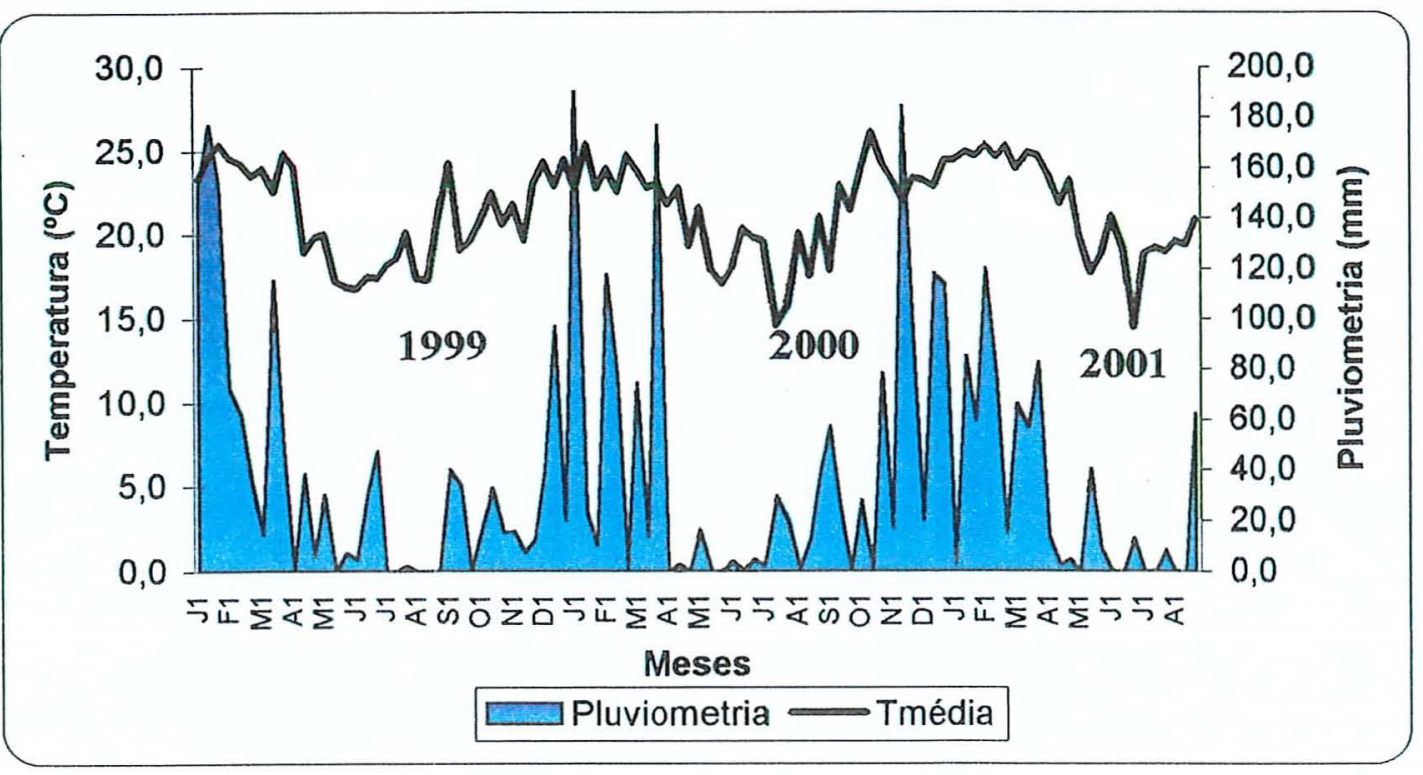

Figura 3 - Temperatura máxima, mínima, média e pluviometria do Centro de Ciências Agrárias de Araras.

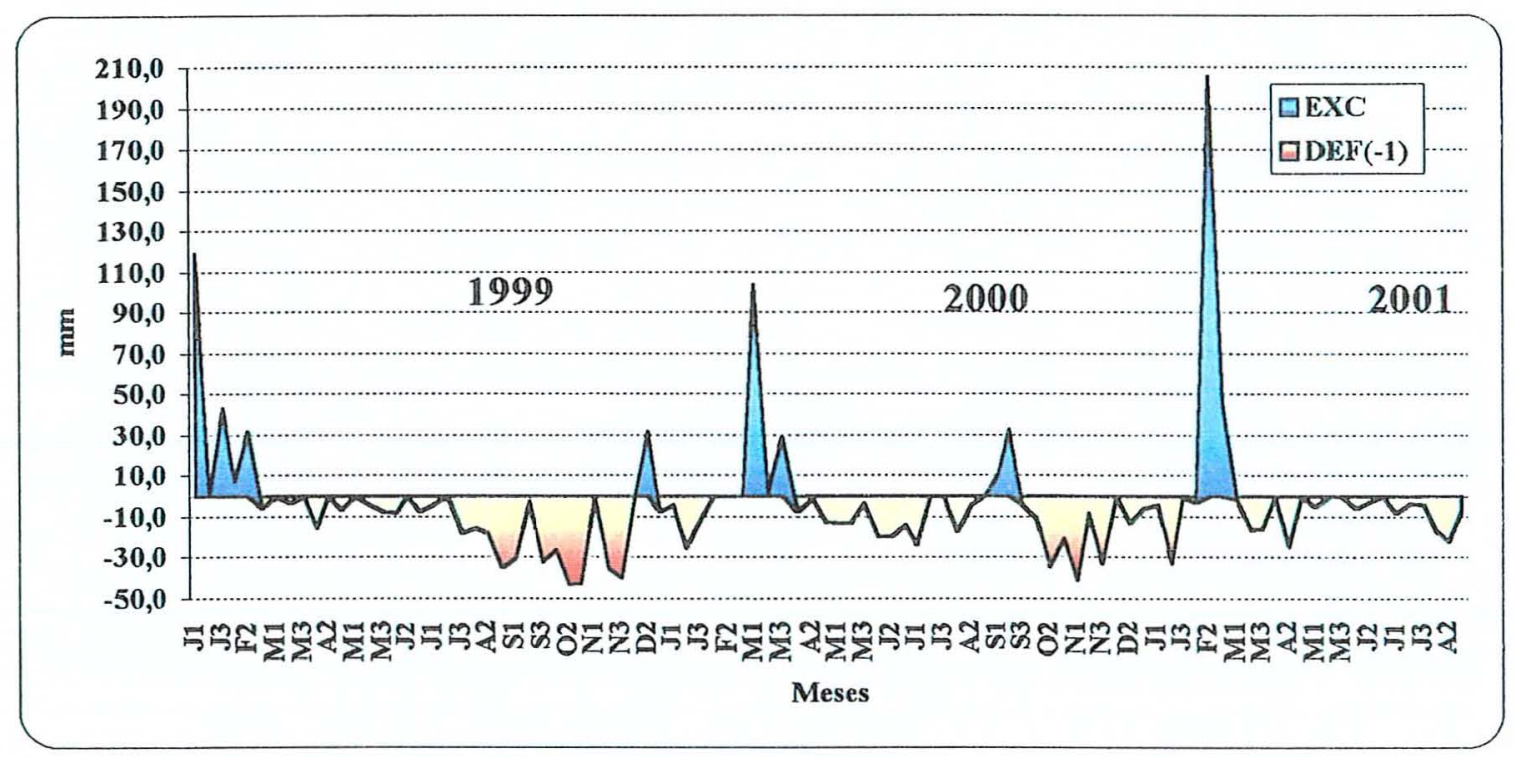

Figura 4 - Extrato do balanço hídrico de Valparaíso. 


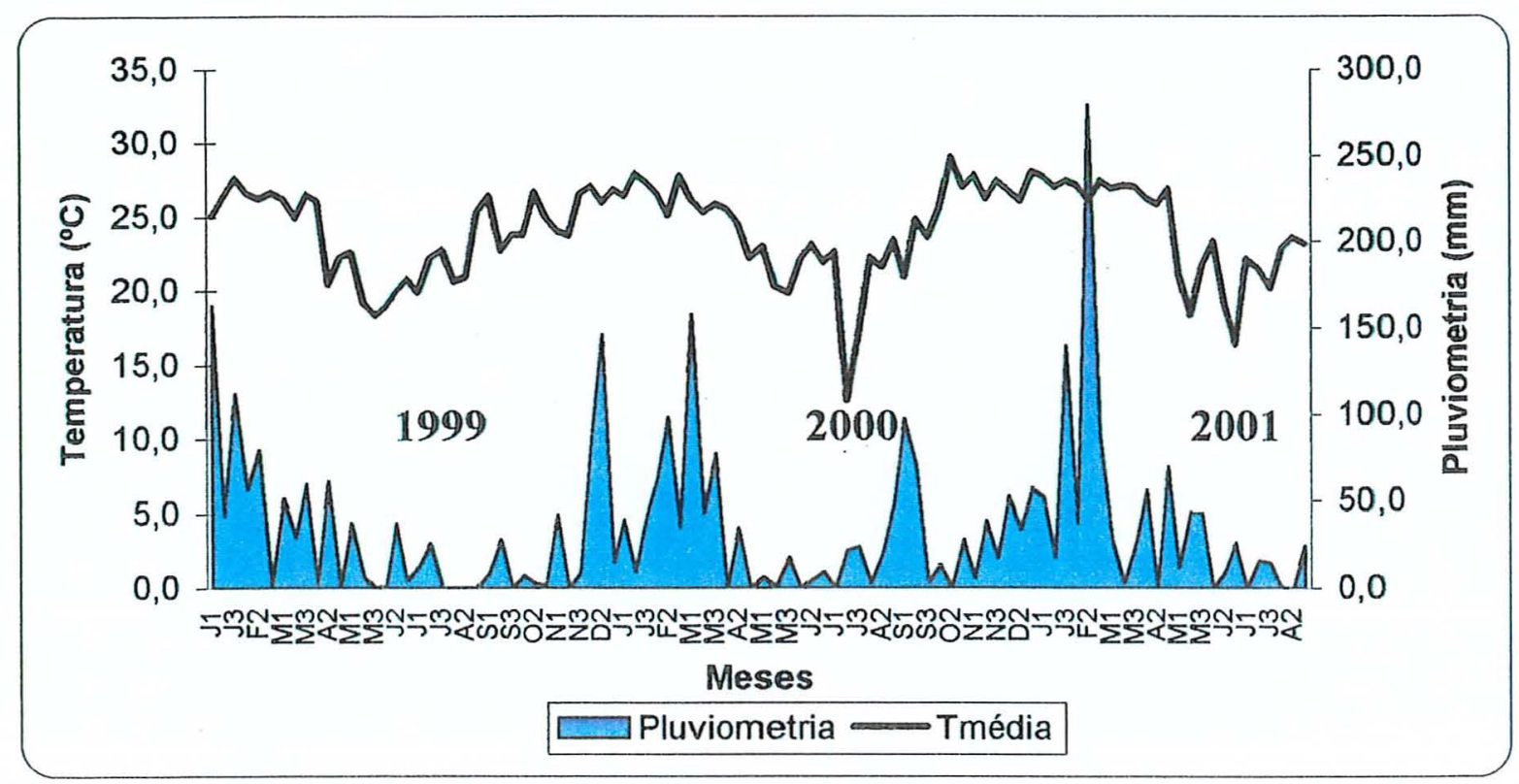

Figura 5 - Temperatura máxima, mínima, média e pluviometria de Valparaíso provenientes da estação meteorológica do IAC - Adamantina.

Como se pode observar, o período em que ocorreu maior precipitação e as temperaturas máximas, mínimas e médias foram mais altas foi de novembro a abril.

\section{CANA-PLANTA}

\subsection{Altura das plantas}

\section{Araras}

Houve interação significativa entre doses e variedades nas amostragens feitas em janeiro e março em cana-planta de Araras (tabela 4). $\mathrm{Na}$ amostragem realizada no momento em que a cana estava com 8 meses, janeiro, verificou-se que na variedade RB835486 a testemunha, dose 0 , apresentou os maiores valores e a. de $240 \mathrm{~kg} \cdot \mathrm{ha}^{-1}$ os menores. Na RB835054 
verificou um aumento de crescimento com o aumento da quantidade de fósforo aplicada ao solo, mas as diferenças não foram significativas estatisticamente. Resultado semelhante foi encontrado nas demais variedades. Em relação às diferenças entre variedades dentro de uma mesma dose de fósforo, os maiores valores foram obtidos na RB835486 e os menores na RB855113.

Tabela 4. Altura de plantas nos diferentes tratamentos e avaliações em Araras.

\begin{tabular}{|c|c|c|c|c|c|}
\hline \multirow[t]{2}{*}{ VARIEDADES } & \multirow{2}{*}{$\begin{array}{l}\text { DOSES DE } \\
\text { FÓSFORO } \\
\left(\mathrm{kg} \mathrm{P}_{2} \mathrm{O}_{5} \cdot \mathrm{ha}^{-1}\right)\end{array}$} & \multicolumn{4}{|c|}{$\begin{array}{c}\text { ALTURA } \\
(\mathrm{m})\end{array}$} \\
\hline & & Set/99 & Nov/99 & $\operatorname{Jan} / 00$ & Mar/00 \\
\hline RB835486 & $\begin{array}{c}0 \\
80 \\
160 \\
240\end{array}$ & $\begin{array}{l}0,26 \mathrm{Aa} \\
0,24 \mathrm{Aa} \\
0,25 \mathrm{Aa} \\
0,23 \mathrm{Aa}\end{array}$ & $\begin{array}{l}0,52 \mathrm{Aa} \\
0,49 \mathrm{Aa} \\
0,49 \mathrm{Aa} \\
0,51 \mathrm{Aa}\end{array}$ & $\begin{array}{c}1,24 \mathrm{Aab} \\
1,10 \mathrm{ABb} \\
1,17 \mathrm{ABb} \\
1,07 \mathrm{Bc}\end{array}$ & $\begin{array}{c}2,23 \mathrm{Aab} \\
2,17 \mathrm{Abc} \\
2,21 \mathrm{Ab} \\
2,15 \mathrm{Ac}\end{array}$ \\
\hline RB835054 & $\begin{array}{c}0 \\
80 \\
160 \\
240\end{array}$ & $\begin{array}{l}0,21 \mathrm{Aa} \\
0,22 \mathrm{Aa} \\
0,27 \mathrm{Aa} \\
0,25 \mathrm{Aa}\end{array}$ & $\begin{array}{l}0,62 \mathrm{Aa} \\
0,60 \mathrm{Aa} \\
0,70 \mathrm{Aa} \\
0,73 \mathrm{Aa}\end{array}$ & $\begin{array}{l}1,37 \mathrm{Aa} \\
1,38 \mathrm{Aa} \\
1,44 \mathrm{Aa} \\
1,50 \mathrm{Aa}\end{array}$ & $\begin{array}{c}2,41 \mathrm{ABa} \\
2,38 \mathrm{Bab} \\
2,47 \mathrm{ABa} \\
2,59 \mathrm{Aa}\end{array}$ \\
\hline RB855113 & $\begin{array}{c}0 \\
80 \\
160 \\
240\end{array}$ & $\begin{array}{l}0,18 \mathrm{Aa} \\
0,19 \mathrm{Aa} \\
0,18 \mathrm{Aa} \\
0,22 \mathrm{Aa}\end{array}$ & $\begin{array}{l}0,40 \mathrm{Aa} \\
0,46 \mathrm{Aa} \\
0,41 \mathrm{Aa} \\
0,44 \mathrm{Aa}\end{array}$ & $\begin{array}{l}1,02 \mathrm{Ac} \\
1,02 \mathrm{Ab} \\
1,06 \mathrm{Ab} \\
1,08 \mathrm{Ac}\end{array}$ & $\begin{array}{l}2,05 \mathrm{Ac} \\
2,12 \mathrm{Ac} \\
2,05 \mathrm{Ab} \\
2,09 \mathrm{Ac}\end{array}$ \\
\hline RB855536 & $\begin{array}{c}0 \\
80 \\
160 \\
240\end{array}$ & $\begin{array}{l}0,20 \mathrm{Aa} \\
0,26 \mathrm{Aa} \\
0,26 \mathrm{Aa} \\
0,25 \mathrm{Aa}\end{array}$ & $\begin{array}{l}0,47 \mathrm{Aa} \\
0,52 \mathrm{Aa} \\
0,55 \mathrm{Aa} \\
0,57 \mathrm{Aa}\end{array}$ & $\begin{array}{l}1,13 \mathrm{Abc} \\
1,14 \mathrm{Ab} \\
1,11 \mathrm{Ab} \\
1,24 \mathrm{Ab}\end{array}$ & $\begin{array}{c}2,23 \mathrm{ABab} \\
2,39 \mathrm{Aa} \\
2,18 \mathrm{Bb} \\
2,36 \mathrm{Abb}\end{array}$ \\
\hline $\begin{array}{l}\text { CV } \\
\text { Média }\end{array}$ & $\begin{array}{l}\%) \\
\text { Geral }\end{array}$ & $\begin{array}{c}14,87 \\
0,23\end{array}$ & $\begin{array}{l}9,93 \\
0,53\end{array}$ & $\begin{array}{l}5,97 \\
1,19\end{array}$ & $\begin{array}{l}3,95 \\
2,25\end{array}$ \\
\hline
\end{tabular}

Em março, comparando doses de fósforo dentro de uma mesma variedade, foram encontradas diferenças significativas apenas na RB835054 e RB855536. Na RB835054 a maior dosagem de fósforo foi a que obteve os melhores resultados e a de 80 os menores. Já na RB855536 essa mesma dose de 80 proporcionou o maior crescimento de plantas, $10 \%$ a superior à de 160 
$\mathrm{kg} \mathrm{ha}^{-1}$, na qual encontraram-se os menores valores. Considerando médias de variedades dentro de uma mesma dose de fósforo, nota-se que o crescimento da RB 835054 foi maior que as demais. A RB855113 foi a que apresentou menor crescimento.

Foram encontradas diferenças significativas entre médias de variedades em todas as épocas amostradas (tabela 5), as quais podem ser melhor visualizadas na figura 6. De forma geral, o maior crescimento foi observado na RB835054 e o menor na RB855113. As RB855536 e RB835486 apresentaram valores intermediários. Este resultado está relacionado com as características genéticas dessas variedades. Plantas que perfilham mais, como é o caso da RB855113, acabam utilizando boa parte dos compostos produzidos na fotossintese e os nutrientes absorvidos no perfilhamento, prejudicando, assim, o seu desenvolvimento vegetativo.

Tabela 5. Diferença varietal em relação ao crescimento em diferentes épocas.

\begin{tabular}{ccccc}
\hline \multirow{2}{*}{ VARIEDADES } & \multicolumn{4}{c}{ ALTURA $(\mathrm{m})$} \\
\cline { 2 - 5 } & Set/99 & Nov/99 & Jan/00 & Mar/00 \\
\hline RB835486 & $0,25 \mathrm{~A}$ & $0,50 \mathrm{~B}$ & $1,15 \mathrm{~B}$ & $2,19 \mathrm{~B}$ \\
RB835054 & $0,24 \mathrm{~A}$ & $0,66 \mathrm{~A}$ & $1,42 \mathrm{~A}$ & $2,46 \mathrm{~A}$ \\
RB855113 & $0,19 \mathrm{~B}$ & $0,43 \mathrm{C}$ & $1,05 \mathrm{C}$ & $2,08 \mathrm{C}$ \\
RB855536 & $0,24 \mathrm{~A}$ & $0,53 \mathrm{~B}$ & $1,16 \mathrm{~B}$ & $2,29 \mathrm{~B}$ \\
\hline
\end{tabular}




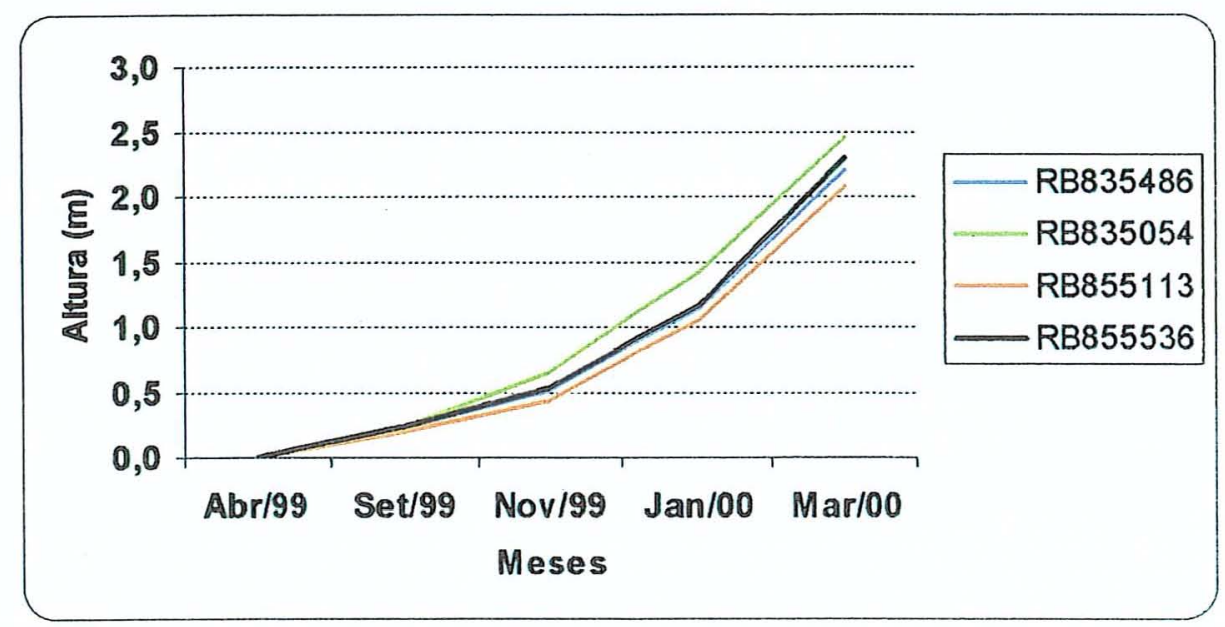

Figura 6 - Altura das plantas em diferentes variedades.

Quanto às médias entre doses de fósforo, ocorreram diferenças significativas entre os tratamentos somente na amostragem feita em novembro (tabela 6). Nesta, verificou-se que o aumento na quantidade de fósforo aplicado ao solo refletiu em maior crescimento. Nas demais épocas, apesar de observar tendência de situação semelhante, não foram detectadas diferenças significativas entre doses.

Tabela 6. Altura de plantas de acordo com as doses de fósforo.

\begin{tabular}{ccccc}
\hline DOSES DE & \multicolumn{4}{c}{ ALTURA $(\mathrm{m})$} \\
\cline { 2 - 5 } $\begin{array}{c}\text { FOSFORO } \\
\left(\mathrm{kg} \mathrm{P}_{2} \mathrm{O}_{5} \cdot \mathrm{ha}^{-1}\right)\end{array}$ & Set/99 & Nov/99 & Jan/00 & Mar/00 \\
\hline 0 & $0,21 \mathrm{~A}$ & $0,50 \mathrm{~B}$ & $1,19 \mathrm{~A}$ & $2,23 \mathrm{~A}$ \\
80 & $0,23 \mathrm{~A}$ & $0,52 \mathrm{AB}$ & $1,16 \mathrm{~A}$ & $2,26 \mathrm{~A}$ \\
160 & $0,24 \mathrm{~A}$ & $0,54 \mathrm{AB}$ & $1,20 \mathrm{~A}$ & $2,23 \mathrm{~A}$ \\
240 & $0,24 \mathrm{~A}$ & $0,56 \mathrm{~A}$ & $1,22 \mathrm{~A}$ & $2,30 \mathrm{~A}$ \\
\hline
\end{tabular}

\section{Valparaíso}

Não foi observada interação significativa entre doses de fósforo e variedades em estudo para altura de plantas (tabela 7), apesar de se verificar tendência de aumento no crescimento de plantas com a elevação das quantidades de f́ósforo aplicada nas variedades RB835054 e RB855536. 
Tabela 7. Altura das plantas nos diferentes tratamentos em Valparaiso

\begin{tabular}{|c|c|c|c|c|c|c|c|}
\hline \multirow[t]{2}{*}{ VARIEDADES } & \multirow{2}{*}{$\begin{array}{c}\text { DOSES DE } \\
\text { FÓSFORO } \\
\left(\mathrm{kg} \mathrm{P}_{2} \mathrm{O}_{5} \cdot \mathrm{ha}^{-1}\right)\end{array}$} & \multicolumn{6}{|c|}{$\begin{array}{c}\text { ALTURA } \\
(\mathrm{m})\end{array}$} \\
\hline & & $04 / 10 / 99$ & $18 / 11 / 99$ & $04 / 01 / 00$ & $21 / 02 / 00$ & $18 / 04 / 00$ & $27 / 06 / 00$ \\
\hline \multirow{4}{*}{ RB835486 } & 0 & $0,26 \mathrm{Aa}$ & $0,45 \mathrm{Aa}$ & $0,96 \mathrm{Aa}$ & $1,84 \mathrm{Aa}$ & $2,87 \mathrm{Aa}$ & $3,12 \mathrm{Aa}$ \\
\hline & 80 & $0,28 \mathrm{Aa}$ & $0,52 \mathrm{Aa}$ & $0,98 \mathrm{Aa}$ & $1,80 \mathrm{Aa}$ & $2,85 \mathrm{Aa}$ & $3,08 \mathrm{Aa}$ \\
\hline & 160 & $0,26 \mathrm{Aa}$ & $0,42 \mathrm{Aa}$ & $0,95 \mathrm{Aa}$ & $1,79 \mathrm{Aa}$ & $2,81 \mathrm{Aa}$ & $3,02 \mathrm{Aa}$ \\
\hline & 240 & $0,26 \mathrm{Aa}$ & $0,46 \mathrm{Aa}$ & $0,97 \mathrm{Aa}$ & $1,83 \mathrm{Aa}$ & $2,81 \mathrm{Aa}$ & $3,13 \mathrm{Aa}$ \\
\hline \multirow{4}{*}{ RB835054 } & 0 & $0,29 \mathrm{Aa}$ & $0,45 \mathrm{Aa}$ & $1,05 \mathrm{Aa}$ & $1,87 \mathrm{Aa}$ & $2,79 \mathrm{Aa}$ & $2,93 \mathrm{Aa}$ \\
\hline & 80 & $0,30 \mathrm{Aa}$ & $0,42 \mathrm{Aa}$ & $1,05 \mathrm{Aa}$ & $1,87 \mathrm{Aa}$ & $2,76 \mathrm{Aa}$ & $2,93 \mathrm{Aa}$ \\
\hline & 160 & $0,27 \mathrm{Aa}$ & $0,49 \mathrm{Aa}$ & $1,01 \mathrm{Aa}$ & $1,84 \mathrm{Aa}$ & $2,73 \mathrm{Aa}$ & $2,81 \mathrm{Aa}$ \\
\hline & 240 & $0,31 \mathrm{Aa}$ & $0,46 \mathrm{Aa}$ & $1,14 \mathrm{Aa}$ & $1,96 \mathrm{Aa}$ & $2,85 \mathrm{Aa}$ & $3.01 \mathrm{Aa}$ \\
\hline \multirow{4}{*}{ RB855113 } & 0 & $0,24 \mathrm{Aa}$ & $0,44 \mathrm{Aa}$ & $0,81 \mathrm{Aa}$ & $1,61 \mathrm{Aa}$ & $2,37 \mathrm{Aa}$ & $2,62 \mathrm{Aa}$ \\
\hline & 80 & $0,23 \mathrm{Aa}$ & $0,51 \mathrm{Aa}$ & $0,87 \mathrm{Aa}$ & $1,70 \mathrm{Aa}$ & $2,58 \mathrm{Aa}$ & $2,74 \mathrm{Aa}$ \\
\hline & 160 & $0,22 \mathrm{Aa}$ & $0,48 \mathrm{Aa}$ & $0,81 \mathrm{Aa}$ & $1,57 \mathrm{Aa}$ & $2,45 \mathrm{Aa}$ & $2,63 \mathrm{Aa}$ \\
\hline & 240 & $0,21 \mathrm{Aa}$ & $0,39 \mathrm{Aa}$ & $0,78 \mathrm{Aa}$ & $1,54 \mathrm{Aa}$ & $2,46 \mathrm{Aa}$ & $2,65 \mathrm{Aa}$ \\
\hline \multirow{4}{*}{ RB855536 } & 0 & $0,25 \mathrm{Aa}$ & $0,54 \mathrm{Aa}$ & $0,92 \mathrm{Aa}$ & $1,76 \mathrm{Aa}$ & $2,66 \mathrm{Aa}$ & $2,84 \mathrm{Aa}$ \\
\hline & 80 & $0,24 \mathrm{Aa}$ & $0,41 \mathrm{Aa}$ & $0,85 \mathrm{Aa}$ & $1,60 \mathrm{Aa}$ & $2,54 \mathrm{Aa}$ & $2,62 \mathrm{Aa}$ \\
\hline & 160 & $0,21 \mathrm{Aa}$ & $0,51 \mathrm{Aa}$ & $0,84 \mathrm{Aa}$ & $1,69 \mathrm{Aa}$ & $2,57 \mathrm{Aa}$ & $2,72 \mathrm{Aa}$ \\
\hline & 240 & $0,23 \mathrm{Aa}$ & $0,45 \mathrm{Aa}$ & $0,87 \mathrm{Aa}$ & $1,66 \mathrm{Aa}$ & $2,57 \mathrm{Aa}$ & $2,76 \mathrm{Aa}$ \\
\hline \multirow{2}{*}{\multicolumn{2}{|c|}{$\begin{array}{c}\text { CV }(\%) \\
\text { Média Geral }\end{array}$}} & 9,98 & 18,56 & 8,41 & 5,26 & 7,12 & 4,83 \\
\hline & & 0,25 & 0,46 & 0,93 & 1,74 & 2,65 & 2,85 \\
\hline
\end{tabular}

letras maiúsculas referem-se a tratamentos dentro de uma mesma variedade e letras minúsculas dentro de uma mesma dose (comparação entre variedades).

Comparando as médias das variedades, a amostragem realizada em novembro foi a única que não apresentou diferenças significativas (tabela 8). Nas demais se verificou que as variedades RB835486 e RB835054 foram as que apresentaram os maiores valores. As menores alturas foram encontradas na RB855113, que não diferiu, na maioria das amostragens, da RB855536. Essa análise pode ser visualizada na figura 7.

Tabela 8. Médias de altura entre variedades em Valparaíso

\begin{tabular}{ccccccc}
\hline \multirow{2}{*}{ VARIEDADES } & \multicolumn{7}{c}{ ALTURA $(\mathrm{m})$} \\
\cline { 2 - 7 } & $04 / 10 / 99$ & $18 / 11 / 99$ & $04 / 01 / 00$ & $21 / 02 / 00$ & $18 / 04 / 00$ & $27 / 06 / 00$ \\
\hline RB835486 & $0,27 \mathrm{~A}$ & $0,46 \mathrm{~A}$ & $0,97 \mathrm{~B}$ & $1,81 \mathrm{~A}$ & $2,83 \mathrm{~A}$ & $3,09 \mathrm{~A}$ \\
RB835054 & $0,29 \mathrm{~A}$ & $0,46 \mathrm{~A}$ & $1,06 \mathrm{~A}$ & $1,87 \mathrm{~A}$ & $2,78 \mathrm{~A}$ & $2.92 \mathrm{~B}$ \\
RB855113 & $0,23 \mathrm{~B}$ & $0,46 \mathrm{~A}$ & $0,82 \mathrm{C}$ & $1,60 \mathrm{~B}$ & $2,46 \mathrm{C}$ & $2,66 \mathrm{C}$ \\
RB855536 & $0,23 \mathrm{~B}$ & $0,48 \mathrm{~A}$ & $0,87 \mathrm{C}$ & $1,68 \mathrm{~B}$ & $2,59 \mathrm{~B}$ & $2,74 \mathrm{C}$ \\
\hline
\end{tabular}




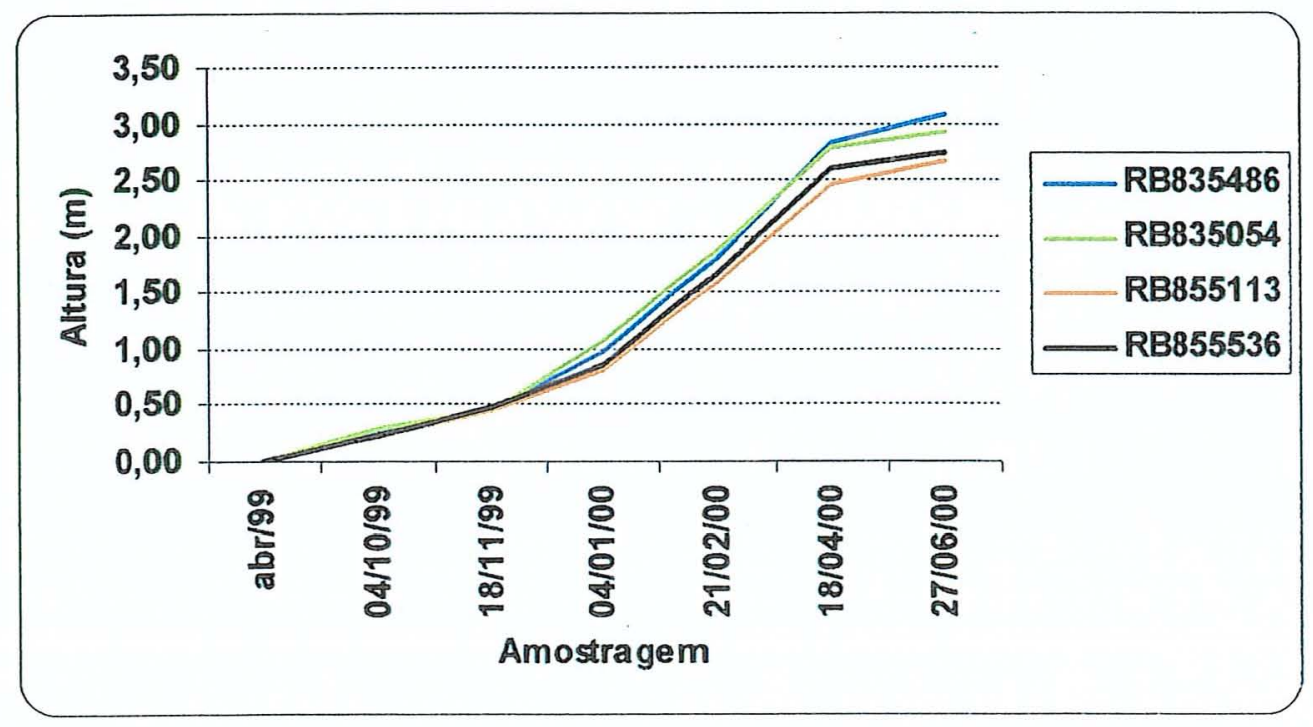

Figura 7 - Altura média das variedades em estudo em Valparaíso.

Em relação às doses de fósforo, com exceção da primeira amostragem, não se verificaram diferenças entre as médias. Nessa amostragem, as plantas das parcelas em que foram aplicadas $80 \mathrm{~kg} \mathrm{P}_{2} \mathrm{O}_{5}$. ha ${ }^{-1}$ foram, em média, as que mais cresceram, ainda que não diferindo significativamente das doses 0 e $240 \mathrm{~kg} \mathrm{P}_{2} \mathrm{O}_{5} \cdot$ ha $^{-1}$ (tabela 9).

Tabela 9. Médias de altura entre variedades em Valparaíso

\begin{tabular}{ccccccc}
\hline DOSES DE & \multicolumn{6}{c}{ ALTURA $(\mathrm{m})$} \\
\cline { 2 - 6 } $\begin{array}{c}\text { FÓSFORO } \\
\left(\mathrm{kg} \mathrm{P}_{2} \mathrm{O}_{5} \text { ha }^{-1}\right)\end{array}$ & $04 / 10 / 99$ & $18 / 11 / 99$ & $04 / 01 / 00$ & $21 / 02 / 00$ & $18 / 04 / 00$ & $27 / 06 / 00$ \\
\hline 0 & $0,27 \mathrm{AB}$ & $0,47 \mathrm{~A}$ & $0,94 \mathrm{~A}$ & $1,43 \mathrm{~A}$ & $2,67 \mathrm{~A}$ & $2,88 \mathrm{~A}$ \\
80 & $0,26 \mathrm{~A}$ & $0,46 \mathrm{~A}$ & $0,94 \mathrm{~A}$ & $1,38 \mathrm{~A}$ & $2,68 \mathrm{~A}$ & $2,85 \mathrm{~A}$ \\
160 & $0,24 \mathrm{~B}$ & $0,48 \mathrm{~A}$ & $0,90 \mathrm{~A}$ & $1,39 \mathrm{~A}$ & $2,64 \mathrm{~A}$ & $2,80 \mathrm{~A}$ \\
240 & $0,25 \mathrm{AB}$ & $0,44 \mathrm{~A}$ & $0,94 \mathrm{~A}$ & $1,37 \mathrm{~A}$ & $2,67 \mathrm{~A}$ & $2,89 \mathrm{~A}$ \\
\hline
\end{tabular}

Nas duas localidades, Araras e Valparaíso, o crescimento mais acentuado ocorreu entre os meses de novembro e abril. No início as plantas apresentaram valores semelhantes nas duas localidades, mas com a melhoria 
nas condições climáticas (temperaturas altas e maiores precipitações), as plantas cultivadas em Araras tenderam a apresentar maior altura. Considera-se que isso seja resultado da melhor condição química do solo de Araras. Resultado esperado levando em consideração as diferenças dos solos.

Miocque (1999), relacionando o crescimento com o acúmulo de matéria verde mensal de várias variedades em inúmeras safras, observou também que nesse período de setembro/outubro a março foi onde se encortrou o crescimento mais acentuado. Resultados semelhantes também foi encontrado por Machado et al. (1982) e Sordi \& Braga (1996).

\subsection{População de perfilhos}

\section{Araras}

Na tabela 10 está apresentada a população de perfilhos encontrada na cana-planta para os diferentes tratamentos em Araras. Não foi observada interação significativa entre doses de fósforo e variedades nessa localidade.

$\mathrm{O}$ aumento do número de perfilhos depois do mês de julho foi bem acentuado. Isto é explicado pelo fato das condições ambientais tem se tornado menos estressante. Nos meses de setembro a novembro foram encontrados os valores mais altos, com destaque para o mês de novembro. Isto foi resultado da combinação entre temperatura alta e maior precipitação. Depois deste pico, iniciou-se redução no número de perfilhos por metro, agora devido à competição entre os perfilhos de uma mesma touceira, até chegarem os meses do inverno. Neste período, a queda populacional foi menor, pois a população já estava se estabilizando, priorizando o acúmulo de açúcar.

Dessa forma, no presente estudo o maior crescimento ficou compreendido entre os meses de setembro a janeiro que difere um pouco com o que foi encontrado por Penatti (1991). Este autor encontrou o maior desenvolvimento da cultura no periodo compreendido entre os meses de Novembro a Março. Isto pode ser resultado da combinação de temperatura elevada e precipitações pluviais ocorrerem mais cedo ou mais tardiamente. 
Tabela 10. Quantidade de perfilhos por metro em diferentes doses de fósforo em cana-planta de Araras.

\begin{tabular}{|c|c|c|c|c|c|c|c|}
\hline \multirow{2}{*}{ VARIEDADES } & \multirow{2}{*}{$\begin{array}{l}\text { DOSES DE } \\
\text { FÓSFORO } \\
\left(\mathrm{kg} \mathrm{P}_{2} \mathrm{O}_{5} \cdot \mathrm{ha}^{-1}\right)\end{array}$} & \multicolumn{6}{|c|}{$\begin{array}{l}\text { POPULAÇĀO } \\
\text { (perfilhos. } \mathrm{m}^{-1} \text { ) }\end{array}$} \\
\hline & & Jul/99 & Set/99 & Nov/99 & $\operatorname{Jan} / 00$ & Mar/00 & Mai/00 \\
\hline RB835486 & $\begin{array}{c}0 \\
80 \\
160 \\
240\end{array}$ & $\begin{array}{l}2,98 \mathrm{Aa} \\
2,76 \mathrm{Aa} \\
3,42 \mathrm{Aa} \\
2,60 \mathrm{Aa}\end{array}$ & $\begin{array}{l}15,83 \mathrm{Aa} \\
21,17 \mathrm{Aa} \\
17,33 \mathrm{Aa} \\
20,92 \mathrm{Aa}\end{array}$ & $\begin{array}{l}18,50 \mathrm{Aa} \\
21,83 \mathrm{Aa} \\
17,08 \mathrm{Aa} \\
23,75 \mathrm{Aa}\end{array}$ & $\begin{array}{l}15,00 \mathrm{Aa} \\
15,92 \mathrm{Aa} \\
13,58 \mathrm{Aa} \\
17,50 \mathrm{Aa}\end{array}$ & $\begin{array}{l}14,50 \mathrm{Aa} \\
14,00 \mathrm{Aa} \\
13,25 \mathrm{Aa} \\
14,83 \mathrm{Aa}\end{array}$ & $\begin{array}{l}8,19 \mathrm{Aa} \\
8,14 \mathrm{Aa} \\
8,91 \mathrm{Aa} \\
8,89 \mathrm{Aa}\end{array}$ \\
\hline RB835054 & $\begin{array}{c}0 \\
80 \\
160 \\
240\end{array}$ & $\begin{array}{l}2,61 \mathrm{Aa} \\
3,18 \mathrm{Aa} \\
3,22 \mathrm{Aa} \\
2,93 \mathrm{Aa}\end{array}$ & $\begin{array}{l}17,33 \mathrm{Aa} \\
17,92 \mathrm{Aa} \\
22,75 \mathrm{Aa} \\
28,08 \mathrm{Aa}\end{array}$ & $\begin{array}{l}23,67 \mathrm{Aa} \\
22,00 \mathrm{Aa} \\
22,67 \mathrm{Aa} \\
22,92 \mathrm{Aa}\end{array}$ & $\begin{array}{l}19,25 \mathrm{Aa} \\
16,42 \mathrm{Aa} \\
18,75 \mathrm{Aa} \\
17,33 \mathrm{Aa}\end{array}$ & $\begin{array}{l}16,75 \mathrm{Aa} \\
14,00 \mathrm{Aa} \\
16,58 \mathrm{Aa} \\
15,33 \mathrm{Aa}\end{array}$ & $\begin{array}{l}9,24 \mathrm{Aa} \\
9,52 \mathrm{Aa} \\
9,96 \mathrm{Aa} \\
9,94 \mathrm{Aa}\end{array}$ \\
\hline RB855113 & $\begin{array}{c}0 \\
80 \\
160 \\
240\end{array}$ & $\begin{array}{l}2,69 \mathrm{Aa} \\
3,51 \mathrm{Aa} \\
2,96 \mathrm{Aa} \\
3,28 \mathrm{Aa}\end{array}$ & $\begin{array}{l}14,83 \mathrm{Aa} \\
25,42 \mathrm{Aa} \\
19,75 \mathrm{Aa} \\
23,42 \mathrm{Aa}\end{array}$ & $\begin{array}{l}26,25 \mathrm{Aa} \\
23,00 \mathrm{Aa} \\
25,50 \mathrm{Aa} \\
26,17 \mathrm{Aa}\end{array}$ & $\begin{array}{l}19,17 \mathrm{Aa} \\
16,83 \mathrm{Aa} \\
18,75 \mathrm{Aa} \\
19,00 \mathrm{Aa}\end{array}$ & $\begin{array}{l}15,58 \mathrm{Aa} \\
16,17 \mathrm{Aa} 1 \\
16,33 \mathrm{Aa} 1 \\
16,00 \mathrm{Aa} 1\end{array}$ & $\begin{array}{c}9,99 \mathrm{Aa} \\
10,68 \mathrm{Aa} \\
10,48 \mathrm{Aa} \\
11,03 \mathrm{Aa}\end{array}$ \\
\hline RB855536 & $\begin{array}{c}0 \\
80 \\
160 \\
240\end{array}$ & $\begin{array}{l}2,56 \mathrm{Aa} \\
3,42 \mathrm{Aa} \\
3,68 \mathrm{Aa} \\
3,85 \mathrm{Aa}\end{array}$ & $\begin{array}{l}19,67 \mathrm{Aa} \\
20,67 \mathrm{Aa} \\
23,67 \mathrm{Aa} \\
20,75 \mathrm{Aa}\end{array}$ & $\begin{array}{l}25,17 \mathrm{Aa} \\
25,75 \mathrm{Aa} \\
25,83 \mathrm{Aa} \\
20,75 \mathrm{Aa}\end{array}$ & $\begin{array}{l}19,92 \mathrm{Aa} \\
17,50 \mathrm{Aa} \\
19,00 \mathrm{Aa} \\
16,25 \mathrm{Aa}\end{array}$ & $\begin{array}{l}15,67 \mathrm{Aa} 1 \\
14,00 \mathrm{Aa} 1 \\
14,42 \mathrm{Aa} \\
14,92 \mathrm{Aa} 1\end{array}$ & $\begin{array}{c}10,35 \mathrm{Aa} \\
10,82 \mathrm{Aa} \\
9,81 \mathrm{Aa} \\
10,11 \mathrm{Aa}\end{array}$ \\
\hline $\begin{array}{r}\text { CV } \\
\text { Média }\end{array}$ & \%) & $\begin{array}{c}19,47 \\
3,09 \\
\end{array}$ & $\begin{array}{l}19,47 \\
20,38 \\
\end{array}$ & $\begin{array}{l}14,76 \\
23,04 \\
\end{array}$ & $\begin{array}{l}15,25 \\
17,40 \\
\end{array}$ & $\begin{array}{l}11,09 \\
15,04 \\
\end{array}$ & $\begin{array}{l}8,22 \\
9,70 \\
\end{array}$ \\
\hline
\end{tabular}

Perfilhamento mais intenso ocorreu entre os meses de julho e novembro, resultados que concordam com os encontrados por Rocha (1984) em Piracicaba, que relata um intenso e rápido perfilhamento no início de setembro ao final de outubro.

Não tendo ocorrido diferença significativa da população de perfilhos nos diferentes tratamentos, passou-se à análise das médias varietais. Em tal análise se verificou que os resultados referentes às variedades RB855113 e RB855536 foram significativamente superiores as das demais, sendo que a RB835054, em algumas amostragens, não diferiu estatisticamente das duas anteriores (tabela 11). Essa dinâmica populacional de perfilhos pode ser visualizada na figura $8 \mathrm{e}$ 
que comprovam as diferenças varietais apresentadas pelos materiais em estudo.

Tabela 11. Dinâmica da população de perfilhos em função da variedade em Araras.

\begin{tabular}{ccccccc}
\hline \multirow{2}{*}{ VARIEDADES } & \multicolumn{5}{c}{ POPULAÇÅO (perfilhos. m $^{-1}$ ) } \\
\cline { 2 - 7 } & Jul/99 & Set/99 & Nov/99 & Jan/00 & Mar/00 & Mai/00 \\
\hline RB835486 & $2,94 \mathrm{~A}$ & $18,81 \mathrm{~B}$ & $20,29 \mathrm{C}$ & $15,50 \mathrm{~B}$ & $14,15 \mathrm{~B}$ & $8,53 \mathrm{C}$ \\
RB835054 & $2,98 \mathrm{~A}$ & $21,52 \mathrm{~A}$ & $22,81 \mathrm{BC}$ & $17,94 \mathrm{~A}$ & $15,67 \mathrm{AB}$ & $9,66 \mathrm{~B}$ \\
RB855113 & $3,11 \mathrm{~A}$ & $20,85 \mathrm{~A}$ & $25,23 \mathrm{AB}$ & $18,44 \mathrm{~A}$ & $16,02 \mathrm{~A}$ & $10,55 \mathrm{~A}$ \\
RB855536 & $3,38 \mathrm{~A}$ & $21,19 \mathrm{~A}$ & $24,38 \mathrm{~A}$ & $18,17 \mathrm{~A}$ & $14,75 \mathrm{AB}$ & $10,27 \mathrm{~A}$ \\
\hline
\end{tabular}

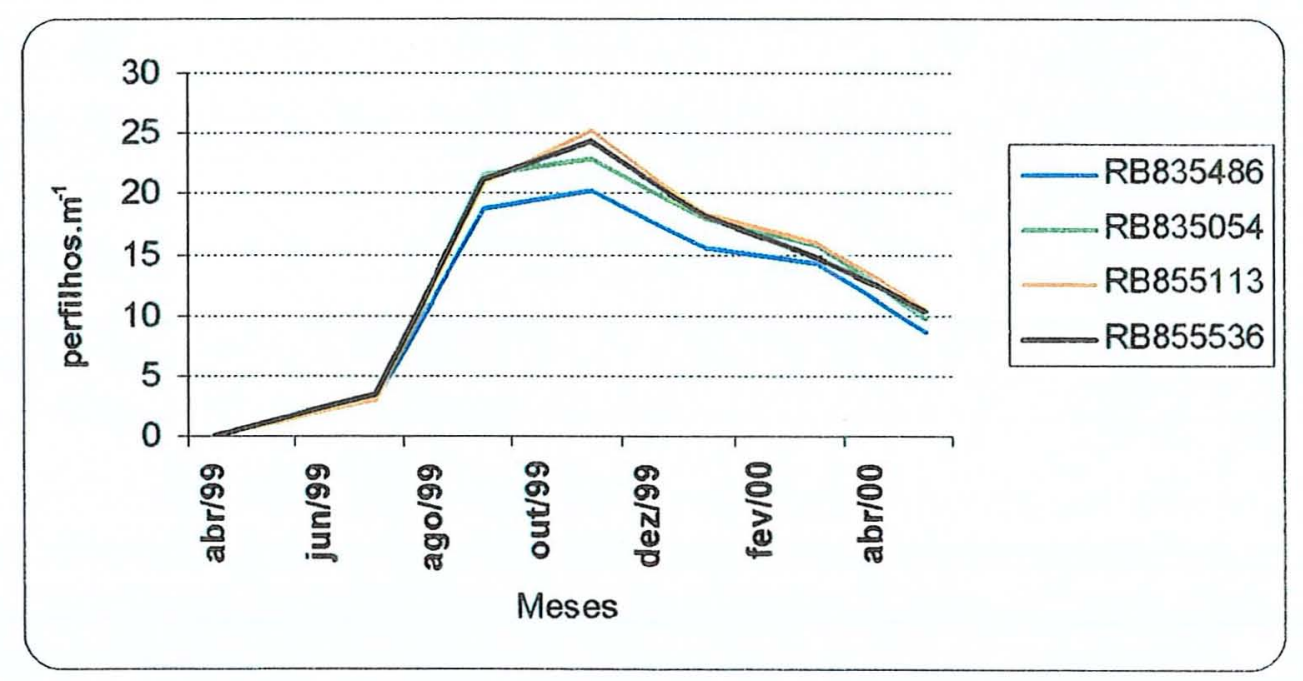

Figura 8 - Quantidade de perfilhos, em cana-planta, por variedade em Araras.

Em relação às doses de fósforo, verificou-se diferença significativa somente na primeira amostragem, na qual a dose de $160 \mathrm{~kg} \mathrm{P}_{2} \mathrm{O}_{5}$.ha ${ }^{-1}$ apresentou o maior valor $e$, o tratamento sem aplicação de fósforo, o menor (tabela 12). 
Tabela 12. População de perfilhos considerando médias por dose de fósforo.

\begin{tabular}{ccccccc}
\hline \multirow{2}{*}{$\begin{array}{c}\text { DOSES DE } \\
\text { FÓSFORO } \\
\left(\mathrm{kg} \mathrm{P}_{2} \mathrm{O}_{5} \cdot \mathrm{ha}^{-1}\right)\end{array}$} & Jul/99 & Set/99 & Nov/99 & Jan/00 & Mar/00 & Mai/00 \\
\cline { 2 - 7 } & (perfilhos. $\left.{ }^{-1}\right)$ \\
80 & $2,71 \mathrm{~B}$ & $16,92 \mathrm{~A}$ & $23,40 \mathrm{~A}$ & $18,33 \mathrm{~A}$ & $15,63 \mathrm{~A}$ & $9,44 \mathrm{~A}$ \\
80 & $3,21 \mathrm{AB}$ & $21,29 \mathrm{~A}$ & $23,15 \mathrm{~A}$ & $16,67 \mathrm{~A}$ & $14,54 \mathrm{~A}$ & $9,79 \mathrm{~A}$ \\
160 & $3,32 \mathrm{~A}$ & $20,88 \mathrm{~A}$ & $22,77 \mathrm{~A}$ & $17,52 \mathrm{~A}$ & $15,15 \mathrm{~A}$ & $9,79 \mathrm{~A}$ \\
240 & $3,16 \mathrm{AB}$ & $23,29 \mathrm{~A}$ & $23,40 \mathrm{~A}$ & $17,52 \mathrm{~A}$ & $15,27 \mathrm{~A}$ & $9,99 \mathrm{~A}$ \\
\hline
\end{tabular}

\section{Valparaiso}

Não foi observada interação significativa entre doses e variedades na população de perfilhos (tabela 13). Nas variedades RB835486 e RB835054 o pico de população foi encontrado no mês de outubro, enquanto que nas demais foi no mês de novembro.

Tabela 13. Número de perfilhos nos diferentes tratamentos em Valparaiso.

\begin{tabular}{|c|c|c|c|c|c|c|c|c|}
\hline \multirow[t]{2}{*}{ VARIEDADES } & \multirow{2}{*}{$\begin{array}{l}\text { DOSES DE } \\
\text { FÓSFORO } \\
\left(\mathrm{kg} \mathrm{P}_{2} \mathrm{O}_{5} \cdot \mathrm{ha}^{-1}\right)\end{array}$} & \multicolumn{7}{|c|}{$\begin{array}{l}\text { POPULAÇĀO } \\
\text { (perfilhos. } m^{-1} \text { ) } \\
\end{array}$} \\
\hline & & \multicolumn{7}{|c|}{$19 / 08 / 9904 / 10 / 9918 / 11 / 9904 / 01 / 0021 / 02 / 0018 / 04 / 0027 / 06 / 00$} \\
\hline \multirow{4}{*}{ RB835486 } & 0 & \multicolumn{7}{|c|}{ 14,42 Aa 15,83 Aa 15,42 Aa 12,08 Aa 11,08 Aa 10,42 Aa $10,25 \mathrm{Aa}$} \\
\hline & 80 & \multicolumn{7}{|c|}{ 15,08 Aa 18,75 Aa 16,83 Aa 12,83 Aa 11,17 Aa 10,83 Aa 10,67 Aa } \\
\hline & 160 & \multirow{2}{*}{\multicolumn{7}{|c|}{$\begin{array}{l}\text { 15,50 } \mathrm{Aa} 15,17 \mathrm{Aa} 14,83 \mathrm{Aa} 11,17 \mathrm{Aa} 10,08 \mathrm{Aa} 9,67 \mathrm{Aa} 9,67 \mathrm{Aa} \\
15,33 \mathrm{Aa} 16,50 \mathrm{Aa} 14,17 \mathrm{Aa} 11,67 \mathrm{Aa} 11,08 \mathrm{Aa} 10,33 \mathrm{Aa} 10,08 \mathrm{Aa}\end{array}$}} \\
\hline & 240 & & & & & & & \\
\hline \multirow{4}{*}{ RB835054 } & 0 & \multirow{4}{*}{\multicolumn{7}{|c|}{$\begin{array}{l}16,25 \mathrm{Aa} 22,25 \mathrm{Aa} 20,75 \mathrm{Aa} 15,08 \mathrm{Aa} 13,25 \mathrm{Aa} 13,17 \mathrm{Aa} 13,08 \mathrm{Aa} \\
20,08 \mathrm{Aa} 26,08 \mathrm{Aa} 24,08 \mathrm{Aa} 16,42 \mathrm{Aa} 14,75 \mathrm{Aa} 13,67 \mathrm{Aa} 13,58 \mathrm{Aa} \\
15,83 \mathrm{Aa} 21,58 \mathrm{Aa} 22,92 \mathrm{Aa} 15,67 \mathrm{Aa} 13,00 \mathrm{Aa} 12,50 \mathrm{Aa} 12,42 \mathrm{Aa} \\
17,08 \mathrm{Aa} 23,67 \mathrm{Aa} 21,83 \mathrm{Aa} 15,58 \mathrm{Aa} 13,50 \mathrm{Aa} 13,08 \mathrm{Aa} 12,92 \mathrm{Aa}\end{array}$}} \\
\hline & 80 & & & & & & & \\
\hline & 160 & & & & & & & \\
\hline & 240 & & & & & & & \\
\hline \multirow{4}{*}{ RB855113 } & 0 & \multirow{4}{*}{\multicolumn{7}{|c|}{$\begin{array}{l}\text { 16,42 } \mathrm{Aa} 26,17 \mathrm{Aa} 25,17 \mathrm{Aa} 17,33 \mathrm{Aa} 13,00 \mathrm{Aa} 12,33 \mathrm{Aa} 12,33 \mathrm{Aa} \\
\text { 16,83 } \mathrm{Aa} 26,92 \mathrm{Aa} 23,33 \mathrm{Aa} 17,92 \mathrm{Aa} 14,75 \mathrm{Aa} 13,17 \mathrm{Aa} 12,83 \mathrm{Aa} \\
\text { 16,42 } \mathrm{Aa} 23,75 \mathrm{Aa} 21,08 \mathrm{Aa} 19,00 \mathrm{Aa} 15,00 \mathrm{Aa} 12,67 \mathrm{Aa} 12,67 \mathrm{Aa} \\
14,33 \mathrm{Aa} 18,42 \mathrm{Aa} 19,67 \mathrm{Aa} 16,25 \mathrm{Aa} 12,50 \mathrm{Aa} 12,08 \mathrm{Aa} 12,08 \mathrm{Aa}\end{array}$}} \\
\hline & 80 & & & & & & & \\
\hline & 160 & & & & & & & \\
\hline & 240 & & & & & & & \\
\hline \multirow{4}{*}{ RB855536 } & 0 & \multirow{4}{*}{\multicolumn{7}{|c|}{$\begin{array}{l}21,50 \mathrm{Aa} 24,00 \mathrm{Aa} 25,33 \mathrm{Aa} 18,50 \mathrm{Aa} 13,00 \mathrm{Aa} 11,92 \mathrm{Aa} 11,92 \mathrm{Aa} \\
19,42 \mathrm{Aa} 23,83 \mathrm{Aa} 25,33 \mathrm{Aa} 16,42 \mathrm{Aa} 13,00 \mathrm{Aa} 10,83 \mathrm{Aa} 10,83 \mathrm{Aa} \\
18,67 \mathrm{Aa} 21,00 \mathrm{Aa} 24,00 \mathrm{Aa} 14,92 \mathrm{Aa} 11,83 \mathrm{Aa} 10,67 \mathrm{Aa} 10,58 \mathrm{Aa} \\
19,83 \mathrm{Aa} 22,00 \mathrm{Aa} 21,58 \mathrm{Aa} 16,92 \mathrm{Aa} 12,67 \mathrm{Aa} 11,67 \mathrm{Aa} 11,58 \mathrm{Aa}\end{array}$}} \\
\hline & 80 & & & & & & & \\
\hline & 160 & & & & & & & \\
\hline & 240 & & & & & & & \\
\hline \multirow{2}{*}{\multicolumn{2}{|c|}{$\begin{array}{c}\text { CV }(\%) \\
\text { Média Geral }\end{array}$}} & 15,46 & 13,18 & 14,40 & 12,14 & 13,95 & 13,50 & 12,99 \\
\hline & & 17,09 & 21,60 & 21,07 & 15,56 & 12,75 & 11,81 & 11,71 \\
\hline
\end{tabular}


De forma semelhante do que foi encontrado em Araras antes do período de pico, o que existiu foi um crescimento bem acentuado, que depois foi decaindo até a colheita. A explicação para estes fatos também seria as condições climáticas encontradas no período. Em relação às localidades, o que se verifica numa primeira observação é que em Araras a população foi superior, possivelmente devido às condições edáficas encontradas.

Comparando-se médias de variedades, ocorreram diferenças significativas entre as mesmas nas diferentes amostragens. De forma geral, como era de se esperar, devido às características varietais, o menor número de perfilhos foi encontrado nas parcelas com a RB835486 (tabela 14). Isso pode ser visualizado na figura 9 .

Tabela 14. Número de perfilhos por metro das diferentes variedades em Valparaíso.

\begin{tabular}{cccccccc}
\hline \multirow{2}{*}{ VARIEDADES } & \multicolumn{7}{c}{$\begin{array}{c}\text { POPULAÇÁ̉ } \\
\text { (perfilhos. m }{ }^{-1} \text { ) }\end{array}$} \\
\cline { 2 - 8 } & $19 / 08 / 99$ & $04 / 10 / 99$ & $18 / 11 / 99$ & $04 / 01 / 00$ & $21 / 02 / 00$ & $18 / 04 / 00$ & $27 / 06 / 00$ \\
\hline RB835486 & $15,08 \mathrm{~B}$ & $16,56 \mathrm{~B}$ & $15,31 \mathrm{~B}$ & $11,94 \mathrm{~B}$ & $10,85 \mathrm{~B}$ & $10,31 \mathrm{C}$ & $10,17 \mathrm{C}$ \\
RB835054 & $17,31 \mathrm{AB}$ & $23,40 \mathrm{~A}$ & $22,40 \mathrm{~A}$ & $15,69 \mathrm{~A}$ & $13,63 \mathrm{~A}$ & $13,10 \mathrm{~A}$ & $13,00 \mathrm{~A}$ \\
RB855113 & $16,00 \mathrm{~B}$ & $23,81 \mathrm{~A}$ & $22,31 \mathrm{~A}$ & $17,63 \mathrm{~A}$ & $13,81 \mathrm{~A}$ & $12,56 \mathrm{AB}$ & $12,48 \mathrm{AB}$ \\
RB855536 & $19,85 \mathrm{~A}$ & $22,71 \mathrm{~A}$ & $24,06 \mathrm{~A}$ & $16,69 \mathrm{~A}$ & $12,63 \mathrm{~A}$ & $11,27 \mathrm{BC}$ & $11,23 \mathrm{BC}$ \\
\hline
\end{tabular}

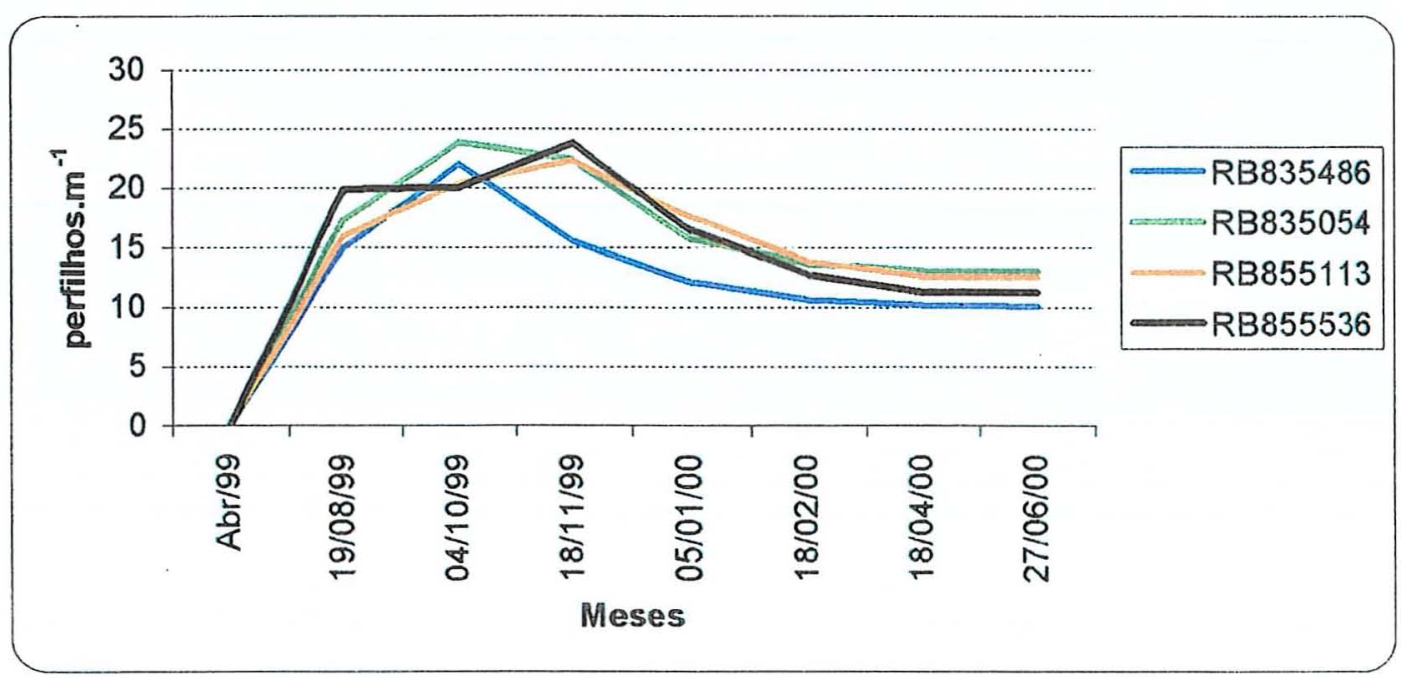

Figura 9 - Perfilhos por metro nas diferentes variedades em Valparaíso. 
Em relação às doses, o que se verifica é que a testemunha teve seu pico de população atrasado em relação aos demais tratamentos. Nestes, o pico ocorreu no mês de novembro (tabela 15).

Tabela 15. População de perfilhos em diferentes doses de fósforo em Valparaiso.

\begin{tabular}{|c|c|c|c|c|c|c|c|}
\hline \multirow{2}{*}{$\begin{array}{l}\text { DOȘES DE } \\
\text { FOSFORO } \\
\left(\mathrm{kg} \mathrm{P}_{2} \mathrm{O}_{5} \cdot \mathrm{ha}^{-1}\right) \\
\end{array}$} & \multicolumn{7}{|c|}{$\begin{array}{l}\text { POPULAÇÃO } \\
\text { (perfilhos. } m^{-1} \text { ) }\end{array}$} \\
\hline & $19 / 08 / 99$ & 04/10/99 & $18 / 11 / 99$ & $04 / 01 / 00$ & $21 / 02 / 00$ & $18 / 04 / 00$ & $27 / 06 / 00$ \\
\hline 0 & $17,15 \mathrm{~A}$ & $22,06 \mathrm{AB}$ & $21,67 \mathrm{AB}$ & $15,75 \mathrm{~A}$ & $12,58 \mathrm{~A}$ & 11,96 & 11,90 \\
\hline 80 & $17,85 \mathrm{~A}$ & $23,90 \mathrm{~A}$ & $22,40 \mathrm{~A}$ & $15,90 \mathrm{~A}$ & $13,42 \mathrm{~A}$ & 12,13 & 11,98 \\
\hline 160 & $16,60 \mathrm{~A}$ & $20,38 \mathrm{~B}$ & $20,71 \mathrm{AB}$ & $15,19 \mathrm{~A}$ & $12,48 \mathrm{~A}$ & 11,38 & 11,33 \\
\hline 240 & $16,65 \mathrm{~A}$ & $20,15 \mathrm{~B}$ & $19,31 \mathrm{~B}$ & $15,10 \mathrm{~A}$ & $12,44 \mathrm{~A}$ & 11,79 & 11,67 \\
\hline
\end{tabular}

As diferenças só foram significativas entre médias de doses nas amostragens feitas nos períodos de maior número de plantas por metro linear, outubro e novembro. Nestas, os valores obtidos na dose de $80 \mathrm{~kg} \mathrm{P}_{2} \mathrm{O}_{5}$. ha- ${ }^{-1}$ foram maiores que as demais e os encontrados para $240 \mathrm{~kg} \mathrm{P}_{2} \mathrm{O}_{5}$ foram os menores. Em ambos os casos os resultados da testemunha não diferiram dos apresentados nas doses 80 e $160 \mathrm{~kg} \mathrm{P} \mathrm{P}_{2} \mathrm{O}_{5} \cdot \mathrm{ha}^{-1}$.

Nas duas localidades o periodo de intenso perfilhamento ficou compreendido entre os meses de agosto e novembro. Resultados semelhantes foram encontrados por Prado (1988) e Tokeshi (1986), que obtiveram o máximo populacional entre o quarto e o sexto mês após o plantio.

Por outro lado, Machado et al. (1982) encontraram o pico populacional em agosto e uma estabilização no mês de dezembro.

\subsection{Dinâmica foliar em Araras}

\subsubsection{Folhas ativas e formadas}

Não houve interação significativa entre doses de fósforo e variedades quanto ao número de folhas ativas e emergidas em cada época de amostragem (tabela 16). 
Verificou-se uma certa tendência de diminuição no número de folhas ativas e surgidas no decorrer do experimento. Possivelmente, o máximo de folhas ativas e surgidas coincida com o periodo de maior desenvolvimento da cultura.

Tabela 16. Número de folhas ativas e formadas durante o experimento nos diferentes tratamentos em Araras.

\begin{tabular}{|c|c|c|c|c|c|c|c|}
\hline & \multirow{2}{*}{$\begin{array}{l}\text { DOSES DE } \\
\text { FOSFORO } \\
\left(\mathrm{kg} \mathrm{P}_{2} \mathrm{O}_{5} \cdot \mathrm{ha}^{-1}\right)\end{array}$} & \multicolumn{3}{|c|}{$\begin{array}{l}\text { FOLHAS ATIVAS } \\
\text { (folhas perfilho }^{-1} \text { ) }\end{array}$} & \multicolumn{3}{|c|}{$\begin{array}{c}\text { FOLHAS FORMADAS } \\
\text { (folhas perfilho-1) }\end{array}$} \\
\hline & & $\mathrm{Jan} / 00$ & Mar/00 & Jun/00 & $\begin{array}{l}\mathrm{Abr} / 99- \\
\operatorname{Jan} / 00^{*}\end{array}$ & $\begin{array}{l}\text { Jan- } \\
\text { Mar/00 }\end{array}$ & $\begin{array}{l}\text { Mar- } \\
\text { Jun/00 }\end{array}$ \\
\hline \multirow{4}{*}{ RB835486 } & 0 & $8,4 \mathrm{Aa}$ & $7,7 \mathrm{Aa}$ & $6,7 \mathrm{Aa}$ & $12,2 \mathrm{Aa}$ & $7,2 \mathrm{Aa}$ & $6,7 \mathrm{Aa}$ \\
\hline & 80 & 7,7 Aa & $8,2 \mathrm{Aa}$ & $7,7 \mathrm{Aa}$ & $11,5 \mathrm{Aa}$ & $7,4 \mathrm{Aa}$ & $8,0 \mathrm{Aa}$ \\
\hline & 160 & $7,6 \mathrm{Aa}$ & $6,6 \mathrm{Aa}$ & $6,7 \mathrm{Aa}$ & $12,2 \mathrm{Aa}$ & $6,5 \mathrm{Aa}$ & $6,7 \mathrm{Aa}$ \\
\hline & 240 & 7,9 Aa & $6,7 \mathrm{Aa}$ & $6,6 \mathrm{Aa}$ & $11,8 \mathrm{Aa}$ & $6,8 \mathrm{Aa}$ & $6,8 \mathrm{Aa}$ \\
\hline \multirow{4}{*}{ RB835054 } & 0 & $9,3 \mathrm{Aa}$ & $9,5 \mathrm{Aa}$ & $7,0 \mathrm{Aa}$ & $12,2 \mathrm{Aa}$ & $8,3 \mathrm{Aa}$ & $7,0 \mathrm{Aa}$ \\
\hline & 80 & $9,3 \mathrm{Aa}$ & $9,3 \mathrm{Aa}$ & $7,2 \mathrm{Aa}$ & $12,0 \mathrm{Aa}$ & $8,3 \mathrm{Aa}$ & 7,2 Aa \\
\hline & 160 & $8,8 \mathrm{Aa}$ & $9,3 \mathrm{Aa}$ & $6,3 \mathrm{Aa}$ & $11,8 \mathrm{Aa}$ & $8,5 \mathrm{Aa}$ & $6,5 \mathrm{Aa}$ \\
\hline & 240 & $10,0 \mathrm{Aa}$ & $9,3 \mathrm{Aa}$ & $6,8 \mathrm{Aa}$ & $13,3 \mathrm{Aa}$ & $8,3 \mathrm{Aa}$ & $6,8 \mathrm{Aa}$ \\
\hline \multirow{4}{*}{ RB855113 } & 0 & $7,8 \mathrm{Aa}$ & 7,5 Aa & $6,8 \mathrm{Aa}$ & $11,7 \mathrm{Aa}$ & 7,3 Aa & $7,0 \mathrm{Aa}$ \\
\hline & 80 & $7,0 \mathrm{Aa}$ & 7,5 Aa & $6,6 \mathrm{Aa}$ & $10,8 \mathrm{Aa}$ & $6,8 \mathrm{Aa}$ & $6,7 \mathrm{Aa}$ \\
\hline & 160 & $7,8 \mathrm{Aa}$ & 7,0 Aa & $6,8 \mathrm{Aa}$ & $11,4 \mathrm{Aa}$ & $6,5 \mathrm{Aa}$ & $6,8 \mathrm{Aa}$ \\
\hline & 240 & $7,8 \mathrm{Aa}$ & 7,5 Aa & $6,4 \mathrm{Aa}$ & $10,5 \mathrm{Aa}$ & $7,1 \mathrm{Aa}$ & $6,8 \mathrm{Aa}$ \\
\hline \multirow{4}{*}{ RB855536 } & 0 & $7,9 \mathrm{Aa}$ & 6,3 Aa & $5,3 \mathrm{Aa}$ & $11,7 \mathrm{Aa}$ & $6,6 \mathrm{Aa}$ & $6,1 \mathrm{Aa}$ \\
\hline & 80 & $6,8 \mathrm{Aa}$ & 7,3 $\mathrm{Aa}$ & $5,7 \mathrm{Aa}$ & $9,8 \mathrm{Aa}$ & 7,2 Aa & $6,0 \mathrm{Aa}$ \\
\hline & 160 & $8,4 \mathrm{Aa}$ & $6,2 \mathrm{Aa}$ & $5,3 \mathrm{Aa}$ & $11,3 \mathrm{Aa}$ & $6,3 \mathrm{Aa}$ & $5,6 \mathrm{Aa}$ \\
\hline & 240 & $7.5 \mathrm{Aa}$ & $7,1 \mathrm{Aa}$ & $6,3 \mathrm{Aa}$ & $10,8 \mathrm{Aa}$ & $6,7 \mathrm{Aa}$ & $6,8 \mathrm{Aa}$ \\
\hline \multirow{2}{*}{\multicolumn{2}{|c|}{$\begin{array}{c}\text { CV }(\%) \\
\text { Média Geral }\end{array}$}} & 8,70 & 9,55 & 10,07 & 7,22 & 7,99 & 10,06 \\
\hline & & 8,15 & 7,69 & 6,51 & 11,56 & 7,26 & 6,74 \\
\hline
\end{tabular}

* desconsiderando os foliolos iniciais que já não estavam mais presentes na planta.

letras maiúsculas referem-se a tratamentos dentro de uma mesma variedade e letras minúsculas dentro de uma mesma dose (comparação entre variedades).

$O$ fato de existir um pequeno número de folhas verdes ou ativas em relação ao número de folhas surgidas no primeiro período se deve ao número de meses compreendidos nessa amostragem. Isso não é notado quando se observa somente o número de folhas verdes que é uma situação de momento, que independe da diferença do número de meses que antecedem. O número de 
folhas verdes é bem semelhante ao de surgidas, sendo a menor relação entre folhas ativas e verdes encontradas em perfilhos da RB855536.

Ao se comparar médias entre variedades, nota-se diferenças significativas entre as mesmas. No geral, a RB835054 foi a que apresentou maior número de folhas ativas e formadas e a RB855536 o menor, nas diferentes avaliações (tabela 17).

Tabela 17. Médias de folhas ativas e formadas, em cana-planta, para diferentes variedades em Araras.

\begin{tabular}{ccccccc}
\hline \multirow{2}{*}{ VARIEDADES } & \multicolumn{3}{c}{$\begin{array}{c}\text { FOLHAS ATIVAS } \\
\text { (folhas.perfilho }\end{array}$} & \multicolumn{2}{c}{$\begin{array}{c}\text { FOLHAS FORMADAS } \\
\text { (folhas.perfilho }{ }^{-1} \text { ) }\end{array}$} \\
\cline { 2 - 7 } & Jan/00 & Mar/00 & Jun/00 & Abr/99-Jan/00* Jan-Mar/00 Mar-Jun/00 \\
\hline RB835486 & $7,9 \mathrm{~B}$ & $7,3 \mathrm{~B}$ & $6,9 \mathrm{~A}$ & $11,9 \mathrm{~A}$ & $7,0 \mathrm{~B}$ & $7,0 \mathrm{~A}$ \\
RB835054 & $9,3 \mathrm{~A}$ & $9,3 \mathrm{~A}$ & $6,8 \mathrm{~A}$ & $12,3 \mathrm{~A}$ & $8,4 \mathrm{~A}$ & $6,9 \mathrm{~A}$ \\
RB855113 & $7,6 \mathrm{~B}$ & $7,4 \mathrm{~B}$ & $6,6 \mathrm{~A}$ & $11,1 \mathrm{~B}$ & $6,9 \mathrm{~B}$ & $6,8 \mathrm{~A}$ \\
RB855536 & $7,7 \mathrm{~B}$ & $6,7 \mathrm{C}$ & $5,6 \mathrm{~B}$ & $10,9 \mathrm{~B}$ & $6,7 \mathrm{~B}$ & $6,1 \mathrm{~B}$ \\
\hline
\end{tabular}

* desconsiderando os foliolos iniciais que já não estavam mais presentes na planta.

A única diferença encontrada quando comparamos as médias de doses de fósforo foi no número de folhas ativas encontradas no mês de março. Nesta amostragem, a dose $80 \mathrm{~kg} . \mathrm{P}_{2} \mathrm{O}_{5} \cdot \mathrm{ha}^{-1}$ foi a que apresentou maiores valores, não diferindo estatisticamente das doses 0 e 240 (tabela 18).

Tabela 18. Médias de folhas ativas e formadas para diferentes variedades em Araras.

\begin{tabular}{|c|c|c|c|c|c|c|}
\hline \multirow{2}{*}{$\begin{array}{l}\text { DOSES DE } \\
\text { FOSFORO } \\
\left(\mathrm{kg} \mathrm{P}_{2} \mathrm{O}_{5} \cdot \mathrm{ha}^{-1}\right)\end{array}$} & \multicolumn{3}{|c|}{$\begin{array}{l}\text { FOLHAS ATIVAS } \\
\text { (folhas perfilho- }\end{array}$} & \multicolumn{3}{|c|}{$\begin{array}{l}\text { FOLHAS FORMADAS } \\
\text { (folhas perfilho-1) }\end{array}$} \\
\hline & $\operatorname{Jan} / 00$ & Mar/00 & Jun/00 & Abr/99-Jan $/ 00$ & Jan-Mar/00 & Mar-Jun/00 \\
\hline 0 & $8,4 \mathrm{~A}$ & $7,8 \mathrm{AB}$ & $6,4 \mathrm{~A}$ & $11,9 \mathrm{~A}$ & $7,3 \mathrm{~A}$ & $6,7 \mathrm{~A}$ \\
\hline 80 & $7,7 \mathrm{~A}$ & $8,1 \mathrm{~A}$ & $6,8 \mathrm{~A}$ & $11,0 \mathrm{~A}$ & $7,4 \mathrm{~A}$ & $7,0 \mathrm{~A}$ \\
\hline 160 & $8,1 \mathrm{~A}$ & $7,3 \mathrm{~B}$ & $6,3 \mathrm{~A}$ & $11,7 \mathrm{~A}$ & $7,0 \mathrm{~A}$ & $6,4 \mathrm{~A}$ \\
\hline 240 & $8,3 \mathrm{~A}$ & $7,6 \mathrm{AB}$ & $6,5 \mathrm{~A}$ & $11,6 \mathrm{~A}$ & $7,2 \mathrm{~A}$ & $6,8 \mathrm{~A}$ \\
\hline
\end{tabular}

* desconsiderando os foliolos iniciais que já não estavam mais presentes na planta. 


\subsection{1 Índice de área foliar em Araras}

Não se verificou interação significativa entre variedades e doses de fósforo para o parãmetro Índice de Área Foliar (IAF) em Araras (tabela 19). Não se pôde observar nenhuma tendência de aumento ou diminuição de IAF com o aumento nas doses de $\mathrm{P}_{2} \mathrm{O}_{5}$. Em relação às médias por variedades, encontrouse diferença entre elas, sendo que a RB855113 foi a variedade que apresentou maior IAF e, a RB835486, o menor índice. Esses resultados acompanham os valores obtidos na avaliação de população de perfilhoss, pois a primeira variedade citada foi a que apresentou maior número de perfilhos e, a outra, o menor número (características genéticas). Os valores são semelhantes aos encontrados por Hermann (1997), quando este acompanhou a variação de IAF nas variedades SP70-1143, SP70-1284 e RB72454, como também aos encontrados por Leme et al. (1984), estudando a CB47-355. Segundo Hermann (1997) o IAF aumenta inicialmente, se estabiliza ao chegar ao máximo e depois vai decrescendo até o momento da maturação e colheita. Já Teruel (1995) estimou valores de IAF sempre crescentes, além de valores superiores ao encontrado neste experimento.

Tabela 19. IAF de diferentes tratamentos em Araras.

\begin{tabular}{cccccc}
\hline \multirow{2}{*}{ DOSES DEP $\mathrm{O}_{5}$} & \multicolumn{4}{c}{ IAF* $^{*}$} & \multirow{2}{*}{ Média por dose } \\
\cline { 2 - 5 } & $\mathrm{RB} 835486$ & $\mathrm{RB} 835054$ & $\mathrm{RB} 855113$ & $\mathrm{RB} 855536$ & \\
\hline $0 \mathrm{~kg} \cdot \mathrm{ha}^{-1}$ & $1,46 \mathrm{~A}$ & $1,58 \mathrm{~A}$ & $1,82 \mathrm{~A}$ & $1,52 \mathrm{~A}$ & $1,59 \mathrm{~A}$ \\
$80 \mathrm{~kg} \cdot \mathrm{ha}^{-1}$ & $1,56 \mathrm{~A}$ & $1,89 \mathrm{~A}$ & $1,77 \mathrm{~A}$ & $1,87 \mathrm{~A}$ & $1,77 \mathrm{~A}$ \\
$160 \mathrm{~kg} \cdot \mathrm{ha}^{-1}$ & $1,55 \mathrm{~A}$ & $1,62 \mathrm{~A}$ & $2,27 \mathrm{~A}$ & $1,59 \mathrm{~A}$ & $1,75 \mathrm{~A}$ \\
$240 \mathrm{~kg} \cdot \mathrm{ha}^{-1}$ & $1,78 \mathrm{~A}$ & $1,56 \mathrm{~A}$ & $1,71 \mathrm{~A}$ & $1,61 \mathrm{~A}$ & $1,66 \mathrm{~A}$ \\
& $1,58 \mathrm{~b}$ & $1,66 \mathrm{ab}$ & $1,89 \mathrm{a}$ & $1,64 \mathrm{ab}$ & 1,70 \\
\hline Média por variedade & Ietras maiúsculas referem-se a doses dentro de uma mesma variedade e média por dose, \\
minúsculas comparam médias por variedade. & & &
\end{tabular}




\subsection{Produção}

\section{Araras}

Não se observou interação significativa entre doses e variedades de cana-de-açúcar na produtividade de colmos, apesar de se observar tendência de aumento de produtividade nas variedades RB835054 e RB855113 (tabela 20). A diferença encontrada foi em relação à média por variedade. Nesta comparação as mais produtivas foram a RB855113 e RB855536, sendo a RB835486 a menos produtiva.

Tabela 20. Produtividade dos tratamentos em estudo em Araras.

\begin{tabular}{|c|c|c|c|c|c|}
\hline \multirow{2}{*}{ DOSES DE $\mathrm{P}_{2} \mathrm{O}_{5}$} & \multicolumn{4}{|c|}{ PRODUTIVIDADE $\left(\text { t.ha }^{-1}\right)^{*}$} & \multirow{2}{*}{ Média por dose } \\
\hline & RB835486 & RB835054 & RB855113 & RB855536 & \\
\hline $0 \mathrm{~kg} \cdot \mathrm{ha}^{-1}$ & $115,89 \mathrm{~A}$ & $120,13 \mathrm{~A}$ & $119,28 \mathrm{~A}$ & $130,03 \mathrm{~A}$ & $121,33 \mathrm{~A}$ \\
\hline $80 \mathrm{~kg} \cdot \mathrm{ha}^{-1}$ & $105,21 \mathrm{~A}$ & $122,17 \mathrm{~A}$ & $130,86 \mathrm{~A}$ & $138,01 \mathrm{~A}$ & $124,06 \mathrm{~A}$ \\
\hline $160 \mathrm{~kg} \cdot \mathrm{ha}^{-1}$ & $116,46 \mathrm{~A}$ & $124,83 \mathrm{~A}$ & $132,53 \mathrm{~A}$ & $121,45 \mathrm{~A}$ & $123,82 \mathrm{~A}$ \\
\hline $240 \mathrm{~kg} \cdot \mathrm{ha}^{-1}$ & $115,55 \mathrm{~A}$ & $132,97 \mathrm{~A}$ & $138,21 \mathrm{~A}$ & $129,89 \mathrm{~A}$ & $129,15 \mathrm{~A}$ \\
\hline Média por variedade & $113,28 b$ & $125,02 a b$ & $130,22 \mathrm{a}$ & $129,85 \mathrm{a}$ & 124,59 \\
\hline
\end{tabular}

Valparaiso

Em Valparaíso também não se verificou interação significativa entre doses e variedades para produtividade de colmos.

Encontrou-se apenas diferença entre médias por variedade (tabela 21). A variedade RB835486, a que menos produziu nas condições de Araras, foi em Valparaíso, junto com a RB835054 e RB855113, a mais produtiva enquanto a RB855536 foi a menos produtiva, mostrando que esta variedade tem menor adaptabilidade a condições estressantes que as demais, já que as chuvas em Valparaíso foram menores e o déficit maior no período que antecedeu a colheita. A média geral de produtividade do experimento foi $13 \%$ menor que a de Araras. 
Tabela 21. Produtividade dos tratamentos em estudo.

\begin{tabular}{|c|c|c|c|c|c|}
\hline \multirow{2}{*}{ DOSES DE $\mathrm{P}_{2} \mathrm{O}_{5}$} & \multicolumn{4}{|c|}{ PRODUTIVIDADE (t.ha $\left.{ }^{-1}\right)^{*}$} & \multirow{2}{*}{ Médias por dose } \\
\hline & RB835486 & RB835054 & RB855113 & RB855536 & \\
\hline O kg.ha- ${ }^{1}$ & $119,56 \mathrm{~A}$ & $101,67 \mathrm{~A}$ & $108,87 \mathrm{~A}$ & $99,39 \mathrm{~A}$ & $107,37 \mathrm{~A}$ \\
\hline $80 \mathrm{~kg} \cdot \mathrm{ha}^{1}$ & $107,96 \mathrm{~A}$ & $115,76 \mathrm{~A}$ & $116,78 \mathrm{~A}$ & $92,61 \mathrm{~A}$ & $108,28 \mathrm{~A}$ \\
\hline $160 \mathrm{~kg} \cdot \mathrm{ha}^{1}$ & $116,22 \mathrm{~A}$ & $110,59 \mathrm{~A}$ & $113,69 \mathrm{~A}$ & $100,20 \mathrm{~A}$ & $110,17 \mathrm{~A}$ \\
\hline $240 \mathrm{~kg} \cdot \mathrm{ha}^{-}$ & $110,24 \mathrm{~A}$ & $122,48 \mathrm{~A}$ & $111,58 \mathrm{~A}$ & $96,43 \mathrm{~A}$ & $110,18 \mathrm{~A}$ \\
\hline Médias por variedade & $113,49 a$ & $112,63 \mathrm{a}$ & $112,73 a$ & $97,16 \mathrm{~b}$ & 109,00 \\
\hline
\end{tabular}

Como esperado, a produtividade da cana em Valparaíso para todos os tratamentos foi menor do que em Araras, isso pode ser explicado pelas características do solo, enquanto em Araras foi comum obter produtividade acima de 120 t.ha $^{-1}$ em Valparaíso todos os tratamentos apresentaram valores menores do que o mencionado anteriormente. A maior diferença observada foi da variedade RB855536, que chegou a 42 t.ha ${ }^{-1}$ na dose $80 \mathrm{~kg} \mathrm{P}_{2} \mathrm{O}_{5}$. ha ${ }^{-1}$.

Falta de resposta em cana-planta a várias fontes de fósforo e superfosfato triplo em doses crescentes $\left(100,200\right.$ e $400 \mathrm{~kg} \mathrm{P}_{2} \mathrm{O}_{5}$. ha ${ }^{-1}$ foi relatado por Cesar et al. (1987) em experimento avaliando a variedade CB4176. ). Resultados semelhantes também foram obtidos por Reis e CabalaRosand (1986) que não observaram resposta ao fósforo $(0,50,100,150$ e 200 $\mathrm{P}_{2} \mathrm{O}_{5} \cdot \mathrm{ha}^{-1}$ ) em parcelas com e sem calagem. Além desses autores, Silva et al. (1976) e Orlando Filho e Zambello Junior (1980) também encontraram resultados que corroboram os resultados obtidos.

Penatti (1991), avaliando resposta ao fósforo em quatro solos diferentes, encontrou respostas crescentes e lineares ao nível de $1 \%$ de probabilidade, contrastando com aqueles resultados. Aumento na produtividade em resposta ao fósforo também foram encontrados por Korndorfer e Alcarde (1992) e Morelli et al. (1994). Os resultados são, portanto, contraditórios. Espironelo (1989), numa ampla revisão de todos os resultados experimentais de adubação 
fosfatada realizada pelo Instituto Agronômico de Campinas com a cultura da cana-de-açúcar, concluiu que em solos intensamente cultivados e adubados com fósforo essa cultura tendeu a não responder a esse nutriente. Ele concluiu que "o fósforo adicionado seguidamente foi "saturando" o solo, tornando esse nutriente cada vez menos necessário nas adubações para a cana-planta". Acrescentou ainda que "isso se deveu principalmente à baixa mobilidade do fósforo, à sua alta fixação no solo e conseqüente baixas perdas por lixiviação e arrastamento, e à sua baixa extração pela planta". É possivel que tal fato tenha ocorrido nos dois experimentos deste estudo.

\subsection{Aspectos Tecnológicos}

\subsubsection{Pol \% cana}

\section{Araras}

Não ocorreu interação significativa entre doses e variedades com relação à pol \% cana. A diferença encontrada foi em relação às médias por variedade (tabela 22), sendo que a variedade com teor mais elevado foi a RB835486, esperado pela sua característica, e as que apresentaram menor valor de foram RB855113 e RB855536. Ao contrário das demais variedades, as parcelas com a variedade RB835054 apresentaram decréscimo de pol\%cana com o aumento das doses de fósforo.

Tabela 22. Pol \% cana em cana-planta de Araras nos diferentes tratamentos em Araras.

\begin{tabular}{|c|c|c|c|c|c|}
\hline \multirow{2}{*}{ DOSES DE $\mathrm{P}_{2} \mathrm{O}_{5}$} & \multicolumn{4}{|c|}{ POL \% CANA* } & \multirow[t]{2}{*}{ Média por dose } \\
\hline & RB835486 & RB835054 & RB855113 & RB855536 & \\
\hline $0 \mathrm{~kg} \cdot \mathrm{ha}^{-1}$ & $17,43 \mathrm{~A}$ & $17.03 \mathrm{~A}$ & $15,92 \mathrm{~A}$ & $15.93 \mathrm{~A}$ & $16.57 \mathrm{~A}$ \\
\hline $80 \mathrm{~kg} \cdot \mathrm{ha}^{-1}$ & $17,59 \mathrm{~A}$ & $16,92 \mathrm{~A}$ & $15,97 \mathrm{~A}$ & $15,82 \mathrm{~A}$ & $16,57 \mathrm{~A}$ \\
\hline $160 \mathrm{~kg} \cdot \mathrm{ha}^{-1}$ & $17.83 \mathrm{~A}$ & $16,70 \mathrm{~A}$ & $16,19 \mathrm{~A}$ & $15,97 \mathrm{~A}$ & $16.67 \mathrm{~A}$ \\
\hline $240 \mathrm{~kg} \cdot \mathrm{ha}^{-1}$ & $17,73 \mathrm{~A}$ & $16,65 \mathrm{~A}$ & $15,67 \mathrm{~A}$ & $16,22 \mathrm{~A}$ & $16.57 \mathrm{~A}$ \\
\hline Média por variedade & $17.64 a$ & $16,82 b$ & $15,94 c$ & $15,98 \mathrm{c}$ & 16,59 \\
\hline
\end{tabular}


As variedades da série 83, RB835486 e RB835054, apresentaram teor de pol maior que as da série 85.

\section{Valparaiso}

Não se notou interação significativa entre doses de fósforo e variedades em pol \% cana de cana-planta em Valparaiso. Verificou-se diferença apenas entre médias por variedade (tabela 23), apesar de se observar tendência de diminuição da pol \% cana com o aumento das doses de fósforo aplicadas no solo. Marinho et al. (1976) observou redução na pol \% cana em solos que não eram deficientes em fósforo e que se aplicou doses acima de 100 $\mathrm{kg} \mathrm{P} \mathrm{O}_{5} \cdot \mathrm{ha}^{-1}$.

As variedades RB835486 e RB835054 apresentaram maior valor de pol \% cana, confirmando assim a "riqueza" em açúcar dessas variedades; as duas outras, como em Araras, foram as que apresentaram os menores valores.

Assim como encontrado no experimento, Korndorfer (1990), Penatti (1991) e Cesar et al. (1987) não encontraram diferenças significativas em relação à pol \% cana com o aumento nas dosagens de fósforo.

Tabela 23. Valores de pol \% cana em cana-planta de Valparaiso nos diferentes tratamentos.

\begin{tabular}{|c|c|c|c|c|c|}
\hline \multirow{2}{*}{ DOSES DE $\mathrm{P}_{2} \mathrm{O}_{5}$} & \multicolumn{4}{|c|}{ POL $\%$ CANA $^{*}$} & \multirow{2}{*}{ Média por dose } \\
\hline & RB835486 & RB835054 & RB855113 & RB855536 & \\
\hline $0 \mathrm{~kg} \cdot$ ha- $^{-1}$ & $16,07 \mathrm{~A}$ & $15,51 \mathrm{~A}$ & $14,53 \mathrm{~A}$ & $14,29 \mathrm{~A}$ & $15,10 \mathrm{~A}$ \\
\hline $80 \mathrm{~kg} \cdot \mathrm{ha}^{+}$ & $15,75 \mathrm{~A}$ & $15,59 \mathrm{~A}$ & $14,07 \mathrm{~A}$ & $14,16 \mathrm{~A}$ & $14,89 \mathrm{~A}$ \\
\hline 160 kg.ha- ${ }^{\prime}$ & $15,79 \mathrm{~A}$ & $15,63 \mathrm{~A}$ & $14,56 \mathrm{~A}$ & $14,33 \mathrm{~A}$ & $15,07 \mathrm{~A}$ \\
\hline $240 \mathrm{~kg} \cdot \mathrm{ha}^{\dagger}$ & $15,66 \mathrm{~A}$ & $15,64 \mathrm{~A}$ & $14,26 \mathrm{~A}$ & $14,29 \mathrm{~A}$ & $14,96 \mathrm{~A}$ \\
\hline Média por variedade & $15,82 \mathrm{a}$ & $15,59 \mathrm{a}$ & $14,35 b$ & $14,27 b$ & 15,00 \\
\hline
\end{tabular}




\subsubsection{Fibra}

A fibra é definida como um conjunto de substâncias insolúveis em água, sendo constituída, principalmente, de celulose, lignina e pentosanas. Normalmente a faixa encontrada em cana é de $10-16 \%$, com média de $12 \%$ para a região Centro-Sul (Stupiello, 1987).

\section{Araras}

Não se observou interação significativa entre doses de fósforo e variedades para teor de fibra em cana-planta de Araras.. A única diferença estatisticamente encontrada foi entre médias de variedades, ocorrendo um resultado semelhante ao encontrado para pol \% cana, ou seja, as variedades da série 83 (RB835486 e RB835054) apresentaram valores de fibra superiores aos encontrados nas variedades RB855113 e RB855536 (tabela 24). Notou-se uma ligeira tendência de aumento no teor de fibra com o aumento da dose de fósforo nas variedades RB835054 e RB855536.

Tabela 24. Teor de fibra em cana-planta de Araras nos diferentes tratamentos.

\begin{tabular}{cccccc}
\hline \multirow{2}{*}{ DOSES DE $\mathrm{P}_{2} \mathrm{O}_{5}$} & \multicolumn{4}{c}{ FIBRA $(\%)^{\star}$} & \multirow{2}{*}{ Média por dose } \\
\cline { 2 - 5 } & RB835486 & RB835054 & RB855113 & RB855536 & \\
\hline 0 kg.ha ${ }^{-1}$ & $11,94 \mathrm{~A}$ & $10,56 \mathrm{~A}$ & $10,08 \mathrm{~A}$ & $9,52 \mathrm{~A}$ & $10,52 \mathrm{~A}$ \\
$80 \mathrm{~kg} \cdot \mathrm{ha}^{-1}$ & $11,08 \mathrm{~A}$ & $10,61 \mathrm{~A}$ & $9,95 \mathrm{~A}$ & $9,99 \mathrm{~A}$ & $10,41 \mathrm{~A}$ \\
$160 \mathrm{~kg}^{-1} \mathrm{ha}^{-1}$ & $10,59 \mathrm{~A}$ & $11,12 \mathrm{~A}$ & $10,40 \mathrm{~A}$ & $9,98 \mathrm{~A}$ & $10,52 \mathrm{~A}$ \\
$240 \mathrm{~kg}^{-1}$ ha $^{-1}$ & $11,18 \mathrm{~A}$ & $11,33 \mathrm{~A}$ & $10,46 \mathrm{~A}$ & $10,71 \mathrm{~A}$ & $10,92 \mathrm{~A}$ \\
Média por variedade & $11,20 \mathrm{a}$ & $10,90 \mathrm{a}$ & $10,22 \mathrm{~b}$ & $10,05 \mathrm{~b}$ & 10,59 \\
\hline *letras maiúsculas referem-se a doses dentro de uma mesma variedade e média por dose, \\
minúsculas comparam médias por variedade.
\end{tabular}

\section{Valparaiso}

Em cana-planta de Valparaíso, tal como em Araras, não houve interação significativa entre dose de fósforo e teor de fibra, a única diferença encontrada sendo entre médias de variedades (tabela 25). . A RB835486 
apresentou o maior teor e, a RB855113, o menor, com a RB835054 e a RB855536 apresentando valores intermediários.

Tabela 25. Teor de fibra em cana-planta das diferentes variedades nas doses de fósforo aplicadas em Valparaíso.

\begin{tabular}{|c|c|c|c|c|c|}
\hline \multirow{2}{*}{ DOSES DE $\mathrm{P}_{2} \mathrm{O}_{5}$} & \multicolumn{4}{|c|}{$\operatorname{FIBRA}(\%)^{\star}$} & \multirow{2}{*}{ Média por dose } \\
\hline & RB835486 & RB835054 & RB855113 & RB855536 & \\
\hline $0 \mathrm{~kg} \cdot \mathrm{ha}^{-1}$ & $10,53 \mathrm{~A}$ & $10,36 \mathrm{~A}$ & $8,84 \mathrm{~A}$ & $10,21 \mathrm{~A}$ & $9,98 \mathrm{~A}$ \\
\hline $80 \mathrm{~kg} \cdot$ ha- $^{1}$ & $10,96 \mathrm{~A}$ & $10,18 \mathrm{~A}$ & $9,01 \mathrm{~A}$ & $10,70 \mathrm{~A}$ & $10,21 \mathrm{~A}$ \\
\hline 160 kg.ha- ${ }^{1}$ & $11,53 \mathrm{~A}$ & $10,55 \mathrm{~A}$ & $9,47 \mathrm{~A}$ & $10,12 \mathrm{~A}$ & $10,42 \mathrm{~A}$ \\
\hline $240 \mathrm{~kg} \cdot$ ha- $^{1}$ & $10,79 \mathrm{~A}$ & $10,50 \mathrm{~A}$ & $9,08 \mathrm{~A}$ & $10,24 \mathrm{~A}$ & $10,15 \mathrm{~A}$ \\
\hline Médias por variedade & $10,95 \mathrm{a}$ & $10,39 b$ & $9,10 \mathrm{c}$ & $10,32 b$ & 10,19 \\
\hline
\end{tabular}

*letras maiúsculas referem-se a doses dentro de uma mesma variedade e média por dose, minúsculas comparam médias por variedade.

No geral, tanto em Araras quanto em Valparaíso, foram observados valores situados entre 10 e 12\%, exceção feita à variedade RB855113 em Valparaíso que apresentou valores ao redor de $9,00 \%$. Aqueles valores estão dentro do considerado normal, um pouco abaixo da média para o Centro-Sul relatada por Stupiello (1987).

\section{CANA-SOCA}

\subsection{Crescimento}

\section{Araras}

Não se verificou interação significativa entre doses de fósforo e variedades para crescimento de cana-planta em Araras (tabela 26). O período em que se observou maior crescimento foi naquele compreendido entre os 
meses de dezembro a março, devido às condições favoráveis de temperatura e precipitação.

Tabela 26. Crescimento da cana-planta em Araras, em quatro doses de fósforo em três períodos.

\begin{tabular}{|c|c|c|c|c|}
\hline \multirow{2}{*}{ VARIEDADES } & \multirow{2}{*}{$\begin{array}{l}\text { DOSES DE } \\
\text { FOSFORO } \\
\left(\mathrm{kg} \mathrm{P}_{2} \mathrm{O}_{5} \cdot \mathrm{ha}^{-1}\right)\end{array}$} & \multicolumn{3}{|c|}{ CRESCIMENTO (m) } \\
\hline & & Jul-Dez & Dez-Mar & Mar-Ago \\
\hline \multirow{4}{*}{ RB835486 } & 0 & $0,58 \mathrm{Aa}$ & $1,49 \mathrm{Aa}$ & $0,82 \mathrm{Aa}$ \\
\hline & 80 & $0,58 \mathrm{Aa}$ & $1,50 \mathrm{Aa}$ & $0,80 \mathrm{Aa}$ \\
\hline & 160 & $0,53 \mathrm{Aa}$ & $1,38 \mathrm{Aa}$ & $0,74 \mathrm{Aa}$ \\
\hline & 240 & $0,58 \mathrm{Aa}$ & $1,31 \mathrm{Aa}$ & $0,82 \mathrm{Aa}$ \\
\hline \multirow{4}{*}{ RB835054 } & 0 & $1,02 \mathrm{Aa}$ & $1,58 \mathrm{Aa}$ & $0,78 \mathrm{Aa}$ \\
\hline & 80 & $0,86 \mathrm{Aa}$ & $1,57 \mathrm{Aa}$ & $0,71 \mathrm{Aa}$ \\
\hline & 160 & $0,91 \mathrm{Aa}$ & $1,47 \mathrm{Aa}$ & $0,82 \mathrm{Aa}$ \\
\hline & 240 & $1,00 \mathrm{Aa}$ & $1,52 \mathrm{Aa}$ & $0,76 \mathrm{Aa}$ \\
\hline \multirow{4}{*}{ RB855113 } & 0 & $0,63 \mathrm{Aa}$ & $1,54 \mathrm{Aa}$ & $0,80 \mathrm{Aa}$ \\
\hline & 80 & $0,70 \mathrm{Aa}$ & $1,50 \mathrm{Aa}$ & $0,78 \mathrm{Aa}$ \\
\hline & 160 & $0,60 \mathrm{Aa}$ & $1,51 \mathrm{Aa}$ & $0,86 \mathrm{Aa}$ \\
\hline & 240 & $0,59 \mathrm{Aa}$ & $1,49 \mathrm{Aa}$ & $0,84 \mathrm{Aa}$ \\
\hline \multirow{4}{*}{ RB855536 } & 0 & $0,82 \mathrm{Aa}$ & $1,60 \mathrm{Aa}$ & $0,84 \mathrm{Aa}$ \\
\hline & 80 & $0,80 \mathrm{Aa}$ & $1,57 \mathrm{Aa}$ & $0,79 \mathrm{Aa}$ \\
\hline & 160 & $0,78 \mathrm{Aa}$ & $1,57 \mathrm{Aa}$ & $0,76 \mathrm{Aa}$ \\
\hline & 240 & $0,81 \mathrm{Aa}$ & $1,47 \mathrm{Aa}$ & $0,75 \mathrm{Aa}$ \\
\hline
\end{tabular}

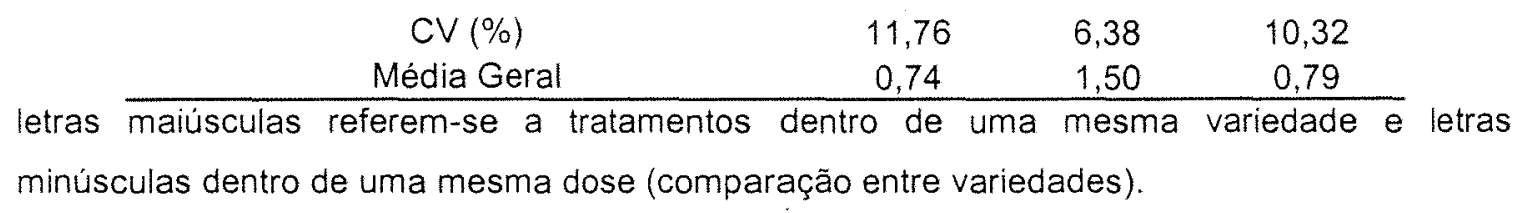

A única diferença encontrada foi entre médias de variedades (tabela 27). A RB855536 e a RB835054 foram as variedades que mais cresceram nas duas primeiras épocas amostradas, sendo que na última não houve diferença significativa entre as variedades em estudo. 
Tabela 27. Diferença varietal quanto ao crescimento de cana-planta em Araras.

\begin{tabular}{cccc}
\hline \multirow{2}{*}{ VARIEDADES } & \multicolumn{3}{c}{ CRESCIMENTO $(\mathrm{m})$} \\
\cline { 2 - 4 } & Jul-Dez & Dez-Mar & Mar-Ago \\
\hline RB835486 & $0,57 \mathrm{C}$ & $1,42 \mathrm{~B}$ & $0,80 \mathrm{~A}$ \\
RB835054 & $0,95 \mathrm{~A}$ & $1,53 \mathrm{~A}$ & $0,77 \mathrm{~A}$ \\
RB855113 & $0,63 \mathrm{C}$ & $1,51 \mathrm{AB}$ & $0,82 \mathrm{~A}$ \\
RB855536 & $0,80 \mathrm{~B}$ & $1,55 \mathrm{~A}$ & $0,78 \mathrm{~A}$ \\
\hline
\end{tabular}

Valparaiso

Tabela 28. Crescimento de cana-planta em Valparaíso em quatro doses de fósforo em três períodos.

\begin{tabular}{|c|c|c|c|c|}
\hline \multirow{2}{*}{ VARIEDADES } & \multirow{2}{*}{$\begin{array}{c}\text { DOSES DE FÓSFORO } \\
\left(\mathrm{kg} \mathrm{P}_{2} \mathrm{O}_{5} \cdot \mathrm{ha}^{-1}\right)\end{array}$} & \multicolumn{3}{|c|}{ CRESCIMENTO $(\mathrm{m})$} \\
\hline & & Jul-Dez & Dez-Mar & Mar-Ago \\
\hline \multirow{4}{*}{ RB835486 } & 0 & $0,97 \mathrm{Abc}$ & $1,62 \mathrm{Aa}$ & $0,62 \mathrm{Aa}$ \\
\hline & 80 & $1,10 \mathrm{Aa}$ & 1,69 Aa & $0,57 \mathrm{Aa}$ \\
\hline & 160 & 1,02 Aab & $1,43 \mathrm{Aa}$ & $0,72 \mathrm{Aa}$ \\
\hline & 240 & $1,06 \mathrm{Aab}$ & $1,65 \mathrm{Aa}$ & $0,60 \mathrm{Aa}$ \\
\hline \multirow{4}{*}{ RB835054 } & 0 & $1,14 \mathrm{Aa}$ & 1,53 Aa & $0,81 \mathrm{Aa}$ \\
\hline & 80 & $0,97 \mathrm{Bab}$ & $1,50 \mathrm{Aa}$ & $0,68 \mathrm{Aa}$ \\
\hline & 160 & $1,10 \mathrm{ABa}$ & $1,51 \mathrm{Aa}$ & $0,73 \mathrm{Aa}$ \\
\hline & 240 & $1,07 \mathrm{ABa}$ & $1,51 \mathrm{Aa}$ & $0,76 \mathrm{Aa}$ \\
\hline \multirow{4}{*}{ RB855113 } & 0 & $0,86 \mathrm{Ac}$ & $1,51 \mathrm{Aa}$ & $0,69 \mathrm{Aa}$ \\
\hline & 80 & $0,92 \mathrm{Ab}$ & $1,56 \mathrm{Aa}$ & $0,65 \mathrm{Aa}$ \\
\hline & 160 & $0,95 \mathrm{Aab}$ & $1,46 \mathrm{Aa}$ & $0.59 \mathrm{Aa}$ \\
\hline & 240 & $0,91 \mathrm{Aab}$ & 1,52 Aa & $0,67 \mathrm{Aa}$ \\
\hline \multirow{4}{*}{ RB855536 } & 0 & $1,05 \mathrm{Aab}$ & $1,53 \mathrm{Aa}$ & $0,71 \mathrm{Aa}$ \\
\hline & 80 & $0,88 \mathrm{Bb}$ & $1,54 \mathrm{Aa}$ & $0,60 \mathrm{Aa}$ \\
\hline & 160 & $0,91 \mathrm{ABb}$ & 1,56 Aa & $0,66 \mathrm{Aa}$ \\
\hline & 240 & $0,91 \mathrm{ABb}$ & $1,57 \mathrm{Aa}$ & $0,65 \mathrm{Aa}$ \\
\hline \multirow{2}{*}{\multicolumn{2}{|c|}{$\begin{array}{c}\text { CV }(\%) \\
\text { Média Geral }\end{array}$}} & 7,48 & 5,70 & 12,85 \\
\hline & & 0,99 & 1,54 & 0,67 \\
\hline
\end{tabular}

letras maiúsculas referem-se a tratamentos dentro de uma mesma variedade e letras minúsculas dentro de uma mesma dose (comparação entre variedades).

Houve interação significativa para crescimento entre doses e variedade em Valparaíso na primeira época amostrada, mas não nas demais (tabela 28). Neste período, notou-se diferença entre doses dentro da mesma 
variedade apenas nas RB835054 e RB855536. Nessas variedades a testemunha apesar de não diferir estatisticamente da dose 160 e $240 \mathrm{~kg}$ $\mathrm{P}_{2} \mathrm{O}_{5}$. ha ${ }^{-1}$, foi a que apresentou maior crescimento. $\mathrm{E}$ a dose 80 foi, para ambas, o tratamento obteve menor crescimento. Ao comparar variedades em uma mesma dose, notou-se diferença significativa em todas as dosagens. A RB835054, de forma geral, foi a que apresentou maior resposta as doses de fósforo e as variedades RB855113 e RB855536 os menores valores.

Apesar de existir interação significativa na primeira amostragem, as médias de doses não diferiram significativamente entre si em nenhum período avaliado.

A única diferença foi entre médias de variedades (tabela 29). Perfilhos da variedade RB835054 foram os que apresentaram maior crescimento. No verão, período de maior crescimento, as variedades não se diferiram entre si.

Tabela 29. Diferença varietal em relação ao crescimento em diferentes épocas em Valparaiso.

\begin{tabular}{cccc}
\hline \multirow{2}{*}{ VARIEDADES } & \multicolumn{3}{c}{ CRESCIMENTO $(\mathrm{m})$} \\
\cline { 2 - 4 } & Jul-Dez & Dez-Mar & Mar-Ago \\
\hline RB835486 & $1,04 \mathrm{~A}$ & $1,60 \mathrm{~A}$ & $0,63 \mathrm{~B}$ \\
RB835054 & $1,07 \mathrm{~A}$ & $1,51 \mathrm{~A}$ & $0,74 \mathrm{~A}$ \\
RB855113 & $0,94 \mathrm{~B}$ & $1,51 \mathrm{~A}$ & $0,65 \mathrm{AB}$ \\
RB855536 & $0,91 \mathrm{~B}$ & $1,55 \mathrm{~A}$ & $0,65 \mathrm{AB}$ \\
\hline
\end{tabular}

\subsection{Perfilhamento}

\section{Araras}

Não houve interação significativa entre doses de fósforo e variedade em nenhum período avaliado. Nota-se existir um decréscimo populacional do primeiro ao último período (tabela 30 ). 
Tabela 30. População de plantas de diferentes tratamentos em Araras.

\begin{tabular}{|c|c|c|c|c|}
\hline \multirow[t]{2}{*}{ VARIEDADES } & \multirow{2}{*}{$\begin{array}{c}\text { DOSES DE } \\
\text { FÓSFORO } \\
\left(\mathrm{kg} \mathrm{P}_{2} \mathrm{O}_{5} \cdot \mathrm{ha}^{-1}\right) \\
\end{array}$} & \multicolumn{3}{|c|}{$\begin{array}{l}\text { POPULAÇÃO } \\
\text { (perfilhos. } m^{-1} \text { ) }\end{array}$} \\
\hline & & Jul-Dez & Dez-Mar & Mar-Ago \\
\hline \multirow{4}{*}{ RB835486 } & 0 & $25,56 \mathrm{Aa}$ & $16,75 \mathrm{Aa}$ & $14,25 \mathrm{Aa}$ \\
\hline & 80 & $27,78 \mathrm{Aa}$ & $17,58 \mathrm{Aa}$ & $15,42 \mathrm{Aa}$ \\
\hline & 160 & $35,22 \mathrm{Aa}$ & $18,42 \mathrm{Aa}$ & $16,33 \mathrm{Aa}$ \\
\hline & 240 & $33,67 \mathrm{Aa}$ & $47,50 \mathrm{Aa}$ & $15,25 \mathrm{Aa}$ \\
\hline \multirow{4}{*}{ RB835054 } & 0 & $25,67 \mathrm{Aa}$ & $14,92 \mathrm{Aa}$ & $12,67 \mathrm{Aa}$ \\
\hline & 80 & $30,78 \mathrm{Aa}$ & $18,42 \mathrm{Aa}$ & $14,92 \mathrm{Aa}$ \\
\hline & 160 & $29,11 \mathrm{Aa}$ & $17,08 \mathrm{Aa}$ & $15,92 \mathrm{Aa}$ \\
\hline & 240 & $29,67 \mathrm{Aa}$ & $17,67 \mathrm{Aa}$ & $13,92 \mathrm{Aa}$ \\
\hline \multirow{4}{*}{ R8855113 } & 0 & $24,33 \mathrm{Aa}$ & $15,46 \mathrm{Aa}$ & $11,50 \mathrm{Aa}$ \\
\hline & 80 & $27,78 \mathrm{Aa}$ & $16,92 \mathrm{Aa}$ & $13,50 \mathrm{Aa}$ \\
\hline & 160 & $33,78 \mathrm{Aa}$ & $18,42 \mathrm{Aa}$ & $15,67 \mathrm{Aa}$ \\
\hline & 240 & $34,44 \mathrm{Aa}$ & $18,50 \mathrm{Aa}$ & $15,42 \mathrm{Aa}$ \\
\hline \multirow{4}{*}{ RB855536 } & 0 & $26,89 \mathrm{Aa}$ & $13,42 \mathrm{Aa}$ & $12,75 \mathrm{Aa}$ \\
\hline & 80 & $32,44 \mathrm{Aa}$ & $19,67 \mathrm{Aa}$ & $14,83 \mathrm{Aa}$ \\
\hline & 160 & $29,56 \mathrm{Aa}$ & $17,00 \mathrm{Aa}$ & $14,58 \mathrm{Aa}$ \\
\hline & 240 & $28,11 \mathrm{Aa}$ & $15,75 \mathrm{Aa}$ & $14,08 \mathrm{Aa}$ \\
\hline \multirow{2}{*}{\multicolumn{2}{|c|}{$\begin{array}{c}\text { CV }(\%) \\
\text { Média Geral }\end{array}$}} & 22,31 & 12,90 & 14,02 \\
\hline & & 30,10 & 17,02 & 14,43 \\
\hline
\end{tabular}

letras maiúsculas referem-se a tratamentos dentro de uma mesma variedade e letras minúsculas dentro de uma mesma dose (comparação entre variedades).

A diferença encontrada foi em relação às médias de variedades (tabela 31). Como era de se esperar, devido às características genéticas, a variedade RB835486 foi a que apresentou menor perfilhamento em todas as avaliações. E a que mais perfilhou foi a variedade RB855113. A RB835486 tende a ser uma variedade que perfilha menos que as demais, mas que no final, na colheita, por ter maior peso por colmo, tende a se equiparar as outras. Por perfilhar muito a variedade RB855113 também foi a que apresentou maior queda de população. Sendo que a diminuição de forma geral para todas as variedades ficou próxima de $50 \%$, ao compararmos o primeiro período com o último. Mostrando ser de extrema importância um bom perfilhamento para que na época da colheita tenha-se um maior número de colmos industrializáveis. 
Tabela 31. População de perfilhos por variedade em Araras.

\begin{tabular}{cccc}
\hline \multirow{2}{*}{ VARIEDADES } & \multicolumn{3}{c}{ POPULAÇÃO (perfilhos. m $^{-1}$ ) } \\
\cline { 2 - 4 } & Jul-Dez & Dez-Mar & Mar-Ago \\
\hline RB835486 & $27,71 \mathrm{~A}$ & $15,13 \mathrm{~B}$ & $12,79 \mathrm{~B}$ \\
RB835054 & $28,98 \mathrm{~A}$ & $18,06 \mathrm{~A}$ & $14,67 \mathrm{AB}$ \\
RB855113 & $32,27 \mathrm{~A}$ & $17,73 \mathrm{~A}$ & $15,62 \mathrm{~A}$ \\
RB855536 & $31,46 \mathrm{~A}$ & $17,17 \mathrm{AB}$ & $14,63 \mathrm{AB}$ \\
\hline
\end{tabular}

\section{Valparaiso}

Apesar de existir uma tendência de aumento do número de perfilhos por metro linear com o aumento nas doses de fósforo, não existiu diferença significativa entre doses de fósforo e variedades em nenhum periodo avaliado (tabela 32). O número de perfilhos por metro foi menor que o de Araras.

Tabela 32. População de perfilhos por variedade em Araras.

\begin{tabular}{|c|c|c|c|c|}
\hline \multirow{2}{*}{ VARIEDADES } & \multirow{2}{*}{$\begin{array}{l}\text { DOSES DE } \\
\text { FÓSFORO } \\
\left(\mathrm{kg} \mathrm{P}_{2} \mathrm{O}_{5} \cdot \mathrm{ha}^{-1}\right)\end{array}$} & \multicolumn{3}{|c|}{ POPULAÇÃO DE PLANTAS (perfilhos $\mathrm{m}^{-1}$ ) } \\
\hline & & Jul-Dez & Dez-Mar & Mar-Ago \\
\hline \multirow{4}{*}{ RB835486 } & 0 & $15,50 \mathrm{Aa}$ & $11,83 \mathrm{Aa}$ & $10,25 \mathrm{Aa}$ \\
\hline & 80 & $16,83 \mathrm{Aa}$ & $12,83 \mathrm{Aa}$ & $10,08 \mathrm{Aa}$ \\
\hline & 160 & $14,75 \mathrm{Aa}$ & $10,75 \mathrm{Aa}$ & $9,00 \mathrm{Aa}$ \\
\hline & 240 & $15,75 \mathrm{Aa}$ & $11,92 \mathrm{Aa}$ & $10,92 \mathrm{Aa}$ \\
\hline \multirow{4}{*}{ RB835054 } & 0 & $14,75 \mathrm{Aa}$ & $14,17 \mathrm{Aa}$ & $12,67 \mathrm{Aa}$ \\
\hline & 80 & $16,58 \mathrm{Aa}$ & $14,83 \mathrm{Aa}$ & $13,00 \mathrm{Aa}$ \\
\hline & 160 & $16,00 \mathrm{Aa}$ & $12,50 \mathrm{Aa}$ & $11,17 \mathrm{Aa}$ \\
\hline & 240 & $17,42 \mathrm{Aa}$ & $14,58 \mathrm{Aa}$ & $12,33 \mathrm{Aa}$ \\
\hline \multirow{4}{*}{ RB855113 } & 0 & $17,92 \mathrm{Aa}$ & $13,42 \mathrm{Aa}$ & $10,17 \mathrm{Aa}$ \\
\hline & 80 & $19,00 \mathrm{Aa}$ & $13,33 \mathrm{Aa}$ & $11,00 \mathrm{Aa}$ \\
\hline & 160 & $19,50 \mathrm{Aa}$ & $13,92 \mathrm{Aa}$ & $12,25 \mathrm{Aa}$ \\
\hline & 240 & $21,58 \mathrm{Aa}$ & $14,92 \mathrm{Aa}$ & $12,25 \mathrm{Aa}$ \\
\hline \multirow{4}{*}{ RB855536 } & 0 & $21,33 \mathrm{Aa}$ & $14,33 \mathrm{Aa}$ & $12,50 \mathrm{Aa}$ \\
\hline & 80 & $19,33 \mathrm{Aa}$ & $13,33 \mathrm{Aa}$ & $11,08 \mathrm{Aa}$ \\
\hline & 160 & $18.75 \mathrm{Aa}$ & $12,75 \mathrm{Aa}$ & $11.33 \mathrm{Aa}$ \\
\hline & 240 & $19,75 \mathrm{Aa}$ & $13,00 \mathrm{Aa}$ & $12,33 \mathrm{Aa}$ \\
\hline \multirow{2}{*}{\multicolumn{2}{|c|}{$\begin{array}{c}\text { CV }(\%) \\
\text { Média Geral }\end{array}$}} & 13,52 & 13,12 & 13.47 \\
\hline & & 18,01 & 13,32 & 11,38 \\
\hline
\end{tabular}


Existe diferença significativa entre as médias de variedade (tabela 33). As variedades RB855536 e RB855113 foram as que apresentaram maior população de plantas durante o experimento, sendo que a última também se destacou em Araras.

Observa-se um decréscimo no número de perfilhos por metro linear com o passar dos meses. A redução nas condições edafoclimáticas de Valparaíso ficou entre 30 e $40 \%$, ou seja, menor que em Araras, que apresentou uma população inicial mais alta.

Tabela 33. População de plantas em diferentes variedades.

\begin{tabular}{cccc}
\hline \multirow{2}{*}{ VARIEDADES } & \multicolumn{3}{c}{ POPULAÇÃO DE PLANTAS (perfilhos.m ${ }^{-1}$ ) } \\
\cline { 2 - 4 } & Jul-Dez & Dez-Mar & Mar-Ago \\
\hline RB835486 & $15,71 \mathrm{~B}$ & $11,83 \mathrm{~B}$ & $10,06 \mathrm{~B}$ \\
RB835054 & $16,92 \mathrm{~B}$ & $14,15 \mathrm{~A}$ & $12,39 \mathrm{~A}$ \\
RB855113 & $19,50 \mathrm{~A}$ & $13,90 \mathrm{~A}$ & $11,31 \mathrm{AB}$ \\
RB855536 & $19,92 \mathrm{~A}$ & $13,42 \mathrm{AB}$ & $11,75 \mathrm{~A}$ \\
\hline
\end{tabular}

Os valores obtidos para população de plantas, tanto para Araras quanto para Valparaiso, foram superiores aos obtidos por Hermann (1997) com outras variedades, que ficaram entre 6 e 16 perfilhos por metro linear, e semelhante aos obtidos por Penatti (1991).

\subsection{Dinâmica foliar em cana-soca}

\subsubsection{Folhas verdes}

Araras

Não existiu interação significativa entre doses de $P$ e variedades em nenhum dos dois primeiros periodos de avaliação, somente na terceira época. Nesse último período, verificou-se diferença entre doses dentro da variedade $\mathrm{RB} 835054$ e entre variedades dentro das doses 0 e $80 \mathrm{~kg} \mathrm{P}_{2} \mathrm{O}_{5}$. ha ${ }^{-1}$ (tabela 34). 
Tabela 34. Número de folhas verdes nos diferentes tratamentos.

\begin{tabular}{|c|c|c|c|c|}
\hline \multirow[t]{2}{*}{ VARIEDADES } & \multirow{2}{*}{$\begin{array}{l}\text { DOSES DE FÓSFORO } \\
\quad\left(\mathrm{kg} \mathrm{P}_{2} \mathrm{O}_{5} \cdot \mathrm{ha}^{-1}\right)\end{array}$} & \multicolumn{3}{|c|}{$\begin{array}{l}\text { FOLHAS VERDES } \\
\text { (folhas.perfilho }^{-1} \text { ) }\end{array}$} \\
\hline & & Jul-Dez & Dez-Mar & Mar-Ago \\
\hline \multirow{4}{*}{ RB835486 } & 0 & $6,40 \mathrm{Aa}$ & $7,23 \mathrm{Aa}$ & $6,05 \mathrm{Ab}$ \\
\hline & 80 & $5,87 \mathrm{Aa}$ & $6,67 \mathrm{Aa}$ & $7,00 \mathrm{Aab}$ \\
\hline & 160 & $6,00 \mathrm{Aa}$ & $6,47 \mathrm{Aa}$ & $7.07 \mathrm{Aa}$ \\
\hline & 240 & $5,60 \mathrm{Aa}$ & $6,76 \mathrm{Aa}$ & $6,53 \mathrm{Aa}$ \\
\hline \multirow{4}{*}{ 'RB835054 } & 0 & $7,53 \mathrm{Aa}$ & 7,93 Aa & $8,53 \mathrm{Aa}$ \\
\hline & 80 & $6,87 \mathrm{Aa}$ & $8,75 \mathrm{Aa}$ & $8,27 \mathrm{ABa}$ \\
\hline & 160 & $6,73 \mathrm{Aa}$ & $7,47 \mathrm{Aa}$ & $7,00 \mathrm{BCa}$ \\
\hline & 240 & 6,93 $\mathrm{Aa}$ & $8,60 \mathrm{Aa}$ & $6,73 \mathrm{Ba}$ \\
\hline \multirow{4}{*}{ RB855113 } & 0 & $6,40 \mathrm{Aa}$ & 7,03 Aa & 7,07 Aa \\
\hline & 80 & $6,07 \mathrm{Aa}$ & $6,33 \mathrm{Aa}$ & $6,60 \mathrm{Ab}$ \\
\hline & 160 & $6,20 \mathrm{Aa}$ & $6,43 \mathrm{Aa}$ & $6,27 \mathrm{Aa}$ \\
\hline & 240 & $6,27 \mathrm{Aa}$ & $6,37 \mathrm{Aa}$ & $6,67 \mathrm{Aa}$ \\
\hline \multirow{4}{*}{ RB855536 } & 0 & $5,93 \mathrm{Aa}$ & $5,75 \mathrm{Aa}$ & 6,33 Aa \\
\hline & 80 & $6,27 \mathrm{Aa}$ & $4,67 \mathrm{Aa}$ & $5,87 \mathrm{Ab}$ \\
\hline & 160 & $6,07 \mathrm{Aa}$ & $5,45 \mathrm{Aa}$ & $6,00 \mathrm{Aa}$ \\
\hline & 240 & $6,00 \mathrm{Aa}$ & $5,48 \mathrm{Aa}$ & $5,93 \mathrm{Aa}$ \\
\hline \multirow{2}{*}{\multicolumn{2}{|c|}{$\begin{array}{c}\text { CV }(\%) \\
\text { Média Geral }\end{array}$}} & 8,21 & 13,56 & 9,27 \\
\hline & & 6,32 & 6,71 & 6,74 \\
\hline
\end{tabular}

letras maiúsculas referem-se a tratamentos dentro de uma mesma variedade e letras minúsculas dentro de uma mesma dose (comparação entre variedades),

Na RB835054 o que se verificou foi uma diminuição no número de folhas fotossintéticamente ativas com o aumento da dose de fósforo.

Em relação às doses, a variedade RB855536 a que apresentou as menores quantidades de folhas fotossintéticamente ativas e a RB835054 os maiores valores.

Como nos outros parâmetros estudados, não se observou diferença significativa entre a média de doses, somente para a de variedades (tabela 35). Sendo que o maior número de folhas verdes por colmo foi a RB835054, sendo que os menores valores foram encontrados na RB855536. 
Tabela 35. Número médio de folhas verdes por variedade em Araras.

\begin{tabular}{cccc}
\hline \multirow{2}{*}{ VARIEDADES } & \multicolumn{3}{c}{$\begin{array}{c}\text { FOLHAS VERDES } \\
\text { (folhas.perfilho-1 }\end{array}$} \\
\cline { 2 - 4 } & Jul-Dez & Dez-Mar & Mar-Ago \\
\hline RB835486 & $5,97 \mathrm{~B}$ & $6,78 \mathrm{~B}$ & $6,66 \mathrm{~B}$ \\
RB835054 & $7,02 \mathrm{~A}$ & $8,19 \mathrm{~A}$ & $7,63 \mathrm{~A}$ \\
RB855113 & $6,23 \mathrm{~B}$ & $6,54 \mathrm{~B}$ & $6,65 \mathrm{~B}$ \\
RB855536 & $6,07 \mathrm{~B}$ & $5,34 \mathrm{C}$ & $6,03 \mathrm{~B}$ \\
\hline
\end{tabular}

Maior número de folhas verdes por colmo foi a RB835054, sendo que os menores valores foram encontrados na RB855536.

\section{Valparaiso}

Tabela 36. Número de folhas verdes encontradas nos diferentes tratamentos em Valparaíso.

\begin{tabular}{|c|c|c|c|c|}
\hline \multirow[t]{2}{*}{ VARIEDADES } & \multirow{2}{*}{$\begin{array}{l}\text { DOSES DE FÓSFORO } \\
\left(\mathrm{kg} \mathrm{P}_{2} \mathrm{O}_{5} \cdot \mathrm{ha}^{-1}\right)\end{array}$} & \multicolumn{3}{|c|}{$\begin{array}{l}\text { FOLHAS VERDES } \\
\text { (folhas.perfilho-1 }\end{array}$} \\
\hline & & Jul-Dez & Dez-Mar & Mar-Ago \\
\hline \multirow{4}{*}{ RB835486 } & 0 & $5,13 \mathrm{Aa}$ & $8,97 \mathrm{Aa}$ & $7,94 \mathrm{Aa}$ \\
\hline & 80 & $5,29 \mathrm{Aa}$ & $8,36 \mathrm{Aa}$ & $8,03 \mathrm{Aa}$ \\
\hline & 160 & $5,35 \mathrm{Aa}$ & $8,33 \mathrm{Aa}$ & $7,40 \mathrm{Aa}$ \\
\hline & 240 & $5,64 \mathrm{Aa}$ & $8,35 \mathrm{Aa}$ & 7,93 Aa \\
\hline \multirow{4}{*}{ RB835054 } & 0 & $6,10 \mathrm{Aa}$ & $9,48 \mathrm{Aa}$ & $8,43 \mathrm{Aa}$ \\
\hline & 80 & $5,68 \mathrm{Aa}$ & $9,51 \mathrm{Aa}$ & 7,76 Aa \\
\hline & 160 & $6,33 \mathrm{Aa}$ & $9,18 \mathrm{Aa}$ & 7,94 Aa \\
\hline & 240 & $6,14 \mathrm{Aa}$ & $9,23 \mathrm{Aa}$ & $8,14 \mathrm{Aa}$ \\
\hline \multirow{4}{*}{ RB855113 } & 0 & $4,90 \mathrm{Aa}$ & $8,12 \mathrm{Aa}$ & $7,44 \mathrm{Aa}$ \\
\hline & 80 & $4,99 \mathrm{Aa}$ & $8,57 \mathrm{Aa}$ & $7,97 \mathrm{Aa}$ \\
\hline & 160 & $5,42 \mathrm{Aa}$ & $8,48 \mathrm{Aa}$ & $7,85 \mathrm{Aa}$ \\
\hline & 240 & $5,07 \mathrm{Aa}$ & $8,16 \mathrm{Aa}$ & $7,60 \mathrm{Aa}$ \\
\hline \multirow{4}{*}{ RB855536 } & 0 & $4,88 \mathrm{Aa}$ & $8,24 \mathrm{Aa}$ & 7,78 $\mathrm{Aa}$ \\
\hline & 80 & $5,04 \mathrm{Aa}$ & $7,49 \mathrm{Aa}$ & 7,63 $\mathrm{Aa}$ \\
\hline & 160 & $4,76 \mathrm{Aa}$ & $8,07 \mathrm{Aa}$ & $7,58 \mathrm{Aa}$ \\
\hline & 240 & $5,01 \mathrm{Aa}$ & 7,52 Aa & $7,58 \mathrm{Aa}$ \\
\hline \multirow{2}{*}{\multicolumn{2}{|c|}{$\begin{array}{c}\text { CV }(\%) \\
\text { Média Geral }\end{array}$}} & 6,07 & 8,80 & 4,36 \\
\hline & & 5,36 & 8,43 & 7,81 \\
\hline
\end{tabular}


Não se verificou interação significativa entre doses de fósforo e variedades em nenhum período avaliado (tabela 36 ). O maior número de folhas verdes foi encontrado no verão.

Dentre as variedades pesquisadas, a RB835054 foi o que apresentou, em todos os períodos analisados, o maior número de folhas fotossintéticamente ativas e a RB835536 a menor quantidade de folhas verdes (tabela 37). Resultado semelhante ao encontrado na outra localidade em estudo.

Tabela 37. Número de folhas verdes de cada variedade em estudo no decorrer do experimento em Valparaíso.

\begin{tabular}{cccc}
\hline \multirow{2}{*}{ VARIEDADES } & \multicolumn{3}{c}{ FOLHAS VERDES (folhas.perfilho ${ }^{-1}$ ) } \\
\cline { 2 - 4 } & Jul-Dez & Dez-Mar & Mar-Ago \\
\hline RB835486 & $5,35 \mathrm{~B}$ & $8,50 \mathrm{~B}$ & $7,83 \mathrm{AB}$ \\
RB835054 & $6,06 \mathrm{~A}$ & $9,35 \mathrm{~A}$ & $8,07 \mathrm{~A}$ \\
RB855113 & $5,09 \mathrm{BC}$ & $8,03 \mathrm{~B}$ & $7,71 \mathrm{AB}$ \\
RB855536 & $4,92 \mathrm{C}$ & $7,83 \mathrm{~B}$ & $7,64 \mathrm{~B}$ \\
\hline
\end{tabular}

\subsubsection{Folhas formadas}

\section{Araras}

Não existiu interação significativa entre doses de fósforo e variedades. O periodo em que se verificou maior formação de folhas foi no verão (tabela 38). Isso aconteceu devido às condições climáticas favoráveis encontradas neste período, apesar de não ter refletido no número de folhas verdes, que se mostrou praticamente constante durante o experimento.

Existiu diferença significativa apenas na média geral entre variedades (tabela 39). Da mesma forma que aconteceu com o número de folhas verdes, o de folhas que surgiram foi maior, nas três épocas, na RB835054. O periodo do verão foi o que apresentou maiores valores. 
Tabela 38. Formação de folhas durante o experimento em diferentes tratamentos em Araras.

\begin{tabular}{|c|c|c|c|c|}
\hline \multirow[t]{2}{*}{ VARIEDADES } & \multirow{2}{*}{$\begin{array}{c}\text { DOSES DE FÓSFORO } \\
\left(\mathrm{kg} \mathrm{P}_{2} \mathrm{O}_{5} \cdot \mathrm{ha}^{-1}\right)\end{array}$} & \multicolumn{3}{|c|}{$\begin{array}{l}\text { FOLHAS SURGIDAS } \\
\text { (folhas perfilho-1) }\end{array}$} \\
\hline & & Jul-Dez & Dez-Mar & Mar-Ago \\
\hline & 0 & $8,07 \mathrm{~A}$ & $11,43 \mathrm{~A}$ & $7,37 \mathrm{~A}$ \\
\hline \multirow{3}{*}{ RB835486 } & 80 & $7,60 \mathrm{~A}$ & $11,27 \mathrm{~A}$ & $8,47 \mathrm{~A}$ \\
\hline & 160 & $7,73 \mathrm{~A}$ & $10,87 \mathrm{~A}$ & $8,73 \mathrm{~A}$ \\
\hline & 240 & $7,47 \mathrm{~A}$ & $10,72 \mathrm{~A}$ & $8,00 \mathrm{~A}$ \\
\hline \multirow{4}{*}{ RB835054 } & 0 & $9,80 \mathrm{~A}$ & $11,47 \mathrm{~A}$ & $9,80 \mathrm{~A}$ \\
\hline & 80 & $9,47 \mathrm{~A}$ & $12,75 \mathrm{~A}$ & $9,87 \mathrm{~A}$ \\
\hline & 160 & $8,80 \mathrm{~A}$ & $11,29 \mathrm{~A}$ & $8,67 \mathrm{~A}$ \\
\hline & 240 & $9,20 \mathrm{~A}$ & $11,87 \mathrm{~A}$ & $8,93 \mathrm{~A}$ \\
\hline \multirow{4}{*}{ RB855113 } & 0 & $8,40 \mathrm{~A}$ & $11,15 \mathrm{~A}$ & $9,00 \mathrm{~A}$ \\
\hline & 80 & $7,60 \mathrm{~A}$ & $10,73 \mathrm{~A}$ & $8,67 \mathrm{~A}$ \\
\hline & 160 & $7,93 \mathrm{~A}$ & $10,33 \mathrm{~A}$ & $8,27 \mathrm{~A}$ \\
\hline & 240 & $8,07 \mathrm{~A}$ & $11,37 \mathrm{~A}$ & $8,33 \mathrm{~A}$ \\
\hline \multirow{4}{*}{ RB855536 } & 0 & $7,60 \mathrm{~A}$ & $10,17 \mathrm{~A}$ & $8,07 \mathrm{~A}$ \\
\hline & 80 & $8,13 \mathrm{~A}$ & $9,43 \mathrm{~A}$ & $8,00 \mathrm{~A}$ \\
\hline & 160 & $7,87 \mathrm{~A}$ & $9,92 \mathrm{~A}$ & $7,67 \mathrm{~A}$ \\
\hline & 240 & $8,00 \mathrm{~A}$ & $10,40 \mathrm{~A}$ & $7,80 \mathrm{~A}$ \\
\hline \multirow{2}{*}{\multicolumn{2}{|c|}{$\begin{array}{c}\text { CV }(\%) \\
\text { Média Geral }\end{array}$}} & 8,21 & 6,55 & 8,44 \\
\hline & & 6,32 & 10,95 & 8,48 \\
\hline
\end{tabular}

letras maiúsculas referem-se a tratamentos dentro de uma mesma variedade e letras minúsculas dentro de uma mesma dose (comparação entre variedades).

Tabela 39. Formação de folhas das variedades em estudo cultivadas em Araras.

\begin{tabular}{cccc}
\hline \multirow{2}{*}{ VARIEDADES } & \multicolumn{3}{c}{$\begin{array}{c}\text { FOLHAS SURGIDAS } \\
\text { (folhas.perfilho }\end{array}{ }^{-1}$ ) } \\
\cline { 2 - 4 } & Jul-Dez & Dez-Mar & Mar-Ago \\
\hline RB835486 & $7,72 \mathrm{~B}$ & $11,07 \mathrm{AB}$ & $8,14 \mathrm{~B}$ \\
RB835054 & $9,32 \mathrm{~A}$ & $11,84 \mathrm{~A}$ & $9,32 \mathrm{~A}$ \\
RB855113 & $8,00 \mathrm{~B}$ & $10,90 \mathrm{~B}$ & $8,57 \mathrm{AB}$ \\
RB855536 & $7,90 \mathrm{~B}$ & $9,98 \mathrm{C}$ & $7,88 \mathrm{~B}$ \\
\hline
\end{tabular}

\section{Valparaíso}

Não houve diferença significativa entre doses de fósforo e variedades, apesar de observar o aumento do número de folhas formadas com o aumento nas doses em algumas variedades. Ao contrário do que ocorreu em Araras, o 
maior número de folhas surgidas foi observado no último período amostrado (tabela 40).

Tabela 40. Número de folhas surgidas em cada época avaliada em Valparaíso.

\begin{tabular}{|c|c|c|c|c|}
\hline \multirow[t]{2}{*}{ VARIEDADES } & \multirow{2}{*}{$\begin{array}{c}\text { DOSES DE } \\
\text { FOSFORO } \\
\left(\mathrm{kg} \mathrm{P}_{2} \mathrm{O}_{5} \cdot \mathrm{ha}^{-1}\right) \\
0\end{array}$} & \multicolumn{3}{|c|}{$\begin{array}{l}\text { FOLHAS SURGIDAS } \\
\text { (folhas.perfilho- }{ }^{-1} \text { ) }\end{array}$} \\
\hline & & $\begin{array}{l}\text { Jul-Dez } \\
9,18 \mathrm{Aa}\end{array}$ & $\begin{array}{l}\text { Dez-Mar } \\
10,91 \mathrm{Aa}\end{array}$ & $\begin{array}{l}\text { Mar-Ago } \\
12,03 \mathrm{Aa}\end{array}$ \\
\hline \multirow{3}{*}{ RB835486 } & 80 & $9,28 \mathrm{Aa}$ & $9,77 \mathrm{Aa}$ & $10,98 \mathrm{Aa}$ \\
\hline & 160 & $9,31 \mathrm{Aa}$ & $9,62 \mathrm{Aa}$ & $12,33 \mathrm{Aa}$ \\
\hline & 240 & $10,01 \mathrm{Aa}$ & $9,59 \mathrm{Aa}$ & $11,54 \mathrm{Aa}$ \\
\hline \multirow{4}{*}{ RB835054 } & 0 & $10,35 \mathrm{Aa}$ & $9,72 \mathrm{Aa}$ & $12,34 \mathrm{Aa}$ \\
\hline & 80 & $8,65 \mathrm{Aa}$ & $10,50 \mathrm{Aa}$ & $11,35 \mathrm{Aa}$ \\
\hline & 160 & $9,47 \mathrm{Aa}$ & $10,51 \mathrm{Aa}$ & $12,65 \mathrm{Aa}$ \\
\hline & 240 & $9,33 \mathrm{Aa}$ & $10,72 \mathrm{Aa}$ & $12,41 \mathrm{Aa}$ \\
\hline \multirow{4}{*}{ RB855113 } & 0 & $8,40 \mathrm{Aa}$ & $8,88 \mathrm{Aa}$ & $11,89 \mathrm{Aa}$ \\
\hline & 80 & $8,69 \mathrm{Aa}$ & $9,72 \mathrm{Aa}$ & $10,63 \mathrm{Aa}$ \\
\hline & 160 & $9,13 \mathrm{Aa}$ & $9,56 \mathrm{Aa}$ & $11,15 \mathrm{Aa}$ \\
\hline & 240 & $8,10 \mathrm{Aa}$ & $9,24 \mathrm{Aa}$ & $10,48 \mathrm{Aa}$ \\
\hline \multirow{4}{*}{ RB855536 } & 0 & $9,25 \mathrm{Aa}$ & $9,95 \mathrm{Aa}$ & $11,72 \mathrm{Aa}$ \\
\hline & 80 & $8,75 \mathrm{Aa}$ & $8,99 \mathrm{Aa}$ & $10,49 \mathrm{Aa}$ \\
\hline & 160 & $8,36 \mathrm{Aa}$ & $10,07 \mathrm{Aa}$ & $11,08 \mathrm{Aa}$ \\
\hline & 240 & $9,08 \mathrm{Aa}$ & $8,13 \mathrm{Aa}$ & $10,70 \mathrm{Aa}$ \\
\hline \multirow{2}{*}{\multicolumn{2}{|c|}{$\begin{array}{c}\text { CV }(\%) \\
\text { Média Geral }\end{array}$}} & 7,04 & 9,58 & 17,22 \\
\hline & & 9,06 & 9,74 & 11,30 \\
\hline
\end{tabular}

letras maiúsculas referem-se a tratamentos dentro de uma mesma variedade e letras minúsculas dentro de uma mesma dose (comparação entre variedades).

Ao analisar as diferenças encontradas em relação à média entre variedades, verificou-se que os resultados apresentados (tabela 41) acompanharam os de folhas verdes apesar de o periodo de maior formação de folhas não coincidir com o de número de folhas verdes encontradas nos perfilhos. Isto ocorre porque as condições de clima encontradas no último periodo não foram adequadas para manter as folhas verdes por muito tempo. A RB835054 foi a que apresentou a maior taxa de formação de folhas e a RB855536. Taiz e Zeiger (1991) afirmam que o número o número de folhas 
verdes tende a diminuir em condições de déficit hídrico, sendo a diminuição da área foliar a primeira resposta ao déficit a menor.

Tabela 41. Número de folhas formadas por variedade em Valparaíso.

\begin{tabular}{cccc}
\hline \multirow{2}{*}{ VARIEDADES } & \multicolumn{3}{c}{$\begin{array}{c}\text { FOLHAS SURGIDAS } \\
\text { (folhas.perfilho-1 }\end{array}$} \\
\cline { 2 - 4 } & Jul-Dez & Dez-Mar & Mar-Ago \\
\hline RB835486 & $9,36 \mathrm{~A}$ & $9,97 \mathrm{AB}$ & $11,72 \mathrm{~A}$ \\
RB835054 & $9,45 \mathrm{~A}$ & $10,36 \mathrm{~A}$ & $12,19 \mathrm{~A}$ \\
RB855113 & $8,58 \mathrm{~B}$ & $9,35 \mathrm{AB}$ & $11,04 \mathrm{~A}$ \\
RB855536 & $8,86 \mathrm{AB}$ & $9,29 \mathrm{~B}$ & $10,25 \mathrm{~A}$ \\
\hline
\end{tabular}

\subsection{3 Área Foliar (AF)}

\section{Araras}

Tabela 42. Número de folhas formadas por variedade em Araras.

\begin{tabular}{|c|c|c|c|c|}
\hline \multirow[t]{2}{*}{ VARIEDADES } & \multirow{2}{*}{$\begin{array}{c}\text { DOSES DE } \\
\text { FOSFORO } \\
\left(\mathrm{kg} \mathrm{P}_{2} \mathrm{O}_{5} \cdot \mathrm{ha}^{-1}\right)\end{array}$} & \multicolumn{3}{|c|}{$\begin{array}{c}\text { AREA FOLIAR } \\
\left(\mathrm{cm}^{2}\right)\end{array}$} \\
\hline & & Jul-Dez & Dez-Mar & Mar-Ago \\
\hline \multirow{4}{*}{ RB835486 } & 0 & $2504,37 \mathrm{~A}$ & $5699,25 \mathrm{~A}$ & $3914,46 \mathrm{~A}$ \\
\hline & 80 & $3782,97 \mathrm{~A}$ & $6214,74 \mathrm{~A}$ & $4718,12 \mathrm{~A}$ \\
\hline & 160 & $2631,72 \mathrm{~A}$ & $4591,27 \mathrm{~A}$ & $4361,00 \mathrm{~A}$ \\
\hline & 240 & $2958,79 \mathrm{~A}$ & $5179,42 \mathrm{~A}$ & $4007,24 \mathrm{~A}$ \\
\hline \multirow{4}{*}{ RB835054 } & 0 & $3500,26 \mathrm{~A}$ & $5291,28 \mathrm{~A}$ & $4539,56 \mathrm{~A}$ \\
\hline & 80 & $3148,1 \uparrow A$ & $5320,75 \mathrm{~A}$ & $3968,44 \mathrm{~A}$ \\
\hline & 160 & $2573,68 \mathrm{~A}$ & $4360,81 \mathrm{~A}$ & $3778,81 \mathrm{~A}$ \\
\hline & 240 & $3474,69 \mathrm{~A}$ & $6493,36 \mathrm{~A}$ & $4330,36 \mathrm{~A}$ \\
\hline \multirow{4}{*}{ RB855113 } & 0 & $2579,80 \mathrm{~A}$ & $6838,77 \mathrm{~A}$ & $6154,74 \mathrm{~A}$ \\
\hline & 80 & $2696,86 \mathrm{~A}$ & $6143,72 \mathrm{~A}$ & $5417,94 \mathrm{~A}$ \\
\hline & 160 & $2669,42 \mathrm{~A}$ & $6028,34 \mathrm{~A}$ & $4985,73 \mathrm{~A}$ \\
\hline & 240 & $2970,46 \mathrm{~A}$ & $6373,34 \mathrm{~A}$ & $5103,92 \mathrm{~A}$ \\
\hline \multirow{4}{*}{ RB855536 } & 0 & $2585,50 \mathrm{~A}$ & $4875,18 \mathrm{~A}$ & $4431,67 \mathrm{~A}$ \\
\hline & 80 & $2658,10 \mathrm{~A}$ & $4213,16 \mathrm{~A}$ & $4185,30 \mathrm{~A}$ \\
\hline & 160 & $3213,60 \mathrm{~A}$ & $4817,21 \mathrm{~A}$ & $4171,36 \mathrm{~A}$ \\
\hline & 240 & $2369,03 \mathrm{~A}$ & $4997,02 \mathrm{~A}$ & $4314,37 \mathrm{~A}$ \\
\hline \multicolumn{2}{|c|}{$\begin{array}{c}\text { CV }(\%) \\
\text { Média Geral }\end{array}$} & $\begin{array}{c}23,12 \\
2894,84\end{array}$ & $\begin{array}{c}14,25 \\
5464,85\end{array}$ & $\begin{array}{c}9,60 \\
4523,94 \\
\end{array}$ \\
\hline
\end{tabular}

letras maiúsculas referem-se a tratamentos dentro de uma mesma variedade e letras minúsculas dentro de uma mesma dose (comparação entre variedades). 
As variedades da série 83 tiveram um comportamento semelhante durante todo o experimento. Em relação às outras variedades (série 85 ), a variedade RB855113 apresentou maiores valores de AF e a RB855536 os menores, dentre as variedades utilizadas. Foi nesta última variedade também em que se tinha verificado menor número de folhas verdes, valor que entra na fórmula de AF. No caso da AF, da mesma forma que aconteceu no item folhas verdes, verificou-se também que os maiores valores foram encontrados na segunda amostragem (tabela 42).

Em relação às médias de variedades, observaram-se diferenças nas duas últimas amostragens (tabela 43). No geral, a RB855113 foi a que apresentou maior valor, exceto na primeira avaliação, mas não diferiu das demais. Verificou que a RB855113 apresentou rápido crescimento de AF da primeira para segunda amostragem (figura 10).

Tabela 43. Número de folhas formadas por variedade em Araras.

\begin{tabular}{cccc}
\hline \multirow{2}{*}{ VARIEDADES } & \multicolumn{3}{c}{ ÁREA FOLIAR $\left(\mathrm{cm}^{2}\right)$} \\
\cline { 2 - 4 } & Jul-Dez & Dez-Mar & Mar-Ago \\
\hline RB835486 & $2969,46 \mathrm{~A}$ & $5421,17 \mathrm{AB}$ & $4250,21 \mathrm{~B}$ \\
RB835054 & $3174,18 \mathrm{~A}$ & $5366,55 \mathrm{AB}$ & $4154,29 \mathrm{~B}$ \\
RB855113 & $2729,13 \mathrm{~A}$ & $6346,04 \mathrm{~A}$ & $5415,58 \mathrm{~A}$ \\
RB855536 & $2706,56 \mathrm{~A}$ & $4725,64 \mathrm{~B}$ & $4275,68 \mathrm{~B}$ \\
\hline
\end{tabular}




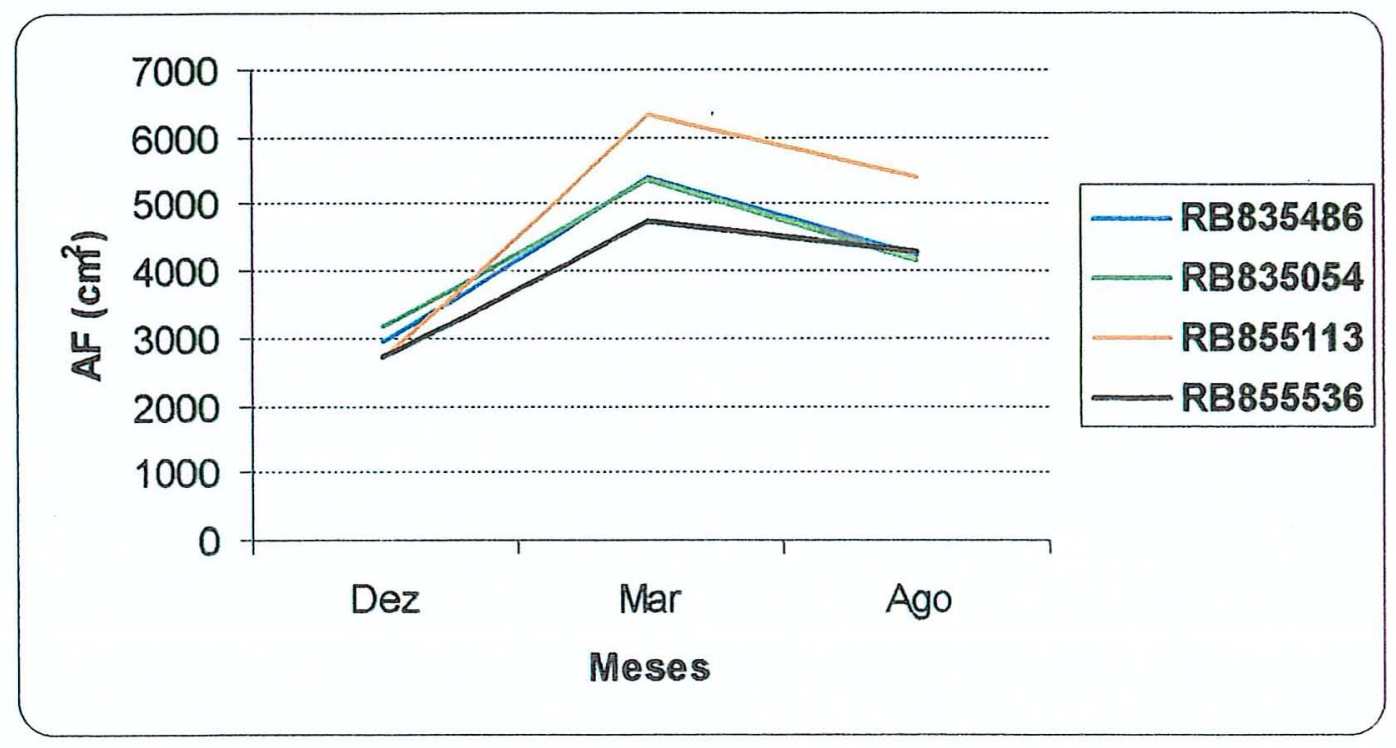

Figura 10 - Evolução da AF, em cana-soca, no decorrer do experimento de Araras.

\section{Valparaiso}

Não houve interação significativa entre doses de fósforo e variedades (tabela 44). A área foliar aumentou da primeira para segunda amostragem, decrescendo ligeiramente na última.

Existem diferenças significativas entre médias de variedades em todas as amostragens. Em todas, a variedade RB835486 apresentou maior AF, juntamente com a RB855113, exceto na primeira amostragem (tabela 45).

Assim como em Araras, a RB835113 foi a que apresentou maior crescimento de AF, dentre as variedades em estudo, principalmente na passagem da primeira para segunda amostragem. Isso vem comprovar que existindo melhores condições de temperatura e precipitação essa variedade responde rápido a essas mudanças e se recupera (figura 11). 
Tabela 44. AF dos diferentes tratamentos analisados em Valparaíso.

\begin{tabular}{|c|c|c|c|c|}
\hline \multirow{2}{*}{ VARIEDADES } & \multirow{2}{*}{$\begin{array}{l}\text { DOSES DE } \\
\text { FOSFORO } \\
\left(\mathrm{kg} \mathrm{P}_{2} \mathrm{O}_{5} \cdot \mathrm{ha}^{-1}\right)\end{array}$} & \multicolumn{3}{|c|}{$\begin{array}{l}\text { AREA FOLIAR } \\
\left(\mathrm{cm}^{2}\right)\end{array}$} \\
\hline & & Jul-Dez & Dez-Mar & Mar-Ago \\
\hline \multirow{4}{*}{ RB835486 } & 0 & $3287,39 \mathrm{Aa}$ & $6075,71 \mathrm{Aa}$ & $5043,05 \mathrm{Aa}$ \\
\hline & 80 & $3427,75 \mathrm{Aa}$ & $5739,80 \mathrm{Aa}$ & $5101,38 \mathrm{Aa}$ \\
\hline & 160 & $3463,30 \mathrm{Aa}$ & $5982,89 \mathrm{Aa}$ & $4931,15 \mathrm{Aa}$ \\
\hline & 240 & $3840,40 \mathrm{Aa}$ & $6014,78 \mathrm{Aa}$ & $5002,22 \mathrm{Aa}$ \\
\hline \multirow{4}{*}{ RB835054 } & 0 & $3256,79 \mathrm{Aa}$ & $4871,41 \mathrm{Aa}$ & $3529,90 \mathrm{Aa}$ \\
\hline & 80 & $2822,62 \mathrm{Aa}$ & $5312,38 \mathrm{Aa}$ & $3461,61 \mathrm{Aa}$ \\
\hline & 160 & $2579,67 \mathrm{Aa}$ & $5172,05 \mathrm{Aa}$ & $3566,02 \mathrm{Aa}$ \\
\hline & 240 & $2739,88 \mathrm{Aa}$ & $4648,57 \mathrm{Aa}$ & $3269,00 \mathrm{Aa}$ \\
\hline \multirow{4}{*}{ RB855113 } & 0 & $2610,42 \mathrm{Aa}$ & $5899,31 \mathrm{Aa}$ & $5176,52 \mathrm{Aa}$ \\
\hline & 80 & $2600,72 \mathrm{Aa}$ & $6297,99 \mathrm{Aa}$ & $5436,78 \mathrm{Aa}$ \\
\hline & 160 & $2885,00 \mathrm{Aa}$ & $6319,24 \mathrm{Aa}$ & $5131,75 \mathrm{Aa}$ \\
\hline & 240 & $2719,34 \mathrm{Aa}$ & $6306,81 \mathrm{Aa}$ & $5360,55 \mathrm{Aa}$ \\
\hline \multirow{4}{*}{ RB855536 } & 0 & $2439,70 \mathrm{Aa}$ & $5304,14 \mathrm{Aa}$ & $4095,56 \mathrm{Aa}$ \\
\hline & 80 & $2115,86 \mathrm{Aa}$ & $4505,26 \mathrm{Aa}$ & $4106,96 \mathrm{Aa}$ \\
\hline & 160 & $2178,90 \mathrm{Aa}$ & $4923,74 \mathrm{Aa}$ & $3786,18 \mathrm{Aa}$ \\
\hline & 240 & $2331,41 \mathrm{Aa}$ & $5062,09 \mathrm{Aa}$ & $4257,30 \mathrm{Aa}$ \\
\hline \multicolumn{2}{|c|}{$\begin{array}{c}\text { CV }(\%) \\
\text { Média Geral }\end{array}$} & $\begin{array}{c}13,63 \\
2817,98\end{array}$ & $\begin{array}{c}10,06 \\
5507,64\end{array}$ & $\begin{array}{c}7,96 \\
4455,82\end{array}$ \\
\hline
\end{tabular}

Tabela 45. AF das variedades em estudo em Valparaíso.

\begin{tabular}{cccc}
\hline \multirow{2}{*}{ VARIEDADES } & \multicolumn{3}{c}{$\begin{array}{c}\text { ÁREA FOLIAR } \\
\left(\mathrm{cm}^{2}\right)\end{array}$} \\
\cline { 2 - 4 } & Jul-Dez & Dez-Mar & Mar-Ago \\
\hline RB835486 & $3504,71 \mathrm{~A}$ & $5953,30 \mathrm{~A}$ & $5019,45 \mathrm{~A}$ \\
RB835054 & $2849,74 \mathrm{~B}$ & $5001,11 \mathrm{~B}$ & $3456,63 \mathrm{C}$ \\
RB855113 & $2703,87 \mathrm{~B}$ & $6205,84 \mathrm{~A}$ & $5276,40 \mathrm{~A}$ \\
RB855536 & $2266,47 \mathrm{C}$ & $4948,81 \mathrm{~B}$ & $4061,50 \mathrm{~B}$ \\
\hline
\end{tabular}




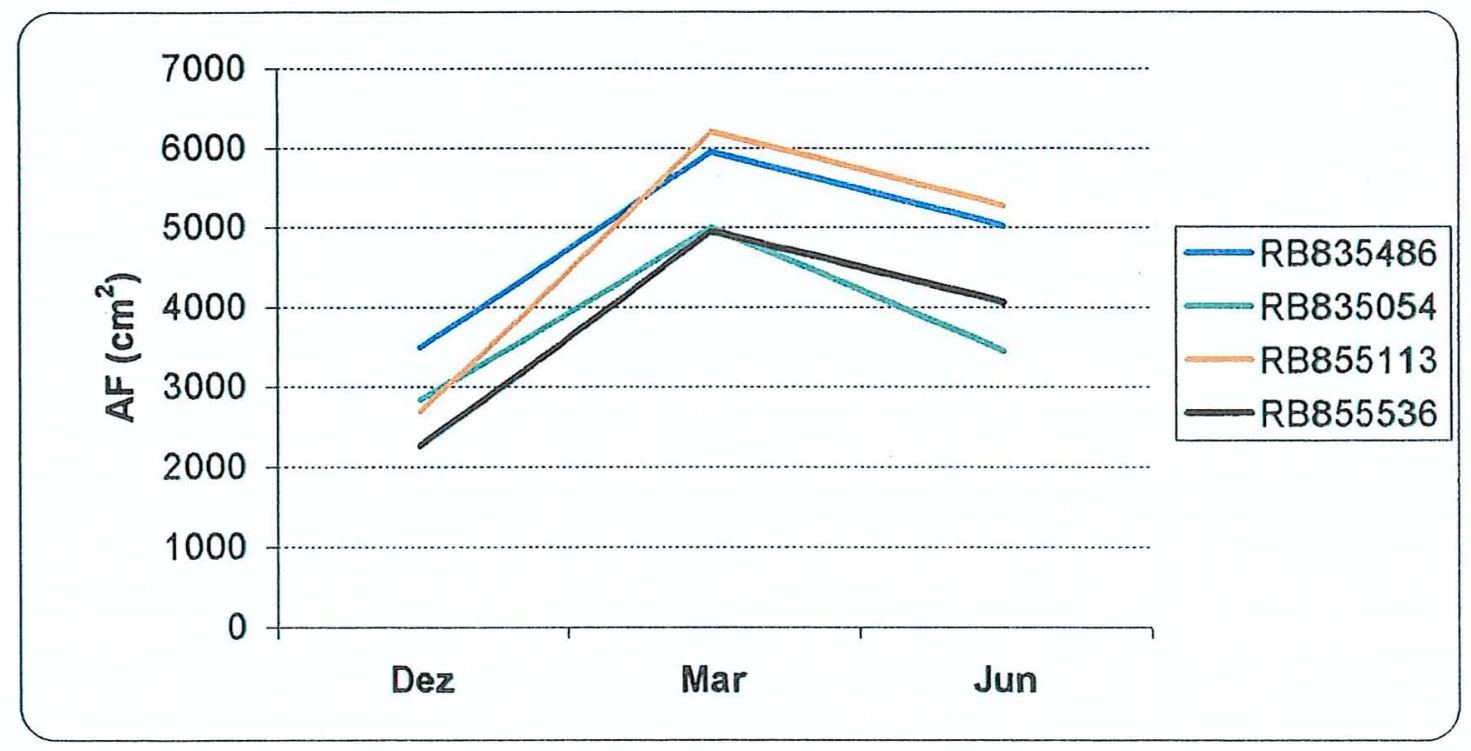

Figura 11 - Evolução do AF nas diferentes variedades cultivadas em Valparaíso.

\subsection{4 Índice de área foliar (IAF) em Araras}

Todos os tratamentos apresentaram maior IAF na segunda amostragem, no final do período do verão, exceção feita ao tratamento no qual se utilizou a variedade RB835054 na maior dose de fósforo (tabela 46). Houve uma tendência de aumento no IAF de dezembro a março e depois um decréscimo até a última amostragem. Esse resultado deve-se as condições climáticas que antecedem a amostragem e fase fenológica em que se encontra a cana-de-açúcar. O período compreendido entre a primeira e a segunda amostragem é onde encontramos melhor disponibilidade hídrica e também é quando a cultura está em seu pleno crescimento vegetativo. 
Tabela 46. IAF dos diferentes tratamentos em Araras.

\begin{tabular}{ccccc}
\hline \multirow{2}{*}{ VARIEDADES } & $\begin{array}{c}\text { DOSES DE } \\
\text { FÓSFORO } \\
\left(\mathrm{kg} \mathrm{P}_{2} \mathrm{O}_{5} \cdot \mathrm{ha}^{-1}\right)\end{array}$ & Dez & Mar & Ago \\
\cline { 2 - 5 } & 0 & 1,16 & 1,79 & 1,40 \\
RB835486 & 80 & 1,49 & 1,92 & 1,39 \\
& 160 & 1,16 & 1,98 & 1,71 \\
& 240 & 1,59 & 1,90 & 1,73 \\
& 0 & 1,11 & 1,81 & 1,49 \\
RB835054 & 80 & 1,30 & 1,84 & 1,42 \\
& 160 & 1,56 & 1,93 & 1,47 \\
& 240 & 1,20 & 1,71 & 1,56 \\
& 0 & 1,45 & 2,04 & 1,65 \\
RB855113 & 80 & 1,31 & 1,83 & 1,28 \\
& 160 & 1,19 & 2,01 & 1,89 \\
& 240 & 1,51 & 1,82 & 1,49 \\
& 0 & 1,01 & 1,92 & 1,41 \\
RB855536 & 80 & 1,47 & 1,54 & 1,55 \\
& 160 & 1,21 & 1,82 & 1,72 \\
& 240 & 1,64 & 2,12 & 1,59 \\
\hline
\end{tabular}

Ao comparar as médias das variedades, observa-se que a variedade RB855113 foi a que apresentou maior valor e a RB835486 os menores índices, isso pode ser explicado pelo modo de perfilhamento das mesmas (tabela 46). A primeira tende a perfilhar mais e com isso fechar mais rapidamente a entrelinha, enquanto que a outra variedade apresenta um perfilhamento menos denso, precisando de mais tempo para cobrir toda a área de cultivo.

Tabela 47. Médias de IAF por variedade em Araras.

\begin{tabular}{cccc}
\hline \multirow{2}{*}{ VARIEDADES } & \multicolumn{3}{c}{ IAF } \\
\cline { 2 - 4 } & Dez & Mar & Ago \\
\hline RB835486 & 1,18 & 1,89 & 1,49 \\
RB835054 & 1,39 & 1,78 & 1,41 \\
RB855113 & 1,28 & 1,93 & 1,70 \\
RB855536 & 1,49 & 1,89 & 1,59 \\
\hline
\end{tabular}




\subsection{Fitomassa da parte aérea}

\section{Araras}

Não foi verificada interação significativa entre doses e variedades. Ao analisar os dados apresentados na tabela 48, verifica-se que o período de dezembro a março foi onde a cana-de-açúcar acumulou mais massa, correspondendo a mais de $50 \%$ do total de fitomassa acumulado em toda a soca (figura 13). As variedades RB835054 e RB855536 apresentaram valores ligeiramente maiores que as demais.

Tabela 48. Fitomassa da parte aérea dos diferentes tratamentos em Araras.

\begin{tabular}{|c|c|c|c|c|}
\hline \multirow[t]{2}{*}{ VARIEDADES } & \multirow{2}{*}{$\begin{array}{c}\text { DOSES DE } \\
\text { FÓSFORO } \\
\left(\mathrm{kg} \mathrm{P}_{2} \mathrm{O}_{5} \cdot \mathrm{ha}^{-1}\right)\end{array}$} & \multicolumn{3}{|c|}{$\begin{array}{l}\text { FITOMASSA PARTE AEREA } \\
\left(\mathrm{kg}^{\left.\mathrm{col} \mathrm{mo}^{-1}\right)}\right.\end{array}$} \\
\hline & & Jul-Dez & Dez-Mar & Mar-Ago \\
\hline \multirow{4}{*}{ RB835486 } & 0 & $0,33 \mathrm{Aa}$ & $0,87 \mathrm{Aa}$ & $0,37 \mathrm{Aa}$ \\
\hline & 80 & $0,31 \mathrm{Aa}$ & $0,88 \mathrm{Aa}$ & $0,39 \mathrm{Aa}$ \\
\hline & 160 & $0,40 \mathrm{Aa}$ & $0,89 \mathrm{Aa}$ & $0,43 \mathrm{Aa}$ \\
\hline & 240 & $0,34 \mathrm{Aa}$ & $0,89 \mathrm{Aa}$ & $0,44 \mathrm{Aa}$ \\
\hline \multirow{4}{*}{ RB835054 } & 0 & $0,41 \mathrm{Aa}$ & $1,14 \mathrm{Aa}$ & $0,50 \mathrm{Aa}$ \\
\hline & 80 & $0,36 \mathrm{Aa}$ & $1,12 \mathrm{Aa}$ & $0,50 \mathrm{Aa}$ \\
\hline & 160 & $0,32 \mathrm{Aa}$ & $0,93 \mathrm{Aa}$ & $0,42 \mathrm{Aa}$ \\
\hline & 240 & $0,39 \mathrm{Aa}$ & $0,99 \mathrm{Aa}$ & $0,42 \mathrm{Aa}$ \\
\hline \multirow{4}{*}{ RB855113 } & 0 & $0,30 \mathrm{Aa}$ & $0,83 \mathrm{Aa}$ & $0,42 \mathrm{Aa}$ \\
\hline & 80 & $0,33 \mathrm{Aa}$ & $0,91 \mathrm{Aa}$ & $0,39 \mathrm{Aa}$ \\
\hline & 160 & $0,31 \mathrm{Aa}$ & $0,83 \mathrm{Aa}$ & $0,40 \mathrm{Aa}$ \\
\hline & 240 & $0,31 \mathrm{Aa}$ & $0,82 \mathrm{Aa}$ & $0,42 \mathrm{Aa}$ \\
\hline \multirow{4}{*}{ RB855536 } & 0 & $0,31 \mathrm{Aa}$ & $1,10 \mathrm{Aa}$ & $0,36 \mathrm{Aa}$ \\
\hline & 80 & $0,34 \mathrm{Aa}$ & $1,00 \mathrm{Aa}$ & $0,37 \mathrm{Aa}$ \\
\hline & 160 & $0,35 \mathrm{Aa}$ & $1,00 \mathrm{Aa}$ & $0,29 \mathrm{Aa}$ \\
\hline & 240 & $0,32 \mathrm{Aa}$ & $0,87 \mathrm{Aa}$ & $0,31 \mathrm{Aa}$ \\
\hline \multirow{2}{*}{\multicolumn{2}{|c|}{$\begin{array}{c}\text { CV }(\%) \\
\text { Média Geral }\end{array}$}} & 16,30 & 9,93 & 11,61 \\
\hline & & 0,35 & 0,94 & 0,40 \\
\hline
\end{tabular}

No primeiro periodo em estudo, de julho a dezembro, as plantas acumularam cerca de $20 \%$ do total de massa fresca e no último, de março a agosto, um pouco mais de $25 \%$, exceção feita a RB855536 que apresentou 
$20 \%$ (figura 12).Nesta última variedade, por tanto, houve um acúmulo de fitomassa de $60 \%$ entre os meses de dezembro e março.

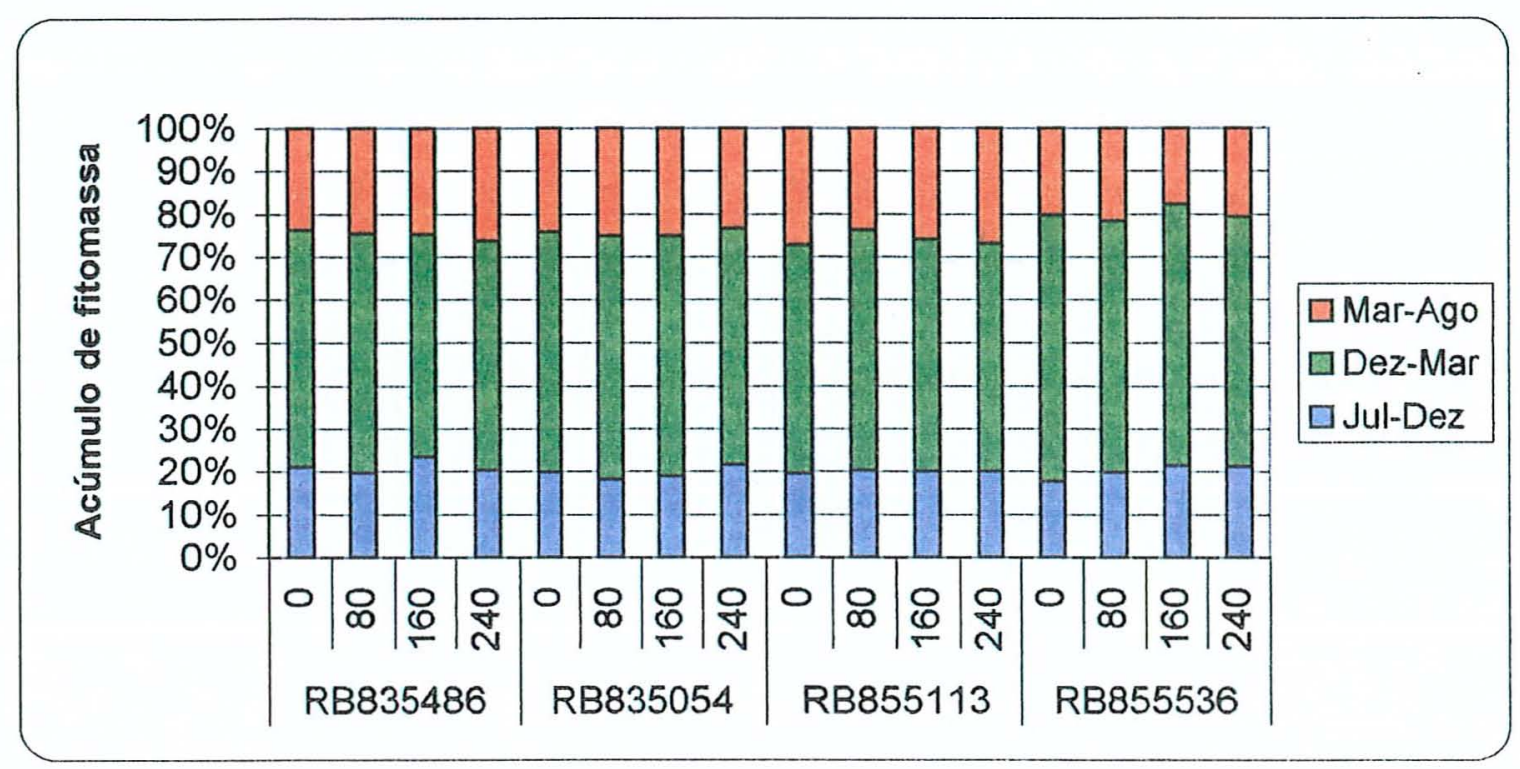

Figura 12 - Acúmulo de fitomassa referente aos tratamentos utilizados em Araras.

A única diferença encontrada foi em relação as médias varietais, sendo que a RB835054 foi a que obteve maiores valores e a RB855113, de forma geral, os menores (tabela 49).

Tabela 49. Média de fitomassa por variedade em Araras.

\begin{tabular}{cccc}
\hline \multirow{2}{*}{ VARIEDADES } & \multicolumn{3}{c}{ FITOMASSA PARTE AÉREA } \\
\cline { 2 - 4 } & Jul-Dez & Dez-Mar Mar $\left.^{-1}\right)$ & Mar-Ago \\
\hline RB835486 & $0,35 \mathrm{~A}$ & $0,88 \mathrm{~B}$ & $0,41 \mathrm{~B}$ \\
RB835054 & $0,37 \mathrm{~A}$ & $1,05 \mathrm{~A}$ & $0,46 \mathrm{~A}$ \\
RB855113 & $0,31 \mathrm{~A}$ & $0,85 \mathrm{~B}$ & $0,41 \mathrm{~B}$ \\
RB855536 & $0,33 \mathrm{~A}$ & $0,99 \mathrm{~A}$ & $0,33 \mathrm{C}$ \\
\hline
\end{tabular}


Valparaíso

Observa-se que, como ocorrido na outra localidade, as plantas acumularam maior fitomassa no segundo periodo (tabela 50 ), sendo que a RB835486 foi a que destacou nestes meses.

Tabela 50. Fitomassa da parte aérea dos diferentes tratamentos em Valparaíso.

\begin{tabular}{|c|c|c|c|c|}
\hline \multirow{2}{*}{ VARIEDADES } & \multirow{2}{*}{$\begin{array}{l}\text { DOSES DE } \\
\text { FÓSFORO } \\
\left(\mathrm{kg} \mathrm{P}_{2} \mathrm{O}_{5} \cdot \mathrm{ha}^{-1}\right) \\
\end{array}$} & \multicolumn{3}{|c|}{$\begin{array}{c}\text { FITOMASSA PARTE AÉREA } \\
\left(\mathrm{kg} \cdot \text { colmo }^{-1}\right)\end{array}$} \\
\hline & & Jul-Dez & Dez-Mar & Mar-Ago \\
\hline \multirow{4}{*}{ RB835486 } & 0 & $0,31 \mathrm{Aa}$ & $1,05 \mathrm{Aa}$ & $0,59 \mathrm{Aa}$ \\
\hline & 80 & $0,33 \mathrm{Aa}$ & $1,10 \mathrm{Aa}$ & $0,48 \mathrm{Aa}$ \\
\hline & 160 & $0,26 \mathrm{Aa}$ & $1,02 \mathrm{Aa}$ & $0,61 \mathrm{Aa}$ \\
\hline & 240 & $0,26 \mathrm{Aa}$ & $1,23 \mathrm{Aa}$ & $0,54 \mathrm{Aa}$ \\
\hline \multirow{4}{*}{ RB835054 } & 0 & $0,37 \mathrm{Aa}$ & $0,82 \mathrm{Aa}$ & $0,51 \mathrm{Aa}$ \\
\hline & 80 & $0,28 \mathrm{Aa}$ & $0,78 \mathrm{Aa}$ & $0,48 \mathrm{Aa}$ \\
\hline & 160 & $0,36 \mathrm{Aa}$ & $0,85 \mathrm{Aa}$ & $0,57 \mathrm{Aa}$ \\
\hline & 240 & $0,32 \mathrm{Aa}$ & $0,78 \mathrm{Aa}$ & $0,45 \mathrm{Aa}$ \\
\hline \multirow{4}{*}{ RB855113 } & 0 & $0,27 \mathrm{Aa}$ & $0,88 \mathrm{Aa}$ & $0,54 \mathrm{Aa}$ \\
\hline & 80 & $0,32 \mathrm{Aa}$ & $1,02 \mathrm{Aa}$ & $0,59 \mathrm{Aa}$ \\
\hline & 160 & $0,40 \mathrm{Aa}$ & $0,85 \mathrm{Aa}$ & $0,44 \mathrm{Aa}$ \\
\hline & 240 & $0,19 \mathrm{Aa}$ & $1,04 \mathrm{Aa}$ & $0,63 \mathrm{Aa}$ \\
\hline \multirow{4}{*}{ RB855536 } & 0 & $0,30 \mathrm{Aa}$ & $0,77 \mathrm{Aa}$ & $0,43 \mathrm{Aa}$ \\
\hline & 80 & $0,20 \mathrm{Aa}$ & $0,89 \mathrm{Aa}$ & $0,34 \mathrm{Aa}$ \\
\hline & 160 & $0,23 \mathrm{Aa}$ & $0,88 \mathrm{Aa}$ & $0,41 \mathrm{Aa}$ \\
\hline & 240 & $0,25 \mathrm{Aa}$ & $0,94 \mathrm{Aa}$ & $0,45 \mathrm{Aa}$ \\
\hline \multirow{2}{*}{\multicolumn{2}{|c|}{$\begin{array}{c}\text { CV }(\%) \\
\text { Média Geral }\end{array}$}} & 28,15 & 13,51 & 20,35 \\
\hline & & 0,29 & 0,93 & 0,50 \\
\hline
\end{tabular}

No primeiro período foi observado um acúmulo de 10 a $20 \%$ da fitomassa total, o segundo corresponde a mais de $50 \%$ e o último período a cerca de $30 \%$ do total (figura 13). Comparando as localidades, verifica-se que em Araras as plantas acumularam, percentualmente, mais que em Valparaíso e menos entre os meses do outono. 


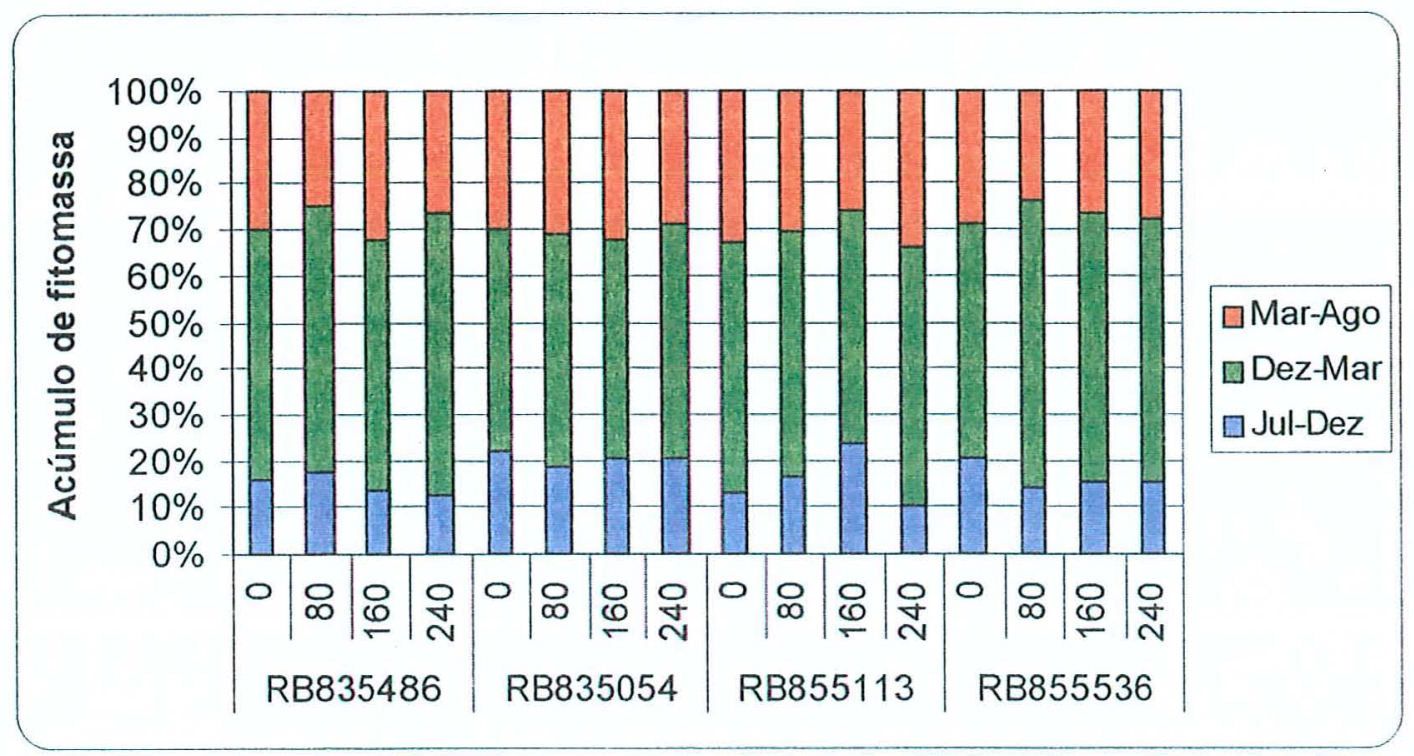

Figura 13 - Acúmulo de fitomassa da parte aérea dos tratamentos de Valparaíso.

Em relação às médias das variedades, houve diferença significativa dentro de cada época. Ao contrário do que ocorreu em Araras, a RB835486 foi a que acumulou maior fitomassa e a RB855536 obteve os menores valores (tabela 51).

Tabela 51. Quantidade de fitomassa acumulada por variedade em Valparaíso.

\begin{tabular}{cccc}
\hline \multirow{2}{*}{ VARIEDADES } & \multicolumn{3}{c}{ FITOMASSA PARTE AÉREA } \\
& Jul-Dez & Dez-Mar $\left.{ }^{-1}\right)$ & Mar-Ago \\
\cline { 2 - 4 } & Jur & Mar \\
\hline RB835486 & $0,29 \mathrm{~A}$ & $10 \mathrm{~A}$ & $0,55 \mathrm{~A}$ \\
RB835054 & $0,33 \mathrm{~A}$ & $0,81 \mathrm{~B}$ & $0,50 \mathrm{AB}$ \\
RB855113 & $0,29 \mathrm{~A}$ & $0,95 \mathrm{~B}$ & $0,55 \mathrm{~A}$ \\
RB855536 & $0,25 \mathrm{~A}$ & $0,87 \mathrm{~B}$ & $0,41 \mathrm{~B}$ \\
\hline
\end{tabular}




\subsection{Análises tecnológicas}

\subsubsection{Brix}

Araras

Não foi observada interação entre doses de fósforo e variedades (tabela 52). Como esperado, nota-se que o ponteiro, porção mais recente e formada entre março e agosto, apresentou menor valor de brix, sendo que as partes central e basal obtiveram valores semelhantes e maiores que $22 \%$.

Tabela 52. Valores de brix para diferentes tratamentos em Araras.

\begin{tabular}{|c|c|c|c|c|}
\hline \multirow[t]{2}{*}{ VARIEDADES } & \multirow{2}{*}{$\begin{array}{c}\text { DOSES DE } \\
\text { FÓSFORO } \\
\left(\mathrm{kg} \mathrm{P}_{2} \mathrm{O}_{5} \cdot \mathrm{ha}^{-1}\right) \\
\end{array}$} & \multicolumn{3}{|c|}{$\begin{array}{c}\text { BRIX } \\
(\%) \\
\end{array}$} \\
\hline & & Jul-Dez & Dez-Mar & Mar-Ago \\
\hline \multirow{4}{*}{ RB835486 } & 0 & $24,03 \mathrm{Aa}$ & $23,63 \mathrm{Aa}$ & $22,00 \mathrm{Aa}$ \\
\hline & 80 & $23,63 \mathrm{Aa}$ & $23,37 \mathrm{Aa}$ & $21,50 \mathrm{Aa}$ \\
\hline & 160 & $23,90 \mathrm{Aa}$ & $23,47 \mathrm{Aa}$ & $21,47 \mathrm{Aa}$ \\
\hline & 240 & $23,77 \mathrm{Aa}$ & $23,50 \mathrm{Aa}$ & $21,10 \mathrm{Aa}$ \\
\hline \multirow{4}{*}{ RB835054 } & 0 & $23,17 \mathrm{Aa}$ & $23,07 \mathrm{Aa}$ & $20,27 \mathrm{Aa}$ \\
\hline & 80 & $23,87 \mathrm{Aa}$ & $23,43 \mathrm{Aa}$ & $21,33 \mathrm{Aa}$ \\
\hline & 160 & $22,93 \mathrm{Aa}$ & $22,63 \mathrm{Aa}$ & $21,00 \mathrm{Aa}$ \\
\hline & 240 & $22,73 \mathrm{Aa}$ & $22,37 \mathrm{Aa}$ & $20,70 \mathrm{Aa}$ \\
\hline \multirow{4}{*}{ RB855113 } & 0 & $23,63 \mathrm{Aa}$ & $22,73 \mathrm{Aa}$ & $19,40 \mathrm{Aa}$ \\
\hline & 80 & $23,47 \mathrm{Aa}$ & $22,37 \mathrm{Aa}$ & $19,10 \mathrm{Aa}$ \\
\hline & 160 & $23,57 \mathrm{Aa}$ & $22,70 \mathrm{Aa}$ & $19,50 \mathrm{Aa}$ \\
\hline & 240 & $23,87 \mathrm{Aa}$ & $22,77 \mathrm{Aa}$ & $19,63 \mathrm{Aa}$ \\
\hline \multirow{4}{*}{ RB855536 } & 0 & $23,70 \mathrm{Aa}$ & $22,53 \mathrm{Aa}$ & $20,33 \mathrm{Aa}$ \\
\hline & 80 & $24,03 \mathrm{Aa}$ & $22,97 \mathrm{Aa}$ & $21,43 \mathrm{Aa}$ \\
\hline & 160 & $24,17 \mathrm{Aa}$ & $22,47 \mathrm{Aa}$ & $20,03 \mathrm{Aa}$ \\
\hline & 240 & $24,00 \mathrm{Aa}$ & $22,63 \mathrm{Aa}$ & $20,03 \mathrm{Aa}$ \\
\hline \multicolumn{2}{|c|}{$\begin{array}{c}\text { CV }(\%) \\
\text { Média Geral }\end{array}$} & $\begin{array}{c}2,12 \\
23,65\end{array}$ & $\begin{array}{c}2,28 \\
22,91\end{array}$ & $\begin{array}{c}3,87 \\
20,55\end{array}$ \\
\hline
\end{tabular}

letras maiúsculas referem-se a tratamentos dentro de uma mesma variedade e letras minúsculas dentro de uma mesma dose (comparação entre variedades).

Foram encontradas diferenças entre médias de brix das variedades em todas as épocas amostradas (tabela 53). A RB835486 foi a que obteve maiores valores de brix, diferindo significativamente das demais, e a RB855113 os menores teores. 
Tabela 53. Médias de brix das diferentes variedades cultivadas em Araras.

\begin{tabular}{cccc}
\hline \multirow{2}{*}{ VARIEDADES } & \multicolumn{3}{c}{ BRIX $(\%)$} \\
\cline { 2 - 4 } & Jul-Dez & Dez-Mar & Mar-Ago \\
\hline RB835486 & $23,83 \mathrm{~A}$ & $23,49 \mathrm{~A}$ & $21,52 \mathrm{~A}$ \\
RB835054 & $23,18 \mathrm{~B}$ & $22,88 \mathrm{~B}$ & $20,83 \mathrm{AB}$ \\
RB855113 & $23,63 \mathrm{AB}$ & $22,64 \mathrm{~B}$ & $19,41 \mathrm{C}$ \\
RB855536 & $23,98 \mathrm{~A}$ & $22,65 \mathrm{~B}$ & $20,46 \mathrm{~B}$ \\
\hline
\end{tabular}

Valparaíso

Não houve interação significativa entre variedades e doses de fósforo (tabela 54).

Tabela 54. Teor de brix dos tratamentos em Valparaiso.

\begin{tabular}{|c|c|c|c|c|}
\hline \multirow[t]{2}{*}{ VARIEDADES } & \multirow{2}{*}{$\begin{array}{c}\text { DOSES DE } \\
\text { FOSFORO } \\
\left(\mathrm{kg} \mathrm{P}_{2} \mathrm{O}_{5} \cdot \mathrm{ha}^{-1}\right)\end{array}$} & \multicolumn{3}{|c|}{$\begin{array}{c}\text { BRIX } \\
(\%)\end{array}$} \\
\hline & & Jul-Dez & Dez-Mar & Mar-Ago \\
\hline \multirow{4}{*}{ RB835486 } & 0 & $21,30 \mathrm{Aa}$ & $20,97 \mathrm{Aa}$ & $19,90 \mathrm{Aa}$ \\
\hline & 80 & $20,23 \mathrm{Aa}$ & $19,83 \mathrm{Aa}$ & $19,23 \mathrm{Aa}$ \\
\hline & 160 & $20,67 \mathrm{Aa}$ & $20,07 \mathrm{Aa}$ & $19,60 \mathrm{Aa}$ \\
\hline & 240 & $21,17 \mathrm{Aa}$ & $20,20 \mathrm{Aa}$ & $18,87 \mathrm{Aa}$ \\
\hline \multirow{4}{*}{ RB835054 } & 0 & $21,53 \mathrm{Aa}$ & $21,17 \mathrm{Aa}$ & $20,13 \mathrm{Aa}$ \\
\hline & 80 & $22,30 \mathrm{Aa}$ & $21,50 \mathrm{Aa}$ & $19,80 \mathrm{Aa}$ \\
\hline & 160 & $21,53 \mathrm{Aa}$ & $21,23 \mathrm{Aa}$ & $20,00 \mathrm{Aa}$ \\
\hline & 240 & $21,47 \mathrm{Aa}$ & $21,33 \mathrm{Aa}$ & $19,67 \mathrm{Aa}$ \\
\hline \multirow{4}{*}{ RB855113 } & 0 & $20,70 \mathrm{Aa}$ & $21,47 \mathrm{Aa}$ & $18,90 \mathrm{Aa}$ \\
\hline & 80 & $21,23 \mathrm{Aa}$ & $20,60 \mathrm{Aa}$ & $18,67 \mathrm{Aa}$ \\
\hline & 160 & $22,20 \mathrm{Aa}$ & $21,13 \mathrm{Aa}$ & $19,10 \mathrm{Aa}$ \\
\hline & 240 & $21,33 \mathrm{Aa}$ & $21,13 \mathrm{Aa}$ & $18,57 \mathrm{Aa}$ \\
\hline \multirow{4}{*}{ RB855536 } & 0 & $21,43 \mathrm{Aa}$ & $20,50 \mathrm{Aa}$ & $18,80 \mathrm{Aa}$ \\
\hline & 80 & $22,20 \mathrm{Aa}$ & $21,17 \mathrm{Aa}$ & $19,50 \mathrm{Aa}$ \\
\hline & 160 & $22,13 \mathrm{Aa}$ & $20,87 \mathrm{Aa}$ & $19,47 \mathrm{Aa}$ \\
\hline & 240 & $21,87 \mathrm{Aa}$ & $21,00 \mathrm{Aa}$ & $19,17 \mathrm{Aa}$ \\
\hline \multicolumn{2}{|c|}{$\begin{array}{c}\text { CV }(\%) \\
\text { Média Geral }\end{array}$} & $\begin{array}{r}3,07 \\
2146\end{array}$ & $\begin{array}{c}4,03 \\
20.89\end{array}$ & $\begin{array}{c}3,48 \\
19,36\end{array}$ \\
\hline
\end{tabular}


Assim como em Araras, os valores de brix decrescem da porção basal para superior. No geral, os resultados encontrados em Araras foram maiores do que os de Valparaíso.

Ao compararmos médias de variedades, verificamos existir diferenças significativas entre as mesmas (tabela 55). Observamos que os decréscimos de brix ao longo do colmo são mais acentuados nas variedades RB855113 e os menores valores foram encontrados na variedade RB855113.

Tabela 55. Brix médio das variedades em Valparaiso.

\begin{tabular}{cccc}
\hline \multirow{2}{*}{ VARIEDADES } & \multicolumn{3}{c}{$\begin{array}{c}\text { BRIX } \\
(\%)\end{array}$} \\
\cline { 2 - 4 } & Jul-Dez & Dez-Mar & Mar-Ago \\
\hline RB835486 & $20,84 \mathrm{~B}$ & $20,27 \mathrm{~B}$ & $19,40 \mathrm{AB}$ \\
RB835054 & $21,71 \mathrm{~A}$ & $21,31 \mathrm{~A}$ & $19,90 \mathrm{~A}$ \\
RB855113 & $21,37 \mathrm{AB}$ & $21,08 \mathrm{AB}$ & $18,81 \mathrm{~B}$ \\
RB855536 & $21,91 \mathrm{~A}$ & $20,88 \mathrm{AB}$ & $19,23 \mathrm{~B}$ \\
\hline
\end{tabular}

\subsubsection{Pol\%cana}

Araras

Não se encontrou diferença significativa tanto na interação doses de fósforo e variedades quanto entre médias de doses (tabela 56).

Ao compararmos médias de variedades, observa-se que a RB835486 foi o que apresentou os maiores valores e as RB855113 e RB855536 os menores (tabela 57). 
Tabela 56. Pol\%cana dos tratamentos em Araras.

\begin{tabular}{|c|c|c|c|c|}
\hline \multirow[t]{2}{*}{ VARIEDADES } & \multirow{2}{*}{$\begin{array}{l}\text { DOSES DE } \\
\text { FÓSFORO } \\
\left(\mathrm{kg} \mathrm{P}_{2} \mathrm{O}_{5} \cdot \mathrm{ha}^{-1}\right)\end{array}$} & \multicolumn{3}{|c|}{$\begin{array}{c}\text { POL CANA } \\
(\%)\end{array}$} \\
\hline & & Jul-Dez & Dez-Mar & Mar-Ago \\
\hline \multirow{4}{*}{ RB835486 } & 0 & $19,73 \mathrm{Aa}$ & $19,47 \mathrm{Aa}$ & $15,73 \mathrm{Aa}$ \\
\hline & 80 & $19,81 \mathrm{Aa}$ & $19,48 \mathrm{Aa}$ & $15,87 \mathrm{Aa}$ \\
\hline & 160 & $19,66 \mathrm{Aa}$ & $19,34 \mathrm{Aa}$ & $15,85 \mathrm{Aa}$ \\
\hline & 240 & $19,09 \mathrm{Aa}$ & $19,30 \mathrm{Aa}$ & $15,38 \mathrm{Aa}$ \\
\hline \multirow{4}{*}{ RB835054 } & 0 & $19,14 \mathrm{Aa}$ & $19,27 \mathrm{Aa}$ & $14,89 \mathrm{Aa}$ \\
\hline & 80 & $19,25 \mathrm{Aa}$ & $19,28 \mathrm{Aa}$ & $15,89 \mathrm{Aa}$ \\
\hline & 160 & $18,60 \mathrm{Aa}$ & $18,63 \mathrm{Aa}$ & $15,54 \mathrm{Aa}$ \\
\hline & 240 & $18,30 \mathrm{Aa}$ & $18,29 \mathrm{Aa}$ & $15,32 \mathrm{Aa}$ \\
\hline \multirow{4}{*}{ RB855113 } & 0 & $19,49 \mathrm{Aa}$ & $18,46 \mathrm{Aa}$ & $13,58 \mathrm{Aa}$ \\
\hline & 80 & $19,14 \mathrm{Aa}$ & $17,59 \mathrm{Aa}$ & $13,21 \mathrm{Aa}$ \\
\hline & 160 & $19,03 \mathrm{Aa}$ & $18,19 \mathrm{Aa}$ & $13,38 \mathrm{Aa}$ \\
\hline & 240 & $19,42 \mathrm{Aa}$ & $18,39 \mathrm{Aa}$ & $13,44 \mathrm{Aa}$ \\
\hline \multirow{4}{*}{ RB855536 } & 0 & $18,77 \mathrm{Aa}$ & $18,43 \mathrm{Aa}$ & $14,15 \mathrm{Aa}$ \\
\hline & 80 & $19,41 \mathrm{Aa}$ & $18,78 \mathrm{Aa}$ & $13,75 \mathrm{Aa}$ \\
\hline & 160 & $19,21 \mathrm{Aa}$ & $18,15 \mathrm{Aa}$ & $13,22 \mathrm{Aa}$ \\
\hline & 240 & $19,53 \mathrm{Aa}$ & $18,24 \mathrm{Aa}$ & $13,86 \mathrm{Aa}$ \\
\hline \multirow{2}{*}{\multicolumn{2}{|c|}{$\begin{array}{c}\text { CV }(\%) \\
\text { Média Geral }\end{array}$}} & $\begin{array}{l}3,15 \\
10 ? 2\end{array}$ & $\begin{array}{c}2,65 \\
1871\end{array}$ & 5,26 \\
\hline & & 19,22 & 18,11 & 14,57 \\
\hline
\end{tabular}

Tabela 57. Pol\%cana das das variedades em diferentes períodos em Araras.

\begin{tabular}{cccc}
\hline \multirow{2}{*}{ VARIEDADES } & \multicolumn{3}{c}{ POL CANA (\%) } \\
\cline { 2 - 4 } & Jul-Dez & Dez-Mar & Mar-Ago \\
\hline RB835486 & $19,57 \mathrm{~A}$ & $19,40 \mathrm{~A}$ & $15,71 \mathrm{~A}$ \\
RB835054 & $18,82 \mathrm{~B}$ & $18,87 \mathrm{AB}$ & $15,41 \mathrm{~A}$ \\
RB855113 & $19,27 \mathrm{AB}$ & $18,16 \mathrm{C}$ & $13,40 \mathrm{~B}$ \\
RB855536 & $19,23 \mathrm{AB}$ & $18,40 \mathrm{BC}$ & $13,75 \mathrm{~B}$ \\
\hline
\end{tabular}




\section{Valparaiso}

Não houve diferença significativa entre doses de fósforo e variedades (tabela 58). O teor de pol foi semelhante entre as porções formadas nos períodos de julho a dezembro e dezembro a março. Estes valores encontrados foram aproximadamente $20 \%$ superiores aos encontrados no último período amostrado.

Tabela 58. Pol\%cana dos diferentes tratamentos analisados em Valparaíso.

\begin{tabular}{|c|c|c|c|c|}
\hline \multirow[t]{2}{*}{ VARIEDADES } & \multirow{2}{*}{$\begin{array}{l}\text { DOSES DE } \\
\text { FÓSFORO } \\
\left(\mathrm{kg} \mathrm{P}_{2} \mathrm{O}_{5} \cdot \mathrm{ha}^{-1}\right)\end{array}$} & \multicolumn{3}{|c|}{$\begin{array}{c}\text { POL CANA } \\
(\%)\end{array}$} \\
\hline & & Jul-Dez & Dez-Mar & Mar-Ago \\
\hline \multirow{4}{*}{ RB835486 } & 0 & $16,79 \mathrm{~A}$ & $16,53 \mathrm{~A}$ & $14,13 \mathrm{~A}$ \\
\hline & 80 & $15,38 \mathrm{~A}$ & $15,52 \mathrm{~A}$ & $13,29 \mathrm{~A}$ \\
\hline & 160 & $15,70 \mathrm{~A}$ & $15,26 \mathrm{~A}$ & $14,27 \mathrm{~A}$ \\
\hline & 240 & $16,39 \mathrm{~A}$ & $15,87 \mathrm{~A}$ & $12,95 \mathrm{~A}$ \\
\hline \multirow{4}{*}{ RB835054 } & 0 & $16,77 \mathrm{~A}$ & $17,04 \mathrm{~A}$ & $13,88 \mathrm{~A}$ \\
\hline & 80 & $17,49 \mathrm{~A}$ & $16,94 \mathrm{~A}$ & $13,84 \mathrm{~A}$ \\
\hline & 160 & $16,75 \mathrm{~A}$ & $16,50 \mathrm{~A}$ & $14,56 \mathrm{~A}$ \\
\hline & 240 & $16,74 \mathrm{~A}$ & $17,11 \mathrm{~A}$ & $13,62 \mathrm{~A}$ \\
\hline \multirow{4}{*}{ RB855113 } & 0 & $16,08 \mathrm{~A}$ & $16,91 \mathrm{~A}$ & $13,63 \mathrm{~A}$ \\
\hline & 80 & $16,48 \mathrm{~A}$ & $16,44 \mathrm{~A}$ & $12,76 \mathrm{~A}$ \\
\hline & 160 & $17,24 \mathrm{~A}$ & $16,90 \mathrm{~A}$ & $13,42 \mathrm{~A}$ \\
\hline & 240 & $16,10 \mathrm{~A}$ & $16,72 \mathrm{~A}$ & $13,43 \mathrm{~A}$ \\
\hline \multirow{4}{*}{ RB855536 } & 0 & $16,74 \mathrm{~A}$ & $16,19 \mathrm{~A}$ & $13,20 \mathrm{~A}$ \\
\hline & 80 & $17,33 \mathrm{~A}$ & $16,60 \mathrm{~A}$ & $13,35 \mathrm{~A}$ \\
\hline & 160 & $17,38 \mathrm{~A}$ & $16,18 \mathrm{~A}$ & $13,36 \mathrm{~A}$ \\
\hline & 240 & $16,42 \mathrm{~A}$ & $16,38 \mathrm{~A}$ & $13,20 \mathrm{~A}$ \\
\hline \multirow{2}{*}{\multicolumn{2}{|c|}{$\begin{array}{c}\text { CV }(\%) \\
\text { Média Geral }\end{array}$}} & 4,14 & 4,45 & 5,45 \\
\hline & & 16,61 & 16,44 & 13,56 \\
\hline
\end{tabular}

letras maiúsculas referem-se a tratamentos dentro de uma mesma variedade e letras minúsculas dentro de uma mesma dose (comparação entre variedades).

Existem diferenças significativas entre médias de variedades, sendo que a variedade que as variedades RB835054, RB855113 e RB855536 apresentaram valores semelhantes e superiores a RB835486. Resultados que diferem aos encontrados em Araras (tabela 59). 
Tabela 59. Pol\%cana das diferentes variedades em Valparaíso.

\begin{tabular}{cccc}
\hline \multirow{2}{*}{ VARIEDADES } & \multicolumn{3}{c}{ POL CANA (\%) } \\
\cline { 2 - 4 } & Jul-Dez & Dez-Mar & Mar-Ago \\
\hline RB835486 & $16,06 \mathrm{~B}$ & $15,80 \mathrm{~B}$ & $13,66 \mathrm{~A}$ \\
RB835054 & $16,94 \mathrm{~A}$ & $16,90 \mathrm{~A}$ & $13,98 \mathrm{~A}$ \\
RB855113 & $16,48 \mathrm{AB}$ & $16,74 \mathrm{~A}$ & $13,31 \mathrm{~A}$ \\
RB855536 & $16,97 \mathrm{~A}$ & $16,34 \mathrm{AB}$ & $13,28 \mathrm{~A}$ \\
\hline
\end{tabular}

\subsubsection{Fibra}

\section{Araras}

Não foi encontrada interação significativa entre doses de fósforo e variedades nas diferentes porções da planta (tabela 60).

Tabela 60. Pol\%cana das diferentes variedades em Valparaiso.

\begin{tabular}{|c|c|c|c|c|}
\hline \multirow[t]{2}{*}{ VARIEDADES } & \multirow{2}{*}{$\begin{array}{l}\text { DOSES DE } \\
\text { FOSFORO } \\
\left(\mathrm{kg} \mathrm{P}_{2} \mathrm{O}_{5} \cdot \mathrm{ha}^{-1}\right)\end{array}$} & \multicolumn{3}{|c|}{$\begin{array}{c}\text { FIBRA } \\
(\%) \\
\end{array}$} \\
\hline & & Jul-Dez & Dez-Mar & Mar-Ago \\
\hline \multirow{4}{*}{ RB835486 } & 0 & $9,81 \mathrm{Aa}$ & $10,06 \mathrm{Aa}$ & $11,70 \mathrm{Aa}$ \\
\hline & 80 & $9,45 \mathrm{Aa}$ & $10,05 \mathrm{Aa}$ & $11,89 \mathrm{Aa}$ \\
\hline & 160 & $10,01 \mathrm{Aa}$ & $10,83 \mathrm{Aa}$ & $11,51 \mathrm{Aa}$ \\
\hline & 240 & $10,45 \mathrm{Aa}$ & $9,98 \mathrm{Aa}$ & $11,31 \mathrm{Aa}$ \\
\hline \multirow{4}{*}{ RB835054 } & 0 & $12,08 \mathrm{Aa}$ & $10,77 \mathrm{Aa}$ & $11,52 \mathrm{Aa}$ \\
\hline & 80 & $12,73 \mathrm{Aa}$ & $11,19 \mathrm{Aa}$ & $10,85 \mathrm{Aa}$ \\
\hline & 160 & $11,77 \mathrm{Aa}$ & $11,38 \mathrm{Aa}$ & $11,78 \mathrm{Aa}$ \\
\hline & 240 & $13,38 \mathrm{Aa}$ & $11,41 \mathrm{Aa}$ & $11,68 \mathrm{Aa}$ \\
\hline \multirow{4}{*}{ RB855113 } & 0 & $10,76 \mathrm{Aa}$ & $12,02 \mathrm{Aa}$ & $12,11 \mathrm{Aa}$ \\
\hline & 80 & $12,39 \mathrm{Aa}$ & $12,84 \mathrm{Aa}$ & $12,63 \mathrm{Aa}$ \\
\hline & 160 & $12,96 \mathrm{Aa}$ & $11,98 \mathrm{Aa}$ & $12,41 \mathrm{Aa}$ \\
\hline & 240 & $12,33 \mathrm{Aa}$ & $12,45 \mathrm{Aa}$ & $12,34 \mathrm{Aa}$ \\
\hline \multirow{4}{*}{ RB855536 } & 0 & $13,11 \mathrm{Aa}$ & $11,30 \mathrm{Aa}$ & $11,29 \mathrm{Aa}$ \\
\hline & 80 & $11,60 \mathrm{Aa}$ & $10,62 \mathrm{Aa}$ & $11,65 \mathrm{Aa}$ \\
\hline & 160 & $12,27 \mathrm{Aa}$ & $10,92 \mathrm{Aa}$ & $11,26 \mathrm{Aa}$ \\
\hline & 240 & $11,98 \mathrm{Aa}$ & $10.94 \mathrm{Aa}$ & $11.69 \mathrm{Aa}$ \\
\hline \multirow{2}{*}{\multicolumn{2}{|c|}{$\begin{array}{c}\text { CV }(\%) \\
\text { Média Geral }\end{array}$}} & 10,24 & 5,08 & 4,84 \\
\hline & & 11,69 & 11,17 & 11,73 \\
\hline
\end{tabular}


O teor de fibra encontrado na porção superior da planta foi maior do que nas demais. Isso pode ser explicado pelo fato desta porção ser nova e estar ainda em desenvolvimento. A parte basal apresenta valores de fibra maiores que a intermediária, pois é responsável pela sustentação da planta. Mesmo assim a diferenças entre as porções não passam de $5 \%$.

Não se consegue verificar tendências de aumento ou decréscimo com aumento no teor de fósforo, pois além das diferenças varietais verificam-se mudanças de resposta de doses de uma época para outra.

A única diferença encontrada foi entre médias de variedade (tabela 61). A RB835486 foi que apresentou os menores valores, e a RB835113 os maiores. Resultados que são conseqüência das características das variedades em estudo, o que está de acordo com os valores de brix e população de plantas.

Tabela 61. Fibra das variedades em estudo utilizadas em Araras.

\begin{tabular}{cccc}
\hline \multirow{2}{*}{ VARIEDADES } & \multicolumn{3}{c}{ FIBRA (\%) } \\
\cline { 2 - 4 } & Jul-Dez & Dez-Mar & Mar-Ago \\
\hline RB835486 & $9,93 \mathrm{~B}$ & $10,23 \mathrm{C}$ & $11,60 \mathrm{~B}$ \\
RB835054 & $12,49 \mathrm{~A}$ & $11,19 \mathrm{~B}$ & $11,46 \mathrm{~B}$ \\
RB855113 & $12,11 \mathrm{~A}$ & $12,32 \mathrm{~A}$ & $12,37 \mathrm{~A}$ \\
RB855536 & $12,24 \mathrm{~A}$ & $10,95 \mathrm{~B}$ & $11,47 \mathrm{~B}$ \\
\hline
\end{tabular}

$\underline{\text { Valparaiso }}$

Assim como em Araras, não foi encontrada interação significativa entre variedades e doses (tabela 62).

Além disso, verifica-se que a porção mediana foi a que apresentou os menores valores. Ao compararmos os valores da porção superior com as demais, nota-se que os resultados são $30 \%$ e $20 \%$ menores nas partes intermediárias e basais, respectivamente. Os valores obtidos em Valparaíso são maiores que os de Araras. 
Tabela 62. Fibra das variedades em estudo utilizadas em Valparaíso.

\begin{tabular}{|c|c|c|c|c|}
\hline \multirow[t]{2}{*}{ VARIEDADES } & \multirow{2}{*}{$\begin{array}{c}\text { DOSES DE } \\
\text { FÓSFORO } \\
\left(\mathrm{kg} \mathrm{P}_{2} \mathrm{O}_{5} \cdot \mathrm{ha}^{-1}\right)\end{array}$} & \multicolumn{3}{|c|}{$\begin{array}{l}\text { FIBRA } \\
(\%)\end{array}$} \\
\hline & & Jul-Dez & Dez-Mar & Mar-Ago \\
\hline \multirow{4}{*}{ RB835486 } & 0 & $11,23 \mathrm{Aa}$ & $10,50 \mathrm{Aa}$ & $15,33 \mathrm{Aa}$ \\
\hline & 80 & $11,17 \mathrm{Aa}$ & $10,16 \mathrm{Aa}$ & $15,01 \mathrm{Aa}$ \\
\hline & 160 & $12,31 \mathrm{Aa}$ & $11,06 \mathrm{Aa}$ & $13,48 \mathrm{Aa}$ \\
\hline & 240 & $11,71 \mathrm{Aa}$ & $10,79 \mathrm{Aa}$ & $16,09 \mathrm{Aa}$ \\
\hline \multirow{4}{*}{ RB835054 } & 0 & $11,26 \mathrm{Aa}$ & $10,31 \mathrm{Aa}$ & 15,37 Aa \\
\hline & 80 & $10,82 \mathrm{Aa}$ & $10,26 \mathrm{Aa}$ & $15,79 \mathrm{Aa}$ \\
\hline & 160 & $11,15 \mathrm{Aa}$ & $10,23 \mathrm{Aa}$ & $14,25 \mathrm{Aa}$ \\
\hline & 240 & $11,04 \mathrm{Aa}$ & $9,98 \mathrm{Aa}$ & $15,61 \mathrm{Aa}$ \\
\hline \multirow{4}{*}{ RB855113 } & 0 & $11,28 \mathrm{Aa}$ & $9,92 \mathrm{Aa}$ & $12,68 \mathrm{Aa}$ \\
\hline & 80 & $11,12 \mathrm{Aa}$ & $9,40 \mathrm{Aa}$ & $12,95 \mathrm{Aa}$ \\
\hline & 160 & $11,09 \mathrm{Aa}$ & $9,92 \mathrm{Aa}$ & $13,06 \mathrm{Aa}$ \\
\hline & 240 & $12,06 \mathrm{Aa}$ & $9,90 \mathrm{Aa}$ & $13,25 \mathrm{Aa}$ \\
\hline \multirow{4}{*}{ RB855536 } & 0 & $11,20 \mathrm{Aa}$ & $9,24 \mathrm{Aa}$ & $13,85 \mathrm{Aa}$ \\
\hline & 80 & $11,80 \mathrm{Aa}$ & $11,00 \mathrm{Aa}$ & $15,52 \mathrm{Aa}$ \\
\hline & 160 & $11,37 \mathrm{Aa}$ & $10,22 \mathrm{Aa}$ & $14,75 \mathrm{Aa}$ \\
\hline & 240 & $12,73 \mathrm{Aa}$ & $9,55 \mathrm{Aa}$ & $15,42 \mathrm{Aa}$ \\
\hline \multicolumn{2}{|c|}{$\begin{array}{c}\text { CV }(\%) \\
\text { Média Geral }\end{array}$} & $\begin{array}{c}8,47 \\
11,46\end{array}$ & $\begin{array}{c}7,27 \\
10,16\end{array}$ & $\begin{array}{c}8,31 \\
14,53\end{array}$ \\
\hline
\end{tabular}

Em relação às médias varietais, foram encontradas diferenças significativas nos dois últimos periodos (tabela 63). Os maiores valores foram encontrados na RB835486, que não diferiu das RB835054 e RB855536, o menor teor de fibra foi encontrado na variedade RB855113. Era esperado que esta última variedade apresentasse valor de fibra superior as demais e a RB835486 estivesse entre as que apresentam menor teor de fibra.

Não foram observadas diferenças significativas entre médias de doses de fósforo. 
Tabela 63. Fibra das variedades avaliadas em Valparaíso.

\begin{tabular}{cccc}
\hline \multirow{2}{*}{ VARIEDADES } & \multicolumn{3}{c}{ FIBRA (\%) } \\
\cline { 2 - 4 } & Jul-Dez & Dez-Mar & Mar-Ago \\
\hline RB835486 & $11,60 \mathrm{~A}$ & $10,63 \mathrm{~A}$ & $14,98 \mathrm{~A}$ \\
RB835054 & $11,07 \mathrm{~A}$ & $10,19 \mathrm{AB}$ & $15,26 \mathrm{~A}$ \\
RB855113 & $11,39 \mathrm{~A}$ & $9,78 \mathrm{~B}$ & $12,99 \mathrm{~B}$ \\
RB855536 & $11,77 \mathrm{~A}$ & $10,00 \mathrm{AB}$ & $14,88 \mathrm{~A}$ \\
\hline
\end{tabular}




\section{CONCLUSÕES}

Não houve interação significativa entre variedades e doses, com exceção de alguns parâmetros que apresentaram interação em alguma das amostragens.

O crescimento da cana planta foi mais acentuado nos meses de novembro a abril, por ser um periodo que apresenta maior quantidade de chuva e temperaturas adequadas para bom desenvolvimento.

O perfilhamento, em cana planta, foi mais intenso de julho a novembro e as variedades RB8551153 e RB855536 foram as que apresentaram maior população. Estas mesmas variedades também foram as que apresentaram maior IAF nas condições de Araras.

A produtividade em Araras da cana-planta acompanhou parâmetros como perfilhamento e IAF. Já em Valparaíso, a variedade RB855536, apesar de apresentar bom número de perfilhos durante o experimento, devido ao déficit hídrico mais acentuado que antecedeu a colheita, teve baixa produção, mostrando ser uma variedade que produz menos fitomassa que as demais em condições estressantes.

As variedades RB835486 e RB835054 foram as que apresentaram maior teor de fibra e pol\%cana em cana soca, nos dois experimentos.

Em cana soca, o maior crescimento das plantas foi no periodo de dezembro a março, devido às chuvas que antecedem e ocorrem neste intervalo de meses.

A variedade RB835486, assim como na cana planta, apresentou menor número de perfilhos por metro na cana soca. 
A fitomassa de cana soca por colmo da RB835054 foi maior que as demais no experimento instalado em Araras. Em Valparaiso, a RB835486 foi a que apresentou maior fitomassa da aérea. A cana-de-açúcar acumulou $20 \%$ do total de massa fresca de julho a dezembro, 50 a $60 \%$ de dezembro a março e 20 a $30 \%$ de março até a colheita.

Houve diminuição no teor de brix e pol\%cana da porção formada na primeira época amostrada para última. No caso da fibra, as duas extremidades do colmo foram as que apresentaram maiores valores. 


\section{REFERÊNCIAS BIBLIOGRÁFICAS}

ALLARD, R.W.; BRADSHAW, A.D. Implications of genotype-environmental interactions in applied plant breeding. Crop Science, v.4, p.503-507, 1964

ANDREOLA, F. Micorrizas vesiculares-arbusculares em cana-de-açúcar. Piracicaba, 1982. 74p. Dissertação (Mestrado) - Escola Superior de Agricultura "Luiz de Queiroz", Universidade de São Paulo.

ARIZONO, H.; GHELLER, A.C.A.; MASUDA, Y.; HOFMANN, H.P.; BASSINELLO, A.I; MATSUOKA, S.; GIGLIOTI, E.A.; MENEZES, L.L. Guia das principais variedades de cana-de-açúcar RB 2000. Araras: UFSCar, CCA, DBV, 2000. 16p.

BASALDI, O.V.; FARIA, C.A.C.; NOVAES FILHO, R. Considerações sobre a dinâmica recente do complexo sucroalcooleiro no estado de São Paulo. Informações Econômicas, v.26, n.4, p.21-29, 1996.

BENINCASA, M.M.P. Análise de crescimento de plantas (noções básicas). Jaboticabal: FUNEP, 1988. 42p.

CAMARGO, P.N. Fisiologia da cana-de-açúcar. Piracicaba: ESALQ, 1968. $38 p$.

CASAGRANDE, A.A. Tópicos de morfologia e fisiologia da cana-de-açúcar. Jaboticabal: FUNEP, 1991. 157p.

CASTRO, P.R.C. Fitofisiologia experimental. Jaboticabal: UNESP, FMVA, 1971. 11p.

CENTRO DE TECNOLOGIA COPERSUCAR. Censo Copersucar 2000. Piracicaba, 2001. 16p. 
CESAR, M.A.A.; DELGADO, A.A.; CAMARGO, A.P.; BISSOLI, B.M.A.A.; SILVA, F.C. Capacidade de fosfatos naturais e artificiais em elevar o teor de fósforo no caldo de cana-de-açúcar (cana-planta), visando o processo industrial. Stab. Açúcar, Álcool \&Subprodutos, v.5, n.5/6, p.32-38, 1987.

CESNIK, R.; VENCOVSK, R. Expected response to selection, heritability, genetic correlations, and response to selection of some characters in sugarcane. In: CONGRESS OF THE INTERNATIONAL SOCIETY OF SUGAR CANE TECHNOLOGISTS,15, Durban, 1974. Proceedings. Durban: ISSCT, 1974, p.96-101.

CHRISTOFFOLETI, P.J. Aspectos fisiológicos da brotação, perfilhamento e florescimento da cana-de-açúcar. Piracicaba, ESALQ, 1986. 80p.

CLEMENTS, H.F. Sugarcane crop logging and crop control: principles and practice. Hawaii: The University of Hawaii Press. 1980. 520p.

DANIELS, J.; ROACH, B.T. Taxonomy and evolution. In: HEINZ, D.J. (Ed.) Sugarcane improvement through breeding. Amsterdam: Elsevier, 1987. p.7-84.

DIAS, F.L.F.; MAZZA, J.A.; MATSUOKA, S.; PERECIN, D.; MAULE, R.F. Produtividade da cana-de-açúcar em relação ao clima e solos da região noroeste do estado de São Paulo. Revista Brasileira de Ciência do Solo, v.23, n.3, p.627-634, 1999.

DILLEWIJN, C. van. Botany of sugar cane. Waltham: Chronica Botanica, 1952. 371p.

ESPIRONELO, A. Contribuição do instituto agronômico de Campinas (IAC) para a nutrição e adubação da cana-de-açúcar. II. Fósforo em cana-planta. Stab. Açúcar, Álcool \&Subprodutos, v.8, n.2, p.15-21, 1989.

ESTÉVES, A.A. Fisiologia de la caña de azucar. In: OSORIO C.E.B. (Ed.) EI cultivo de la caña de azucar. Cali: Tecnicana, 1986. p.27-41.

FIGUEIREDO, P.; LANDELL, M.G.A.; CAMPANA, M.P. et al. Cana-de-açúcar. (disquete) 6. ed. Campinas: IAC, 1995. (IAC. Boletim 200)

FÓSFORO: ele é essencial. Arquivo do Agrônomo, n.10, p.3-4, 1996. 
FRANCIS, C.A.; RUTGER, J.N.; PALMER, A.F.E. A rapid method for plant leaf area estimation in maize (Zea mays L.). Crop Science, v.9, p.537-539, 1969.

GASCHO, G.J.; SHIH, S.F. Sugarcane. In: TEERE, I.D.; PEET, M.M. Crop: water relations. New York: Wiley Interscience, 1983. p.445-479.

HERMANN, E.R.; CÂMARA, G.M.S. Um método simples para estimar a área foliar da cana-de-açúcar. Stab. Açúcar, Álcool \&Subprodutos, v.17, n.5, p.32-34, 1999.

HOFFMANN, H.P. Evolução do potencial produtivo das principais variedades de cana-de-açúcar cultivadas no no Estado de São Paulo nos últimos cinquenta anos. Piracicaba, 1997. 97p. Tese (Doutorado) - Escola Superior de Agricultura "Luiz de Queiroz", Universidade de São Paulo.

HOFFMANN, H.P.; FANCELLI, A.L.; MATSUOKA, S.; MASUDA, Y. Contribuição de variedades melhoradas de cana-de-açpúcar no Estado de São Paulo, nos últimos 50 anos. In: CONGRESSO NACIONAL DA STAB, 7., Londrina, 1999. Anais. Piracicaba: STAB, 1999. p. 49-53.

HUMBERT, R.P. El cultivo de la caña de azucar. México: Continental, 1974. $719 p$.

JAMES, N.I. Yield components in ramdom and selected sugarcane populations. Crop Science, v.11, p.906-908, 1971.

JORGE, L.A.C de. Recomendações práticas para aquisição de imagens digitais analisadas através do SIARCS. São Carlos: EMBRAPA, CNPDIA, 1996. 1V. (Circular Técnica, 1)

KORNDORFER, G.H. Fertilizantes sólidos e fluidos na cana-de-açúcar. Piracicaba, 1990. 91p. Tese (Doutorado) - Escola Superior de Agricultura "Luiz de Queiroz", Universidade de São Paulo.

KORNDORFER, G.H.; ALCARDE, J.C. Acúmulo e teor de fósforo em folhas de cana-de-açúcar. Revista Brasileira de Ciência do Solo, v.16, p.217-222, 1992. 
LEITE, R.C.C. Pró-alcool: a única alternativa para o futuro. Campinas: UNICAMP, 1987. 86p.

LEME, E.J.A.; MANIERO, M.A.; GUIDOLIN, J.C. Estimativa da área foliar da cana-de-açúcar e sua relação com a produtividade. Cadernos PLANALSUCAR, v.3, n.2, p.3-22, 1984.

LOOMIS, R.S.; WILLIAMS, W.A. Productivity and the morphology of crop stands: pattern with leaves. In: EASTIN, J.D.; HASKINS, F.A.; SULLIVAN, C.Y.; VAN BAVEL, C.H.M. (Ed.) Physiology aspects of crop yield. Madison: American Society of Agronomy, 1969. p.27-47.

MACHADO, E.C.; PEREIRA, A.R.; FAHL, J.I.; ARRUDA, J.V.; CIONE, J. Índices biométricos de duas variedades de cana-de-açúcar. Pesquisa Agropecuária Brasileira, v.17, n.9, p.1323-1329, 1982.

MAGALHÃES, A.C.N. Ecofisiologia da cana-de-açúcar: aspectos do metabolismo do carbono na planta. In: CASTRO, P.R.C. Ecofisiologia da produção agrícola. Piracicaba: POTAFOS, 1987. p.113-118.

MALAVOLTA, E.; VITTI, G.C.; OLIVEIRA, S.A. de. Avaliação do estado nutricional das plantas: princípios e aplicações. 2.ed. Piracicaba: POTAFOS, 1997. 319p.

MALAVOLTA, E.; HAAG, H.P.; MELLO, F.A.F.; BRASIL SOBRINHO, M.O.C.

Nutrição mineral de algumas culturas tropicais. São Paulo: Livraria Pioneira; EDUSP, 1967. 251p.

MARINHO, M.L.; CAVALCANTI, G.A.; AMORIM, L.C. Influência do nitrogênio, fósforo e potássio no rendimento dos canaviais de Alagoas. In: CONGRESSO BRASILEIRO DE CIENCIA DO SOLO, 15., Campinas, 1975. Anais. São Paulo: CBCS, 1976. p.193-201.

MARIOTTI, J.A. Associations among yield and quality components in sugarcane hybrid progenies. In: CONGRESS OF THE INTERNATIONAL SOCIETY OF SUGAR CANE TECHNOLOGISTS,14, New Orleans, 1971. Proceedings. New Orleans: ISSCT, 1971, p.177-184. 
MATSUOKA, S.; GARCIA, A.A.F.; ARIZONO, H. Melhoramento da cana-deaçúcar. In: BORÉM, A. Melhoramento de espécies cultivadas. Viçosa: Editora UFV, 1999. p. 205-251.

MATSUOKA, S.; LAVORENTI, N.A.; MENEZES, L.L.; SALIBE, A.C.; GHELLER, A.C.A.; ARIZONO, H. Novas variedades de cana-de-açúcar para a região Oeste do Estado de São Paulo. In: CONGRESSO NACIONAL DA STAB, 7., Londrina, 1999. Anais. Piracicaba: STAB, 1999. p.34-39.

MATSUOKA, S.; ARIZONO, H.; BASSINELLO, A.I.; GARCIA, A.A.F.; GHELLER, A.C.A.; GIGLIOTI, E.A.; HOFMANN, H.P.; MASUDA, Y. Seis novas variedades RB de cana-de-açúcar. Araras, UFSCar, CCA, 1998. $24 p$.

MELLO, F.A.F. de; BRASIL SOBRINHO, M.O.C.; ARZOLLA, S.; SIFVEIRA, R.I; COBRA NETTO, A.; KIEHL, J.C. Fertilidade do solo. São Paulo: Nobel, 1983. 400p.

MILLER, J.D.; JAMES, N.I. The influence of stallk density on cane yield. In: CONGRESS OF THE INTERNATIONAL SOCIETY OF SUGAR CANE TECHNOLOGISTS,15., Durban, 1974. Proceedings. Durban: ISSCT, 1974. p.177-184.

MIOCQUE, J. Avaliação de crescimento e de produtividade de matéria verde da cana-de-açúcar na região de Araraquara-SP. Stab. Açúcar, Álcool \&Subprodutos, v. 17, n.4, p. 45-47, 1999.

MOREIRA, D.R. Influência da umidade do solo na germinação de toletes de cana-de-açúcar. Rio Claro, 1995. 116p. Dissertação (Mestrado) - Instituto de Biociências, Universidade Estadual Paulista "Júlio de Mesquita Filho".

MORELLI, J.; DALBEN, A.E.; NELLY, E.J.; DEMATTÊ. Efeitos de métodos de aplicação de fósforo na produtividade de cana-de-açúcar e propriedades químicas de solo arenoso. In: REUNIÃO BRASILEIRA DE FERTILIDADE DO SOLO E NUTRIÇÃO DE PLANTAS, 21., Petrolina, 1994. Anais. Petrolina: SBCS, EMBRAPA, CPATSA, 1994. p.113-115.

MOVIMENTO do fósforo no solo. Informações Agronômicas, n.52, p.4, 1990. 
ORLANDO FILHO, J.; ZAMBELLO JUNIOR, E. Influência da adubação NPK nas finalidades tecnológicas da cana-planta, variedade CB 41-76. Brasil Açucareiro, v.96, n.9, p. 37-44, 1980.

PENATTI, C.P. Uso de ácido fosfórico ou superfosfato triplo como fonte de fósforo para a cultura da cana-de-açúcar. Piracicaba, 1991. 105p. Dissertação (Mestrado) - Escola Superior de Agricultura "Luiz de Queiroz", Universidade de São Paulo.

PEREIRA, A.R.; MACHADO, E.C. Um simulador dinâmico do crescimento de uma cultura de cana-de-açúcar. Bragantia, v.45, n.1, p.107-122, 1986.

PEREIRA, A.R.; MACHADO, E.C. Análise quantitativa do crescimento de comunidades vegetais. Campinas: Instituto Agronômico, 1987. 33p.

PLANALSUCAR. Cultura da cana-de-açúcar: manual de orientação. Piracicaba: IAA, Coordenadoria Regional Sul, 1986. 56p.

PRADO, A.P.A. Perfilhamento e produção da cana-de-açúcar (Saccharum spp.) em função da densidade de plantio. Piracicaba, 1988. 69p. Dissertação (Mestrado) - Escola Superior de Agricultura "Luiz de Queiroz", Universidade de São Paulo.

RAIJ, B van. Avaliação da fertilidade do solo. 2.ed. Piracicaba: Instituto da Potassa e Fosfato, 1983. 142p.

RAIJ, B. van Fósforo: dinâmica e disponibilidade no solo. In: CURSO DE ATUALIZAÇÃO EM FERTILIDADE DO SOLO, 1., Iha Solteira, 1987. Trabalhos apresentados. Campinas: Fundação Cargill, 1987. p.183-205.

REIS, E.L.; CABALA-ROSAND, P. Respostas da cana-de-açúcar ao nitrogênio, fósforo e potássio em solo de tabuleiro do sul da Bahia. Revista Brasileira de Ciência do Solo, v.10, n.1, p. 129-134, 1986.

ROCHA, A.M.C. Emergência, perfilhamento e produção de colmos da cana-deaçúcar (Saccharum spp.) em função das épocas de plantio no estado de São Paulo. Piracicaba, 1984. 154p. Dissertação (Mestrado) - Escola Superior de Agricultura "Luiz de Queiroz", Universidade de São Paulo. 
RODRIGUEZ, D.; ANDRADE, F.H.; GOUDRIAAN, J. Effects of phosphorus nutrition on tiller emergence in wheat. Plant and Soil, v.209, p.283-295, 1999.

SILVA, G.E., ALONSO, O., MORAIS, R.S. Influência da adubação sobre a produtividade e qualidade tecnológica da cana-de-açúcar. In: SEMINÁRIO COOPERSUCAR DA INDÚSTRIA AÇUCAREIRA, 4., Águas de Lindóia, 1976. Anais. São Paulo: COPERSUCAR, 1977. p.27-35.

SIQUEIRA, J.O. Eficiência de fertilizantes fosfatados em associações micorrizicas. In: ENCONTRO NACIONAL DE ROCHA FOSFÁTICA, 5., São Paulo, 1990. São Paulo: IBRAFOS, 1990. p. 165-193.

SKINNER, J.C. Application of quantitative genetics to breeding of vegetatively reproduced crops. Journal Australian Institute Agriculture Science, v.47, n.2, p.82-83, 1981.

SORDI, R.A.; BRAGA Jr., R.S.L.C. Comportamento de cultivares de cana-deaçúcar durante a safra, em cana-planta e soca, em relação ao ganho de peso, florescimento e isoporização. In: CONGRESSO NACIONAL DA STAB, 6., Maceió, 1996. Anais. Piracicaba: STAB, 1996. p.238-244.

SOUSA, J.A.G.C. Efeito da tensão da água do solo na cultura da cana-deaçúcar (Saccharum spp.). Limeira, 1976. 163p. Tese (Doutorado) Faculdade de Engenharia de Limeira, Universidade Estadual de Campinas.

STEVENSON, G.C. Genetics and breeding of sugar cane. London: Longmans, 1965. 284p.

STOLF, R. Transplante de soqueira de cana-de-açúcar (Saccharum spp.) como técnica de renovação da cultura. Piracicaba, 1982. 119p. Tese (Doutorado) Escola Superior de Agricultura "Luiz de Queiroz", Universidade São Paulo.

STUPIELLO, J.P. A cana-de-açúcar como matéria-prima. In: PARANHOS, S.B. (Coord.) Cana-de-açúcar: cultivo e utilização. Campinas: Fundação Cargill, 1987. p.761-804. 
TAKAHASHI, D.; MATSUOKA, S.; MENEGHIN, S.P. Diferencial de associação de micorrizas arbusculares entre solo virgem e solo cultivado com cana-deaçúcar. (compact disc). In: CONGRESSO DE INICIAÇÃO CIENTÍFICA, 6., São Carlos, 1998. Anais. São Carlos: UFSCar, 1998.

TOKESHI, H. Perfilhamento e perdas pelo carvão da cana-de-açúcar. Stab. Açúcar, Álcool \&Subprodutos, v.4, n.5, p.33-44, 1986.

UFSCar. Programa de melhoramento genético da cana-de-açúcar 2001. http://pmgca.dbv.cca.ufscar.br//nfoPublica/Catalogo/cat_menu.php3. 20/11/01.

UFSCar. Relatório Anual Programa de melhoramento genético da cana-deaçúcar 1997. Araras, 1998. 42p.

WEBER, H.; BOLSANELLO, J. ; AZEREDO, D.F. de. Doses e fontes de fósforo em cana-de-açúcar. In: CONGRESSO NACIONAL DA STAB, 5., Águas de São Pedro, 1993. Anais. Piracicaba: STAB, 1993. p.70-75

ZAMBELLO Jr., E.; ORLANDO FILHO, J.; RODELLA, A. A. Recomendação de adubação fosfatada para cana-de-açúcar através da análise química do solo. Brasil Açucareiro, v.97, n.3, p.38-43, 1981. 